Portland State University

PDXScholar

Dissertations and Theses

Dissertations and Theses

10-8-1993

\title{
Simulation of Switched Linear Networks
}

Dietmar Reinhard Skowronn

Portland State University

Follow this and additional works at: https://pdxscholar.library.pdx.edu/open_access_etds

Part of the Electrical and Computer Engineering Commons Let us know how access to this document benefits you.

\section{Recommended Citation}

Skowronn, Dietmar Reinhard, "Simulation of Switched Linear Networks" (1993). Dissertations and Theses. Paper 4644.

https://doi.org/10.15760/etd. 6528

This Thesis is brought to you for free and open access. It has been accepted for inclusion in Dissertations and Theses by an authorized administrator of PDXScholar. Please contact us if we can make this document more accessible: pdxscholar@pdx.edu. 
AN ABSTRACT OF THE THESIS OF Dietmar Reinhard Skowronn for the Master of Science in Electrical and Computer Engineering presented October 8, 1993.

Title: Simulation of Switched Linear Networks

APPROVED BY THE MEMBERS OF THE THESIS COMMITTEE:

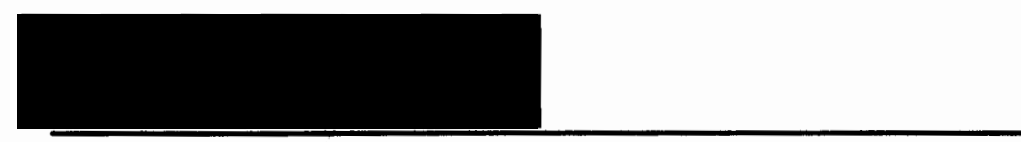

Richard Tymerski, Chair

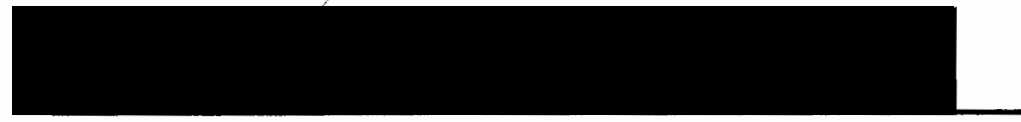

Andrew M. Fraser

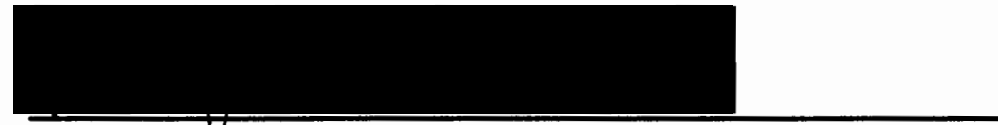

Bradford R. Crain

This thesis deals with the time-domain analysis of switched linear networks and investigates inherent problems which have to be considered when analyzing this class of networks. Computer simulation requires the use of numerical methods and we focus on the transmission-line modelling technique (TLM) and the numerical inverse Laplace transform. A general approach based on the one-graph modified nodal description is given which allows the formulation of circuit equations of a TLM-modelled circuit by inspection. The numerical equivalence of TLM and trapezoidal rule has been found and a proof is given. A variable step size simulator has 
been developed based on the 4th order numerical inverse Laplace transform. The properties of this method are reviewed and its limitations are discussed. Simulation results are given to illustrate capabilities of the simulator. 
by

\section{DIETMAR REINHARD SKOWRONN}

A thesis submitted in partial fulfillment of the requirements for the degree of

MASTER OF SCIENCE

in

ELECTRICAL AND COMPUTER ENGINEERING

Portland State University

1993 


\section{TO THE OFFICE OF GRADUATE STUDIES:}

The members of the Committee approve the thesis of Dietmar Reinhard Skowronn presented October 8, 1993.

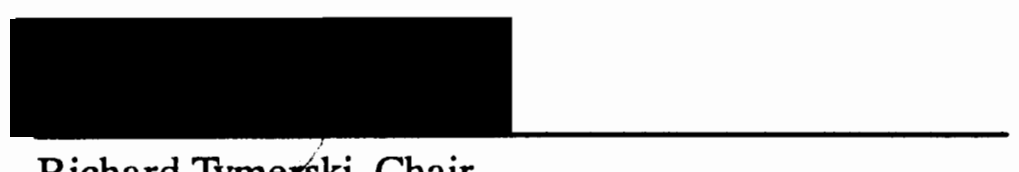

Richard Tymerski, Chair

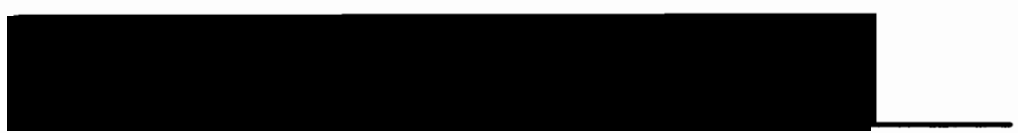

Andrew M. Fraser

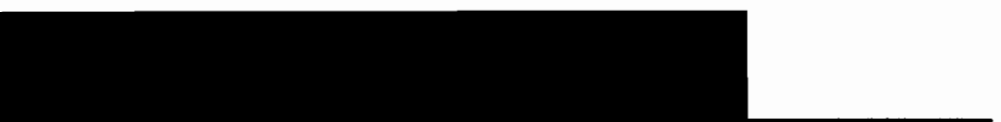

Bradford R. Crain

\section{APPROVED:}

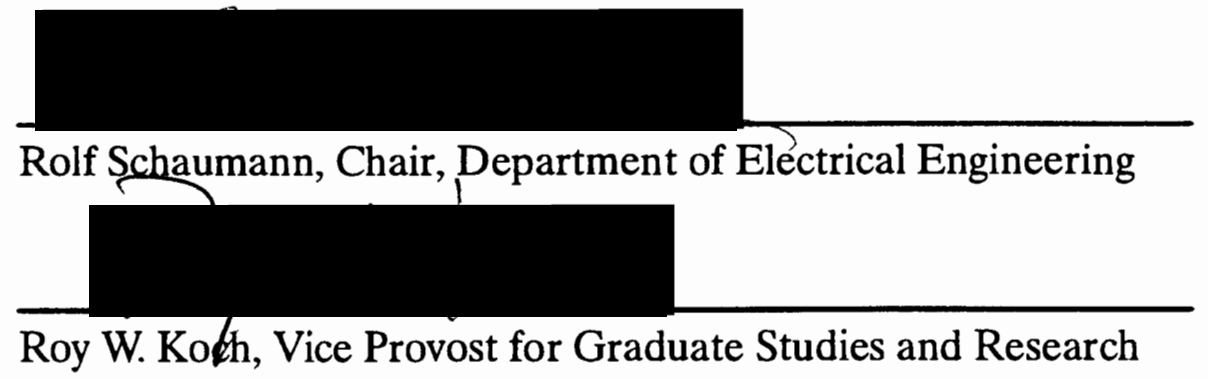




\section{ACKNOWLEDGEMENTS}

I would like to take this opportunity to express my appreciation and gratitude to those who offered support and encouragement during my academic year at Portland State University.

First and foremost, I wish to express my sincere and profound gratitude to my advisor Dr. Richard Tymerski for his professional guidance throughout this work. Without his help and encouragement, the successful completion of the MSEE degree would not have been possible in such a short time.

I would like to thank Dr. Andrew M. Fraser and Dr. Bradford R. Crain for serving on my committee and for the time they spent on reviewing my thesis.

I am grateful to Duwang $\mathrm{Li}$, who helped me in compiling my simulation program onto a PC system. I owe him thanks for the computer programming skills he taught me.

I am thankful to Shirley Clark, Laura Riddell, and the staff of the electrical engineering department who provided me with all kinds of help since the very beginning of my studies at PSU.

Many thanks go out to all my friends that I have met in the past year. I appreciate their company and I will always remember the times we spent together in the Cheerful Tortoise every Thursday evening. Thank you guys for enriching my stay here in Portland. I am especially grateful to my friends Henning Lenz, Karl Mathia, and Frank Ebersbach for their understanding ear, encouragement and direction when I felt stuck.

I would like to express my appreciation to my friend Michael Nichols for proofreading this thesis. 
I gratefully acknowledge the financial support of the Oregon Baden-Württemberg Exchange program and of the Robert Bosch GmbH. Without their generous scholarships, it would have been impossible for me to study in the United States.

Finally, I wish to express my gratitude to my parents in Germany who helped me in many ways throughout the most challenging and rewarding year in my life.

Portland, Oregon

October 1993

Dietmar R. Skowronn 


\section{TABLE OF CONTENTS}

PAGE

ACKNOWLEDGEMENTS $\ldots \ldots \ldots \ldots \ldots \ldots \ldots \ldots \ldots \ldots \ldots \ldots$ iii

LIST OF TABLES $\ldots \ldots \ldots \ldots \ldots \ldots \ldots \ldots \ldots \ldots \ldots \ldots \ldots \ldots \ldots \ldots \ldots \ldots \ldots$ viii

LIST OF FIGURES $\ldots \ldots \ldots \ldots \ldots \ldots \ldots \ldots \ldots \ldots \ldots \ldots \ldots \ldots \ldots \ldots \ldots \ldots \ldots$ ix

\section{CHAPTER}

I.1 The Need for Switched Circuits in Power Electronic Systems $\ldots \ldots \ldots \ldots \ldots \ldots$. 1

I.2 The Buck-Boost Converter and Basic Operation Modes ................ 3

I.3 Time-Domain Analysis of Switched Linear Networks ............... 6

I.4 Outline of the Thesis $\ldots \ldots \ldots \ldots \ldots \ldots \ldots \ldots, 9$

II TRANSMISSION-LINE MODELLING $\ldots \ldots \ldots \ldots \ldots 11$

II.1 Introduction $\ldots \ldots \ldots \ldots \ldots \ldots \ldots \ldots \ldots \ldots, 11$

II.2 Discrete Model of Electrical Components ...... 12

II.2.1 Self inductance $\ldots \ldots \ldots \ldots \ldots \ldots \ldots \ldots, 12$

II.2.2 Capacitor ..................... 14

II.2.3 Mutual inductance ............... 16

II.2.4 Resistor, sources, and controlled sources . . 17

II.2.5 Switch and diode ................ 17

II.3 Operation of the TLM Routine $\ldots \ldots \ldots \ldots \ldots .18$

II.4 Solution of the Transmission-Line Model Using the One-Graph Modified Nodal Description ... 21 
II.4.1 General formulation method ......... 21

II.4.2 One-graph modified nodal formulation by inspection $\ldots \ldots \ldots \ldots \ldots \ldots \ldots, 23$

II.5 TLM Integration Method and Trapezoidal Rule . 26

II.6 Initial Conditions and Example $\ldots \ldots \ldots \ldots \ldots .33$

III NUMERICAL INVERSE LAPLACE TRANSFORM .... 40

III.1 Introduction $\ldots \ldots \ldots \ldots \ldots \ldots \ldots \ldots \ldots \ldots, 40$

III.2 The Inversion Formula ............... 41

III.3 Consistent Initial Conditions and Dirac Impulses 46

IV DEVELOPMENT OF A SIMULATOR FOR SWITCHED

LINEAR NETWORKS BASED ON THE NUMERICAL

INVERSE LAPLACE TRANSFORM . . . . . . . . 51

IV.1 Introduction to Time-Domain Analysis ...... 51

IV.2 Formulation of Circuit Equations with

Ideal Switches ..................... 52

IV.3 Classification of Switches and Switching Variables 54

IV.3.1 Switching variables for externally controlled switches and stepping sources ..........

IV.3.2 Switching variables for internally controlled switches ................... 56

IV.4 Determining the Switching Time of Internally

Controlled Switches

IV.5 Handling of Switching Variables and

Determination of the Network Solution

Immediately Before Switching $\ldots \ldots \ldots \ldots \ldots$

IV.6 Error-Controlled Two-Step Method ........ 68

IV.7 Determination of a Correct Topology Immediately after Switching $\ldots \ldots \ldots \ldots \ldots \ldots \ldots \ldots \ldots, 70$ 
IV.7.1 Review of the method of Dirac impulses .. $\quad 70$

IV.7.2 Problems and limitations of the method of Dirac impulses .............. 72

IV.8 Implementation of Variable Step Size $\ldots \ldots \ldots \ldots \quad 76$

IV.9 Simulation Examples $\ldots \ldots \ldots \ldots \ldots \ldots \ldots . \quad 84$

IV.9.1 Example $1 \ldots \ldots \ldots \ldots \ldots \ldots \ldots \ldots, 84$

IV.9.2 Example $2 \ldots \ldots \ldots \ldots \ldots \ldots \ldots \ldots, 84$

CONCLUSION $\ldots \ldots \ldots \ldots \ldots \ldots \ldots \ldots \ldots \ldots \ldots \ldots \ldots \ldots$

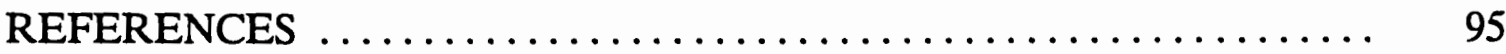




\section{LIST OF TABLES}

TABLE

PAGE

I Vector and Matrix Dimensions $\ldots \ldots \ldots \ldots \ldots \ldots \ldots \ldots, 23$

II Component Values for the Circuit in Figure $23 \ldots \ldots \ldots \ldots .34$

III Poles and Residues for $\xi_{0,4} \ldots \ldots \ldots \ldots \ldots \ldots \ldots \ldots \ldots, 45$

IV Poles and Residues for $\xi_{1,4} \ldots \ldots \ldots \ldots \ldots \ldots \ldots \ldots \ldots, 45$

V Component Values for the Circuit in Figure $29 \ldots \ldots \ldots \ldots .47$

VI Calculated Initial Conditions and Dirac Impulse Area ....... 50

VII Component Values for the Circuit in Figure $31 \ldots \ldots \ldots \ldots \ldots 61$

VIII Component Values for the Circuit in Figure $37 \ldots \ldots \ldots \ldots \ldots 80$

IX Component Values for the Circuit in Figure $44 \ldots \ldots \ldots \ldots .85$

X Component Values for the Circuit in Figure $48 \ldots \ldots \ldots \ldots .90$ 


\section{LIST OF FIGURES}

FIGURE

PAGE

1. Power Processing System $\ldots \ldots \ldots \ldots \ldots \ldots \ldots \ldots \ldots \ldots \ldots \ldots$

2. Linear $\mathrm{dc}-$ to $-\mathrm{dc}$ Power Conversion $\ldots \ldots \ldots \ldots \ldots \ldots \ldots . \ldots . \ldots 2$

3. Switched Mode Power Conversion $\ldots \ldots \ldots \ldots \ldots \ldots \ldots \ldots .2$

4. Voltage Waveform of $\mathrm{V}_{\mathrm{s}}(\mathrm{t})$ in Figure $3 \ldots \ldots \ldots \ldots \ldots \ldots \ldots$

5. Buck-Boost Converter ...................... 4

6. Inductor Current in Steady State CCM Operation .......... 4

7. Inductor Current in Steady State DCM Operation ......... 5

8. Continuous Transmission-Line Model of an Inductor ....... 12

9. Discrete Transmission-Line Model of an Inductor ......... 14

10. Continuous Transmission-Line Model of a Capacitor ....... 15

11. Discrete Transmission-Line Model of a Capacitor $\ldots \ldots \ldots 16$

12. Discrete Transmission-Line Model of a Mutual Inductance ... 16

13. Continuous Transmission-Line Model of a Switch ......... 19

14. Discrete Transmission-Line Model of a Switch ........... 19

15. Transmission-Line Scattering Zone $\ldots \ldots \ldots \ldots \ldots \ldots \ldots .20$

16. TLM Flow Chart for Non-Switched Linear Network ........ 24

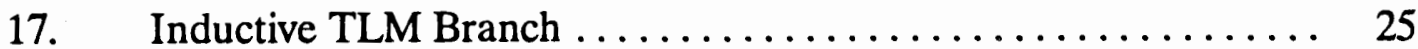

18. Modified Node-Admittance Matrix $Y_{n} \ldots \ldots \ldots \ldots \ldots \ldots . \ldots 27$

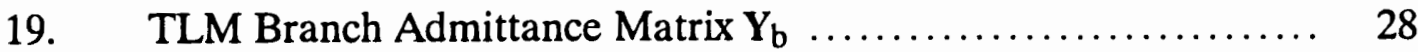

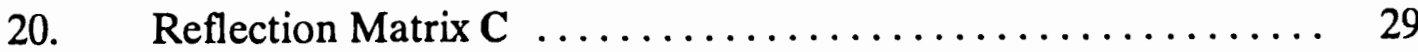

21. Vector of Reflected Pulses $\mathbf{V}^{\boldsymbol{r}} \ldots \ldots \ldots \ldots \ldots \ldots \ldots \ldots, 30$

22. Discrete Inductor Model $\ldots \ldots \ldots \ldots \ldots \ldots \ldots \ldots \ldots \ldots, 32$ 
23. Non-Switched Linear Circuit $\ldots \ldots \ldots \ldots \ldots \ldots \ldots \ldots$

24. Oriented Graph for the Circuit in Figure $23 \ldots \ldots \ldots \ldots \ldots$

25. Analytical Solution of Current i2 $\ldots \ldots \ldots \ldots \ldots \ldots \ldots \ldots \ldots$

26. Relative Error of Simulated Current i2, tstep $=0.01 \mathrm{sec} \ldots \ldots \ldots 38$

27. Relative Error of Simulated Current i2, tstep $=0.001 \mathrm{sec} \ldots \ldots .39$

28. Shifting of the Time Axis $\ldots \ldots \ldots \ldots \ldots \ldots \ldots \ldots \ldots \ldots \ldots$

29. RC-Network with Inconsistent Initial Conditions ......... 47

30. Switching Variable $p_{i n t, j}(t)$ in a Given Interval $\left[t_{1} ; t_{2}\right] \ldots \ldots \ldots 59$

31. Switched $\mathrm{RL}$-Network, $\mathrm{SW}_{1}$ and $\mathrm{SW}_{2}$ Operate in Antiphase $\ldots 61$

32. Simulated Inductor Current for the Circuit in Figure $31 \ldots \ldots 6$

33. Relative Error of Inductor Current $\ldots \ldots \ldots \ldots \ldots \ldots \ldots \ldots 2$

34. Flow Chart of the Error-Controlled Two-Step Method ...... 69

35. Ideal Buck Converter $\ldots \ldots \ldots \ldots \ldots \ldots \ldots \ldots \ldots \ldots \ldots \ldots \ldots \ldots$

36. Flow Chart of the Error-Correction Method ........... 78

37. RLC-Network for Variable Step Size Performance Test ....... 80

38. Simulated Output Voltage $V_{\text {out }} \ldots \ldots \ldots \ldots \ldots \ldots \ldots \ldots \ldots$

39. Selected Time Steps $h_{c} \ldots \ldots \ldots \ldots \ldots \ldots \ldots \ldots \ldots \ldots \ldots \ldots$

40. Absolute Error of Simulated Output Voltage $V_{\text {out }}$ Using the

Error-Correction Method ..................... 81

41. Selected Time Steps $h_{e} \ldots \ldots \ldots \ldots \ldots \ldots \ldots \ldots \ldots \ldots . \ldots 2$

42. Absolute Error of Simulated Output Voltage $V_{\text {out }}$ Using the

Step Size Estimation Method $\ldots \ldots \ldots \ldots \ldots \ldots \ldots \ldots . \quad 82$

43. Required Truncation Error $\varepsilon_{p+1}$ for $h_{e}=k h \ldots \ldots \ldots \ldots \ldots .83$

44. Transistor Circuit with Protection Elements $\ldots \ldots \ldots \ldots \ldots . . \ldots 5$

45. Simulated Transistor Collector Voltage

for the Circuit in Figure $44 \ldots \ldots \ldots \ldots \ldots \ldots \ldots \ldots \ldots .86$ 
46. Simulated Load Current for the Circuit in Figure $44 \ldots \ldots \ldots 86$

47. Schematic Diagram of Regulated Buck Converter ......... 88

48. Regulated Buck Converter as Implemented for Simulation .... 89

49. Simulated Output and Control Voltages for the Circuit in Figure 47 from Start - up $\ldots \ldots \ldots \ldots \ldots \ldots \ldots \ldots . . \ldots$

50. Simulated Inductor Current for the Circuit in Figure 47 from Start - up $\ldots \ldots \ldots \ldots \ldots \ldots \ldots \ldots .91$

51. Detailed Inductor Current of Figure $50 \ldots \ldots \ldots \ldots \ldots . \ldots 1$

52. Simulated Output Voltage for the Circuit in Figure 47 after a Step Change in $E_{\text {in }}$ from $20 \mathrm{~V}$ to $40 \mathrm{~V}$ at $\mathrm{t}=2 \mathrm{~ms} \ldots \ldots .92$

53. Simulated Inductor Current for the Circuit in Figure 47 after a Step Change in $E_{\text {in }}$ from $20 \mathrm{~V}$ to $40 \mathrm{~V}$ at $\mathrm{t}=2 \mathrm{~ms} \ldots \ldots .92$ 


\section{CHAPTER I}

\section{GENERAL INTRODUCTION}

\section{I.1 THE NEED FOR SWITCHED CIRCUITS IN POWER ELECTRONIC SYSTEMS}

Power electronic systems are used for delivery and conversion of electric power from a source to a load in a controllable manner. This is illustrated in Figure 1.

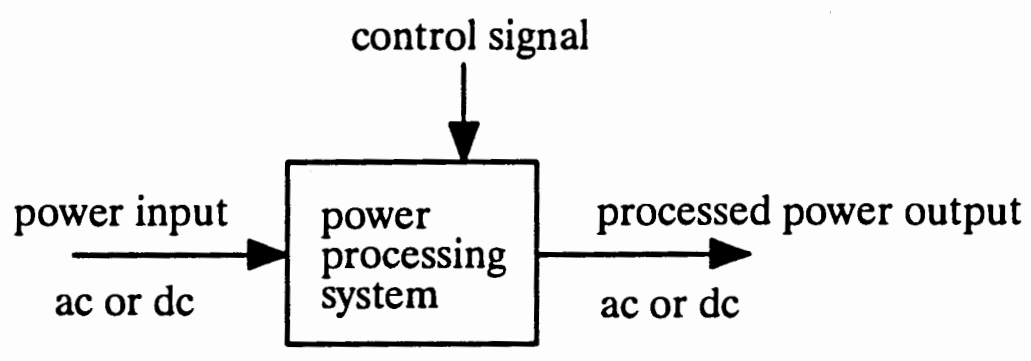

Figure 1. Power processing system.

The actual realization of a power processing system has to consider the demand for high efficiency. To see how this is done, we review two alternatives for delivery of electric power from a dc source to a load.

Linear power conversion relies on the presence of a series linear element (e.g. linear mode semiconductor device) such that the total load current is passed through the series linear element. This is shown in Figure 2. Linear power conversion even in its ideal form is dissipative and insufficient. For example, if we step down the input voltage such that $\mathrm{V}_{\text {load }}=\mathrm{V}_{\mathrm{g}} / 2$ then a maximum of $50 \%$ efficiency is achieved in the ideal case. 


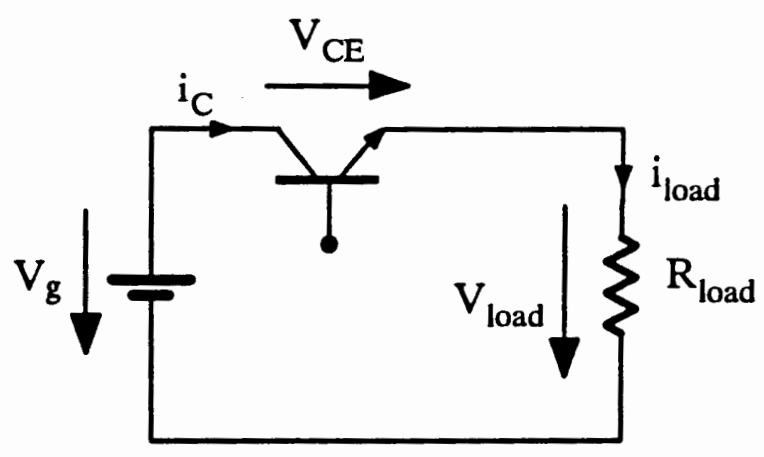

Eigure 2 Linear dc-to-dc power conversion.

In switched mode power conversion the semiconductor device acts as an ideal switch which is either ON or OFF. The power flow from the source to the load is controlled by varying the time intervals the switch spends in its ON- and OFF-state. A schematic diagram of a switched mode power conversion is given in Figure 3.

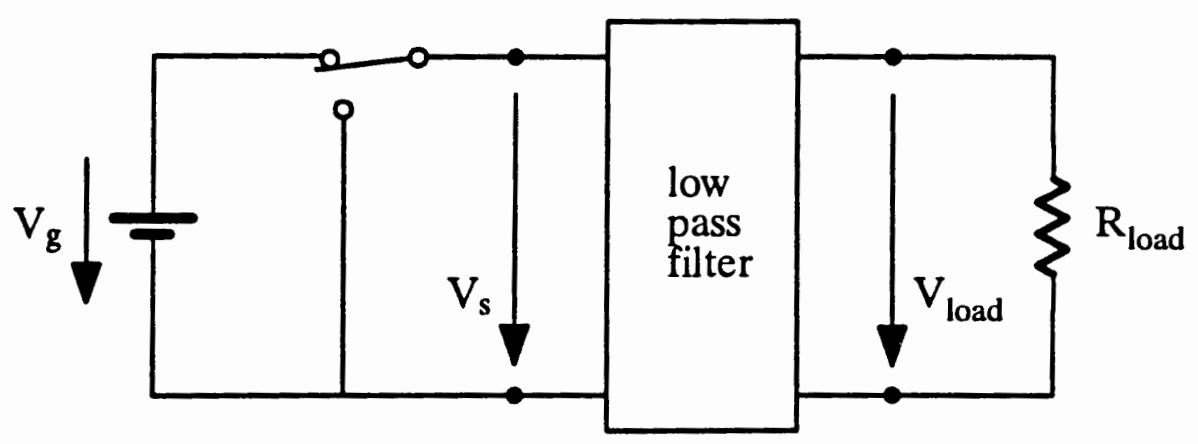

Figure 3. Switched mode power conversion.

The pulse-width-modulated waveform of $\mathrm{V}_{\mathrm{s}}$ is given in the following figure where $\mathrm{D}$ is known as the duty ratio and $\mathrm{T}_{s}$ is the switching frequency. In order to smooth out the power flow to the load a low-pass filter is used. If its corner frequency is well below the switching frequency then the first and higher order harmonics (integer multiples of the switching frequency) are substantially attenuated and only the dc component of $V_{s}(t)$ passes unattenuated to generate the dc output. 


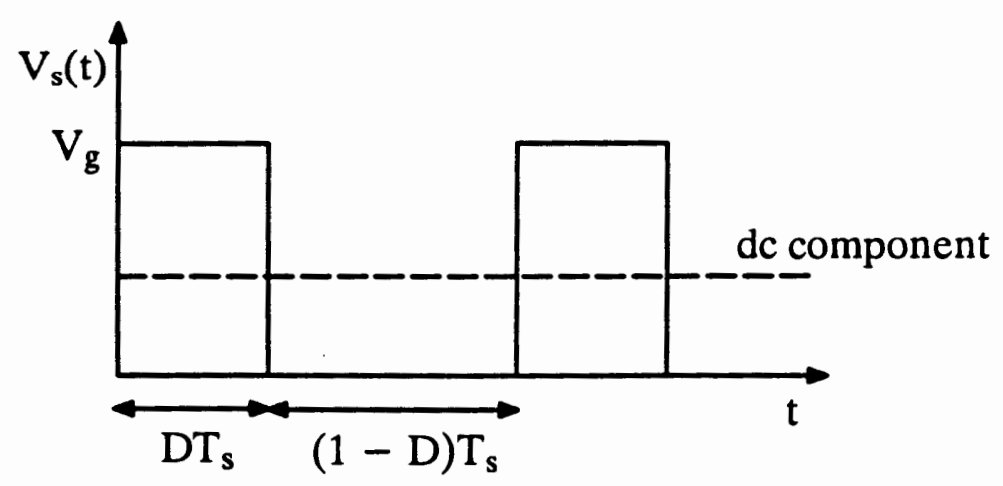

Figure 4. Voltage waveform of $V_{s}(t)$ in Figure 3.

The dc output is the arithmetic average of the pulse-width-modulated voltage $\mathrm{V}_{\mathrm{s}}(\mathrm{t})$ and becomes

$$
V_{\text {load }}=\frac{1}{T_{s}} \int_{0}^{T_{3}} V_{s}(t) d t=D V_{g}
$$

As it can be seen in equation (1), by controlling the duty ratio $D$, the output voltage $\mathrm{V}_{\text {load }}$ is controlled. Switched mode power conversion is ideally $100 \%$ efficient. In practice, the efficiency is degraded somewhat due to non-ideal semiconductor realization of the switch, copper and core losses of inductors and transformers. A well designed power processing system is still able to achieve up to $98 \%$ efficiency.

Switched mode power conversion does not only provide an almost ideal efficiency, it also provides a complete flexibility of input and/or output voltage and/or current values, direction of power flow and frequencies.

\section{I.2 THE BUCK-BOOST CONVERTER AND BASIC OPERATION MODES}

One of the basic dc-to-dc converters is the buck-boost converter and its operation is explained next. 


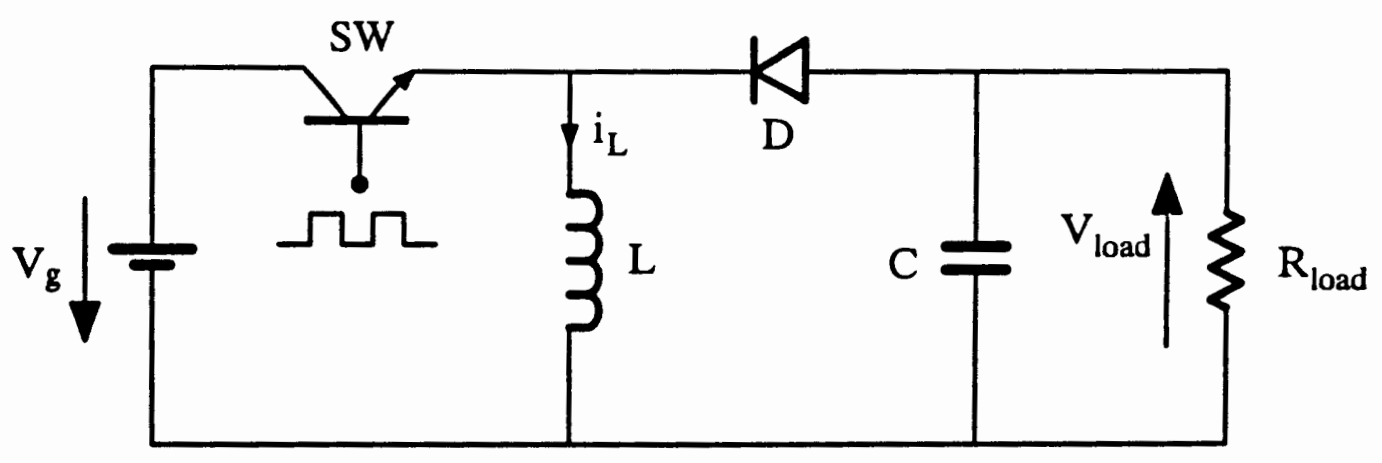

Figure 5. Buck-boost converter.

We find that under most conditions the switch SW (i.e. a semiconductor transistor operating as a switch with a fixed switching frequency) and the diode D operate in antiphase. During the time when $\mathrm{SW}$ is $\mathrm{ON}$, the inductor current increases linearly. The diode D is OFF and isolates the capacitor and the load from the source. When SW is turned OFF, D turns ON immediately and the inductor current can flow uninterrupted into the capacitor and the load. Hereby the inductor current decreases linearly and if SW is turned $\mathrm{ON}$ before the inductor current falls to zero then the converter operates in continuous conduction mode (CCM). This is illustrated in Figure 6 , showing the typical rectangular waveform of the inductor current in steady state. The inductor current ripple results from an incomplete attenuation of high-frequency components by the low-pass filter.

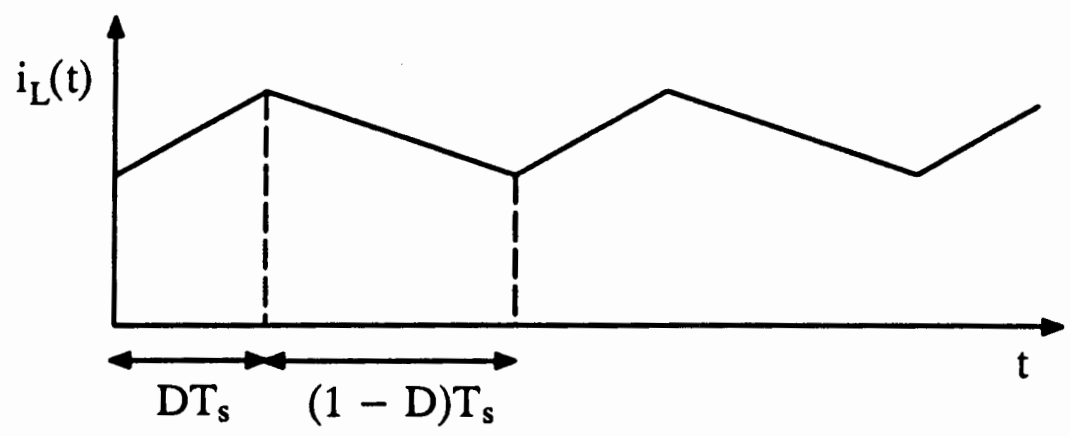

Figure 6. Inductor current in steady state CCM operation. 
The converter can also operate in discontinuous conduction mode (DCM). The inductor current flows only for a portion of the switching period and falls to zero before $\mathrm{SW}$ is turned $\mathrm{ON}$ again. The inductor current in steady state DCM operation is shown in Figure 7.

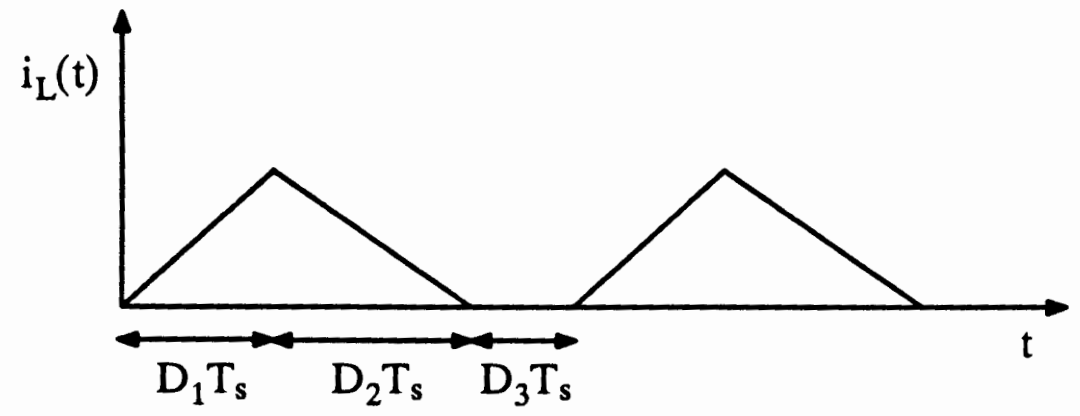

Figure 7. Inductor current in steady state DCM operation.

In the time interval $D_{3} T_{s}$ the inductor current is zero and both switch $S W$ and diode D are OFF. DCM operation may occur if the converter experiences a step change in the load impedance or input voltage or if circuit values are chosen accordingly. The output voltage of the converter shows the same characteristic rectangular waveform as it has been shown in Figure 6 for the inductor current and its dc component is governed by the following equation

$$
\frac{V}{V_{g}}=\frac{D}{1-D}
$$

Equation (2) describes the voltage conversion ratio of the ideal buck-boost converter when operating in steady state. Hence, either a step-up $(D>0.5)$ or a step-down $(\mathrm{D}<0.5)$ function can be achieved in the same converter. Moreover, the buck-boost converter provides an inversion of the output voltage (refer to Figure 5).

Other $\mathrm{dc}-$ to- $\mathrm{dc}$ converter may only provide a boosting of the input voltage (boost converter) or a step-down function (buck converter). A common characteristic 
of the three basic dc-to- dc converter (buck, boost, and buck-boost converter) is its inductive energy transfer. Dc-to-dc converter may be based on a capacitive energy transfer and are known as Cuk converter.

\section{I.3 TIME-DOMAIN ANALYSIS OF SWITCHED LINEAR NETWORKS}

Analysis techniques suitable for the solution of switched linear networks must overcome the nonlinearity introduced by the switching action. Moreover, modelling a switch may lead to a stiff system, i.e. the poles of the system are widely spread in the left half plane for a stable system.

Commonly used analysis techniques for power electronic systems are based on a state space approach. For any topology a set of state equations is derived. By averaging the state equations a large-signal dc model is obtained describing the dc properties of the converter. The model is usually a good approximation provided that the natural converter, regulator, and line variation frequencies are much less than the switching frequency. Using the above averaging technique a small-signal ac model of a switched mode converter can be derived. Hereby, a quiescent operating point is established and the effect of small ac variations in the duty ratio or input voltage about the operating point can be examined. The model neglects the switching harmonics by assuming a small switching ripple and a much higher switching frequency than the low-frequency variations. The small-signal ac model is not applicable when the network experiences large signal changes, e.g. a step change in the input voltage or load impedance.

A general large-signal time-domain analysis of switched linear networks must be free of any assumptions or limitations and proceeds as follows. At any given time each switch is in a particular state and the network is described by a set of circuit equations. The circuit equations are integrated until one or several circumstances 
cause one or several switches to change state. After the exact switching time has been found the topology is updated at the switching instant and the integration continues in time.

Since the switch is a non-linear element, a suitable switch model has to be used to maintain a set of linear circuit equations. The formulation method being used for setting up the circuit equations has to be general such that any circuit element can be handled by the formulation method.

Solving continuous-time circuit equations on a digital computer requires the use of a numerical integration method. Since we are dealing with stiff systems in the power electronic field, only stiffly stable integration methods [1] can be used for a time-efficient solution of the circuit equations. Integration methods which are not stiffly stable require a smaller step size to bring all the poles in to the stability region of the numerical integration method. In this thesis we focus on two numerical methods suitable for the solution of switched linear networks. The transmission-line modelling method $[5-10,12,13]$ models circuit components as transmission-line stubs and the analysis completely operates in the time domain. Since the transmission-line modelling method has been found equal to the trapezoidal rule, the integration method is stable in the whole left half plane. Contrarily, the numerical inverse Laplace transform [1,14-19] operates in the frequency domain and the time-domain response is obtained by taking an inverse transform. It has been shown in $[1,15]$ that the numerical inverse Laplace transform even extends its stability region into the right half plane depending on the order of integration.

The proper handling of switches is an important part in the network analysis. Switches can be grouped in to externally and internally controlled switches. Referring to the buck-boost converter in the previous section the semiconductor device operates with a fixed switching frequency. It is controlled by an external clock and its switching 
times are known at the beginning of the simulation. Contrarily, the diode is internally controlled and its correct state needs to be determined as the analysis progresses in time. When updating the topology at the switching instant, we cannot assume a switch relation between switches contained in the network. If a switched network contains several switches then it might be very difficult or even impossible for the user to specify in advance a switch arrangement. Therefore, every switch in the network is treated as a single element and we like the algorithm to be able to determine the correct switch configuration during the simulation. For example, if the buck-boost converter in Section I.2 switches to DCM operation during the simulation emerging a third valid topology instead of two in CCM operation then the situation has to be handled automatically by the algorithm.

Circuit simulation has become an inevitable tool in analyzing and designing electrical networks. Due to the increased complexity of electrical devices and the demand to reduce or even eliminate time - and cost-intensive steps in product development, it has become essential to use computers for analysis and design. Commercially available simulators like SPICE have been primarily developed for the simulation of non-switched linear and/or non-linear circuits. As it has been shown in [19], the handling of switched networks with SPICE is unreliable and leads to unacceptable errors in the simulation mostly because of the fact that the switching times are not calculated precisely. Only recently advanced analysis techniques for switched linear networks $[5-10,12-20]$ have been presented. Switched circuit simulators become more and more appreciated in the development and design of power electronic supplies. They enable the engineer to verify a design before any prototype is actually built. For example, the engineer may be interested in the transient response of a power electronic supply from start - up or in the stability properties of the system when being subject to a step change in the input voltage or load impedance. 
A simulator featuring variable step size and automatic error control has been written in $\mathrm{C}++$ based on the 4 th order numerical inverse Laplace transform and the one-graph modified nodal description. Several simulation results are given to illustrate properties of the method and capabilities of the simulator.

\section{I.4 OUTLINE OF THE THESIS}

This thesis is divided into 5 chapters. In Chapter 2, the transmission-line modelling method (TLM) is discussed. We review the modelling of electrical components as transmission-line sections and explain the operation of the TLM routine. A general approach to the solution of a transmission-line modelled network is given based on the one-graph modified nodal description. In an example, we compare the TLM integration method with other numerical methods and a proof is given which shows the numerical equivalence of the TLM method and the trapezoidal rule.

Chapter 3 contains a review of the numerical inverse Laplace transform and its properties. A method to calculate consistent initial conditions and Dirac impulses is given. In the analysis of switched linear networks we cannot assume that the circuit response is continuous across the switching boundary. Even Dirac impulses may occur at intermediate steps of the analysis. Therefore it is quite important that the numerical inverse Laplace transform is able to handle discontinuities and Dirac impulses.

In Chapter 4, we discuss the development of a switched circuit simulator based on the numerical inverse Laplace transform. Several problems in the time-domain analysis have to be overcome. This includes the handling of switching variables of externally and internally controlled switches, a precise calculation of switching times and the determination of a correct topology immediately after switching. The 
implementation of a variable step size and automatic error control algorithm is discussed and several difficulties in simulation are identified. Simulation results are given to illustrate properties of the integration method and capabilities of the simulator.

Finally, Chapter 5 discusses conclusions. 


\section{CHAPTER II \\ TRANSMISSION-LINE MODELLING}

\section{II.1 INTRODUCTION}

Describing an electrical network in the time domain leads to the problem of solving coupled integro-differential equations. Several techniques exist in the literature $[1,2,3,4,14]$ to solve these equations numerically by a computer.

Transmission-line modelling (TLM) is a discrete transform technique suitable for the solution of electrical networks. Using this technique $[5-10,12,13]$ a discrete model is derived from the physical system, i.e. electrical network. Since this method operates throughout in the time domain, an inverse transform is not required.

The basic idea of this method is to model those electrical components, which lead to differential or integral terms in the circuit equations, as transmission-line stubs. An ideal inductor is modelled as a lossless short-circuit transmission line and an ideal capacitor is transformed into a lossless open-circuit transmission line. The modelling process leads to linear and discrete-time equations which can be solved on a digital computer.

Computer simulation of electrical networks requires the generation of circuit equations to be done by a computer. Since the modified nodal description is very well suited for use on a computer, a general approach is given in this chapter, which demonstrates how to derive circuit equations by inspection from a transmission-line modelled circuit using the one-graph modified nodal description.

Furthermore a proof is given, which shows the numerical equivalence of the transmission-line modelling method and the trapezoidal rule. 


\section{II.2 DISCRETE MODEL OF ELECTRICAL COMPONENTS}

\section{II.2.1 Self inductance}

As known from transmission-line theory, an ideal inductor can be modelled as a lossless short-circuit transmission line.
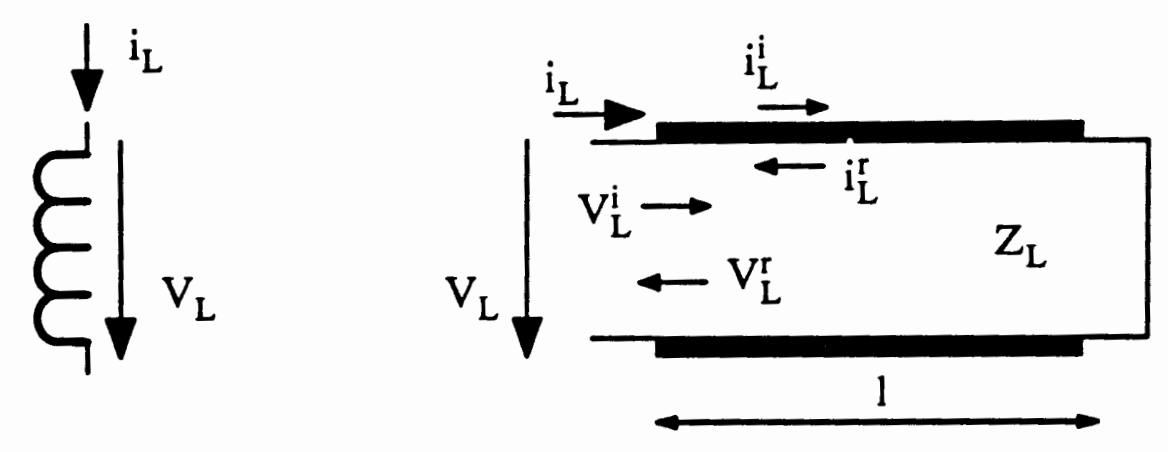

Eigure 8. Continuous transmission-line model of an inductor.

The superscript $i$ denotes an incident wave and the superscript $r$ stands for a reflected wave. The input impedance of a lossless short-circuit transmission line can be shown to be

$$
W=j Z_{L} \tan (\beta 1)
$$

where $\beta$ is the phase constant and $Z_{L}$ is the characteristic impedance.

$$
\begin{gathered}
\beta=\frac{2 \pi}{\lambda}=\frac{\omega}{v_{p h}} \\
Z_{L}=\sqrt{\frac{L^{\prime}}{C^{\prime}}}
\end{gathered}
$$

$L^{\prime}$ and $C^{\prime}$ in equation (5) denote the inductance and capacitance per unit length. Expanding equation (3) into a Taylor series and omitting higher order terms results in

$$
W=\mathrm{j} Z_{\mathrm{L}} \beta l
$$


The phase velocity can be written as

$$
v_{p h}=\frac{1}{\sqrt{L^{\prime} C^{\prime}}}
$$

Substituting (4), (5) and (7) into (6), we finally obtain

$$
\mathcal{W}=j \omega \mathrm{L}
$$

The preceding calculation justifies our previous statement. By choosing the appropriate weightings of the inductive and capacitive components of a transmission line, the input impedance has a dominant inductive component and therefore it can be used as a continuous model of an inductor.

The transmission-line modelling method now uses pulses which are travelling to and from one end of the transmission line to the other. Superposition of incident and reflected pulses at the input of the transmission line leads to the following equations:

$$
\begin{aligned}
V_{L} & =V_{L}^{i}+V_{L}^{r} \\
i_{L} & =i_{L}^{i}-i_{L}^{r}
\end{aligned}
$$

Since the characteristic impedance is the ratio of incident or reflected voltage and current waves respectively

$$
Z_{L}=\frac{V_{L}^{i, r}}{i_{L}^{i, r}}
$$

a simple calculation then results in

$$
V_{L}=Z_{L} i_{L}+2 V_{L}^{r}
$$

Using equations (5) and (7), we can write the characteristic impedance as

$$
Z_{L}=v_{p h} L^{\prime}=\frac{2 L}{T}
$$

where $\mathrm{T}$ is the total propagation time of an impulse travelling from the input of the transmission line to the end and back again. 
The discrete transmission-line model of an inductor is determined by equation (12) and (13) and is shown in Figure 9.
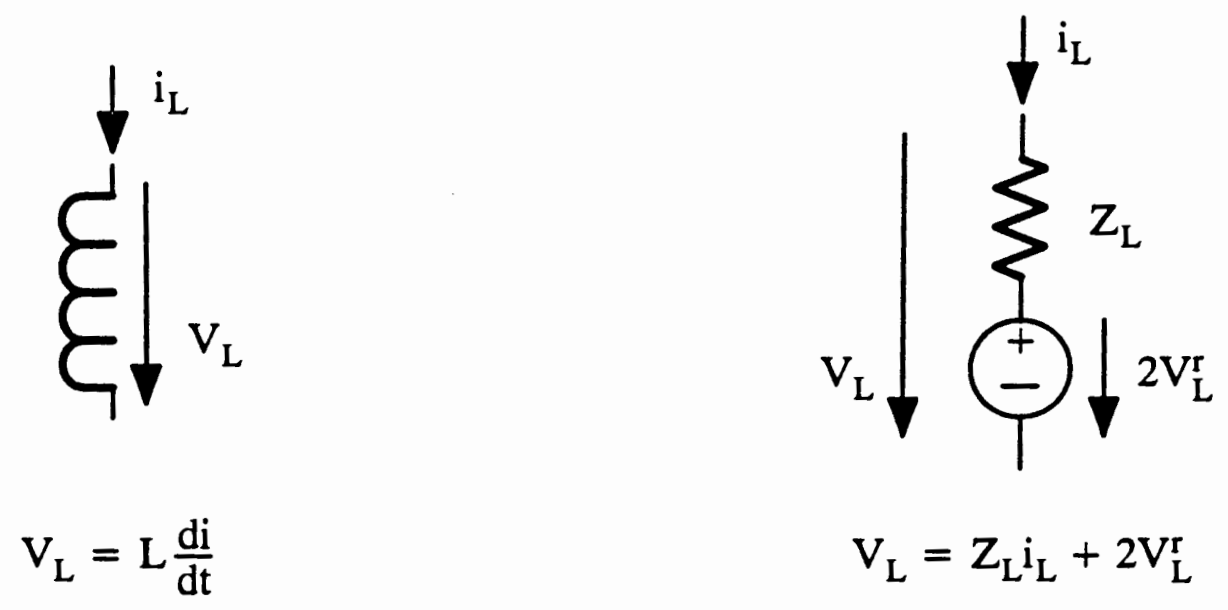

Figure 9. Discrete transmission-line model of an inductor.

Note that the differential term in the continuous-time expression for the inductor voltage has now been replaced by a discrete-time and linear equation.

Since the pulses are present at the input of the transmission line only at discrete time instants

$$
t_{k}=k T, \text { for } k=0,1,2,3, \ldots
$$

$T$ can be seen as the integration time step. The smaller $T$, the more accurate is the discrete model.

\section{II.2.2. Capacitor}

An ideal capacitor can be represented by a lossless open-circuit transmission line, which is illustrated by the following figure. The input impedance of a lossless open-circuit transmission line is

$$
W=-j Z_{C} \cot (\beta 1)
$$



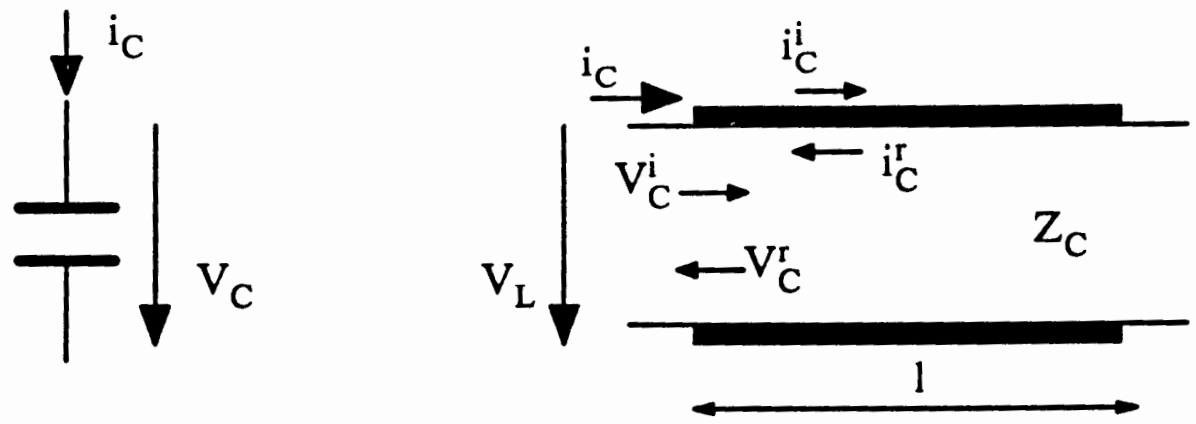

Figure 10. Continuous transmission-line model of a capacitor.

Proceeding in the same way as shown in the previous section, we can show that the input impedance has a dominant capacitive component

$$
W=\frac{1}{j \omega C}
$$

and therefore an open-circuit transmission line can be used as a continuous model of a capacitor. To obtain the discretized version of the continuous capacitor model, we again consider pulses, which are bouncing to and from the nodes of the transmission-line modelled network at each time step. After doing some algebra, we end up with the following two equations that describe the discrete transmission-line model of a capacitor:

$$
\begin{gathered}
V_{C}=Z_{C} i_{C}+2 V_{C}^{r} \\
Z_{C}=\frac{T}{2 C}
\end{gathered}
$$

It is interesting to note that the continuous-time and integral equation has been transformed into a discrete-time and linear equation.

A smaller time step $T$ reduces the modelling error. The reader may refer to Section II.5 for a more detailed treatment of the numerical aspect. 


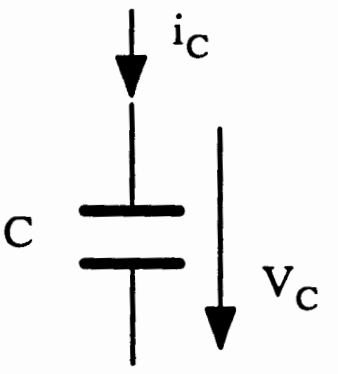

$\mathrm{V}_{\mathrm{C}}=\frac{1}{\mathrm{C}} \int \mathrm{i}_{\mathrm{C}} \mathrm{dt}$

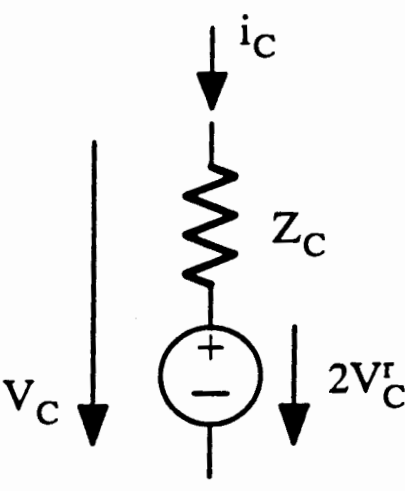

$V_{C}=Z_{C} i_{C}+2 V_{C}^{r}$

Eigure 11. Discrete transmission-line model of a capacitor.

\section{II.2.3 Mutual inductance}

As shown in Section II.2.1, the voltage across an inductive transmission-line section is described by equation (12). This clearly suggests the following discrete transmission-line model of a mutual inductance which is shown in Figure 12.

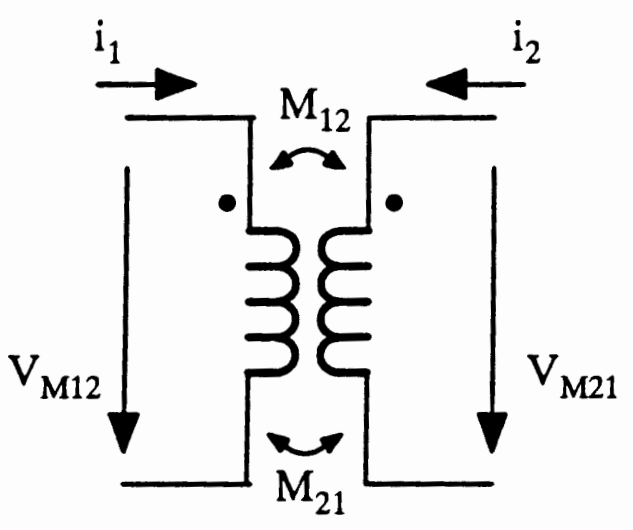

$$
\begin{aligned}
& V_{M 12}=M_{12} \frac{d_{2}}{d t} \\
& V_{M 21}=M_{21} \frac{d_{1}}{d t}
\end{aligned}
$$

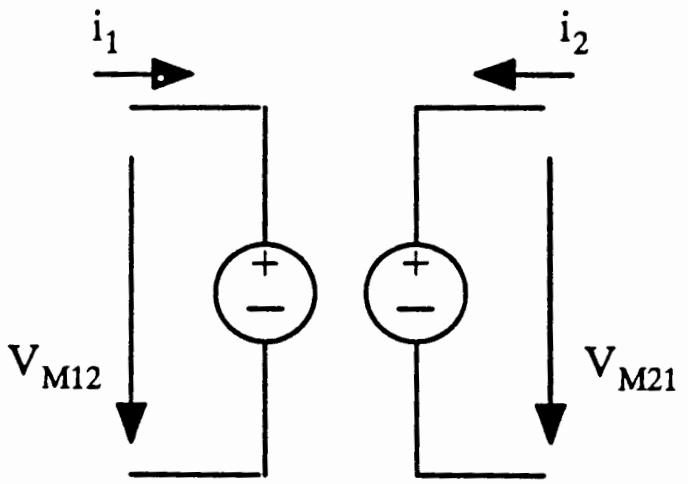

$$
\begin{aligned}
& V_{M 12}=Z_{M 12} i_{2}+2 V_{M 12}^{\mathrm{r}} \\
& V_{M 21}=Z_{M 21} i_{1}+2 V_{M 21}^{r}
\end{aligned}
$$

Figure 12. Discrete transmission-line model of a mutual inductance. 
For the reader's convenience we summarize the formulas below:

$$
\begin{gathered}
\mathrm{V}_{\mathrm{M} 12}=\mathrm{Z}_{\mathrm{M} 12} \mathrm{i}_{2}+2 \mathrm{~V}_{\mathrm{M} 12}^{\mathrm{r}} \\
\mathrm{Z}_{\mathrm{M} 12}=\frac{2 \mathrm{M}_{12}}{\mathrm{~T}} \\
\mathrm{~V}_{\mathrm{M} 21}=\mathrm{Z}_{\mathrm{M} 21} \mathrm{i}_{1}+2 \mathrm{~V}_{\mathrm{M} 21}^{\mathrm{r}} \\
\mathrm{Z}_{\mathrm{M} 21}=\frac{2 \mathrm{M}_{21}}{\mathrm{~T}}
\end{gathered}
$$

\section{II.2.4 Resistor, sources, and controlled sources}

Keeping in mind our original goal to transform differential and integral terms in the circuit equations into discrete and proportional terms, we immediately conclude that there is no need to model elements like resistors, voltage sources, current sources and all types of controlled sources. These elements only add proportional terms to the integro-differential circuit equations and consequently they appear unchanged in the transmission-line modelled network. For example, an ideal resistor is described by Ohm's law, a linear and proportional relation between resistor voltage and resistor current. Therefore the resistor is treated equally in the transmission-line modelled network as in the original untransformed network.

\section{II.2.5 Switch and diode}

Unlike the approach in Chapter III, where a switch or a diode is modelled ideally as a short (open) circuit when it is ON (OFF), the transmission-line modelling method represents switches and diodes as transmission-line stubs. When the switch is $\mathrm{ON}$, it is modelled as a short-circuit transmission line or a very small inductor. In its $\mathrm{OFF}$-state the switch is represented by an open-circuit transmission line or a very small capacitor. This is shown in Figure 13. 
It is important to note that the characteristic impedance is independent of the switching state. When the switch is OFF, the dominant capacitive input impedance of the open-circuit transmission line represents the switch. In its ON-state, the capacitive stub is shorted so that it becomes the associated stray inductor. Hence, the switching action only affects the reflection coefficient at the end of the transmission line and controlling the switch becomes a problem of controlling the polarity of the reflected pulses (for further explanation about how the pulses are reflected and how the integration routine operates the reader may refer to the next section). As long as the integration time step $T$ remains constant ( this is clearly not the case for a variable step size simulator), topology changes don't affect the system matrix, which consequently has to be inverted only once at the beginning of the simulation. The discrete transmission-line model of a switch is given in Figure 14. The discrete model is governed by the following equation

$$
\mathrm{V}_{\mathrm{SW}}=\mathrm{Z}_{\mathrm{SW}} \mathrm{i}_{\mathrm{sW}}+2 \mathrm{~V}_{\mathrm{SW}}^{\mathrm{r}}
$$

\section{II.3 OPERATION OF THE TLM ROUTINE}

In order to explain the operation of the TLM routine, we consider an arbitrary electrical network. Let all inductors, capacitors, and non-linear elements (switches, diodes) contained in the network be connected externally on pairs of nodes termed ports. Consequently the scattering zone $S$ contains only linear resistors, independent voltage and current sources and all types of linear controlled sources. This is shown in Figure 15(a). Applying the TLM method to the electrical network yields the transmission-line modelled network, which is illustrated in Figure 15(b). Inductors, capacitors and non-linear elements are modelled by transmission-line stubs. Recall that in the previous section the discrete transmission-line model of these elements had 

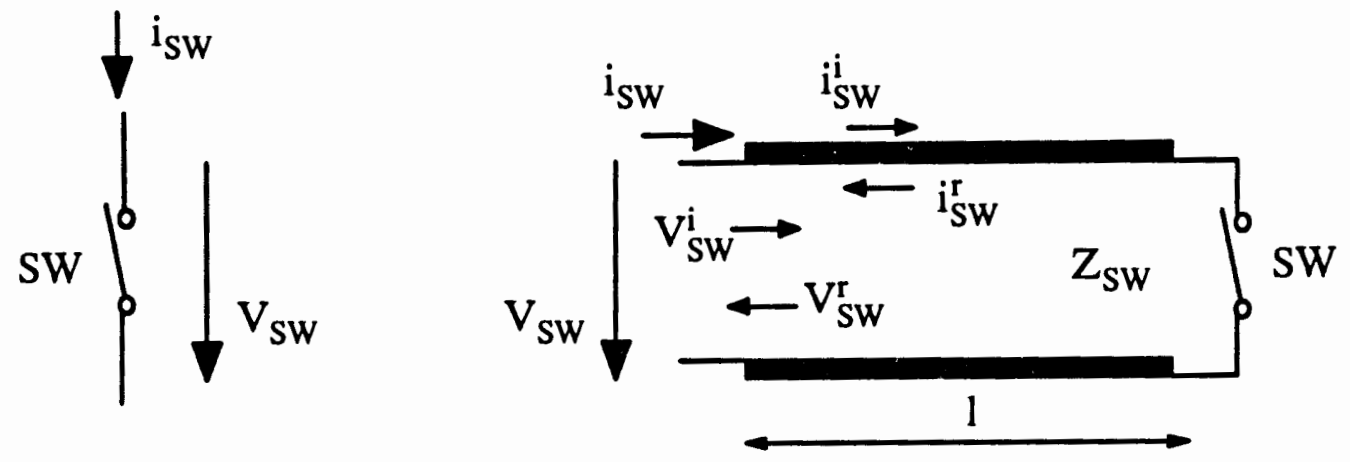

Figure 13. Continuous transmission-line model of a switch.
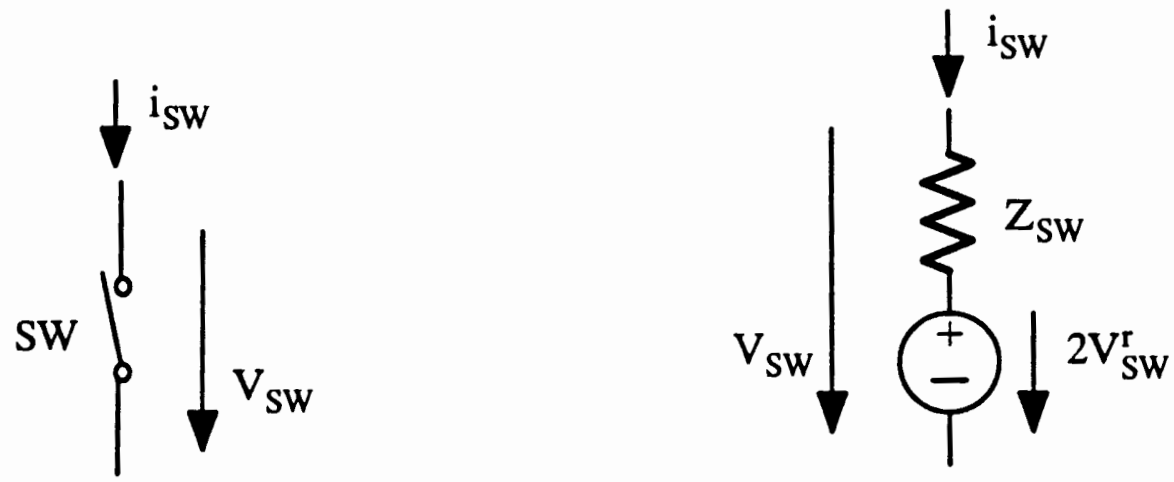

Figure 14. Discrete transmission-line model of a switch. 


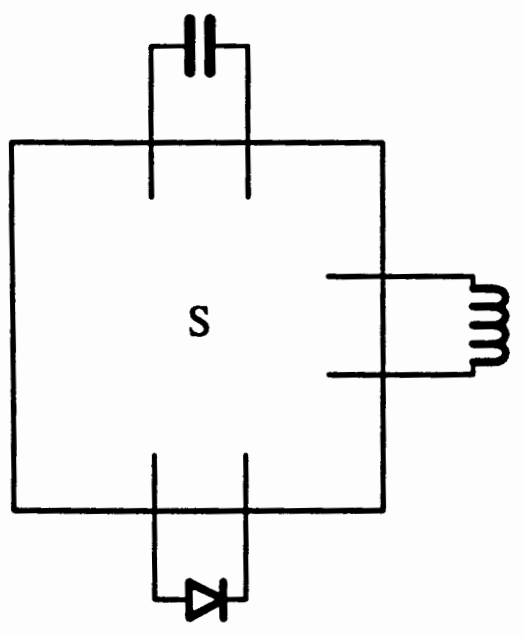

(a)

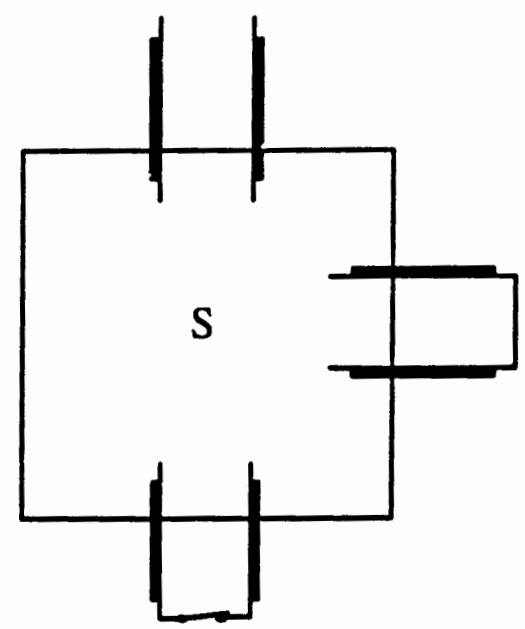

(b)

Figure 15. Transmission-line scattering zone.

been derived and resulted in a voltage generator in series with a linear resistor. The TLM procedure operates by transmitting pulses along the transmission lines. Suppose at time $t_{k}=k T, k=0,1,2,3, \ldots$, the voltage generators inject pulses out of the ports of S. The pulses travel along the transmission lines and are reflected at the distant termination.

The reflection of a pulse is governed by the reflection coefficient, which is defined as

$$
r=\frac{Z-Z_{T L}}{Z+Z_{T L}}=\frac{V r}{V i}
$$

where $\mathrm{Z}_{\mathrm{TL}}$ is the characteristic impedance of the transmission line. An open-circuit transmission line $(Z=\infty)$ forces the reflection coefficient to be $r=+1$, whereas a short-circuit transmission line $(Z=0)$ results in $r=-1$. 
At time $t_{k+1}=(k+1) T$ the pulses scatter into the ports of $S$ and we obtain

$$
k+1 V^{r}=-{ }_{k} V^{i}
$$

for a short-circuit termination and

$$
{ }_{k+1} V^{r}=+{ }_{k} V^{i}
$$

for an open-circuit termination. Together with a new injection of the sources, pulses are launched back into the transmission lines and the process repeats. At each discrete time step the branch voltages have to be calculated using the equations (12), (17) and (23). The new incident pulse of each port is obtained by subtracting the reflected pulse from the branch voltage according to equation (9).

\section{II.4 SOLUTION OF THE TRANSMISSION-LINE MODEL USING THE ONE-GRAPH MODIFIED NODAL DESCRIPTION}

\section{II.4.1 General formulation method}

The implementation of a circuit analysis program on a digital computer requires the automatic generation of circuit equations. Rules have to be known in advance that enable us to build up matrices (a set of circuit equations) bit by bit as the information on each branch is being processed in batch mode by the computer. Moreover, the formulation method being used has to be able to handle components in impedance and admittance form, switches, independent current and voltage sources, and all types of controlled sources in order to achieve a general simulator.

The one-graph modified nodal description demonstrates those features and is explained in detail in reference [1]. Applying this circuit formulation method to a transmission-line modelled network requires the construction of various matrices which can be built up by inspection. 
Let the incident and reflected pulses at time $t_{k}=k T$ be defined by the vectors ${ }_{\mathbf{k}} \mathbf{V}^{\mathrm{i}}$ and ${ }_{\mathbf{k}} \mathbf{V}^{\mathbf{r}}$. The vectors $\mathrm{J}$ and $\mathbf{E}$ describe independent current and voltage sources. The modified nodal source vector is given by

$$
\mathbf{k}^{\mathbf{n}}=\mathbf{J}+\mathbf{E}+2 \mathbf{Y}_{\mathrm{b}} \times{ }_{\mathbf{k}} \mathbf{V}^{\mathbf{r}}
$$

where $Y_{b}$ will further be referred to as the TLM branch admittance matrix. The modified node-to-ground voltage vector is obtained from the modified node-admittance matrix $\mathbf{Y}_{\mathrm{n}}$ through the equation

$$
{ }_{k} V^{n}=Y_{n}^{-1} \times{ }_{k} j^{n}
$$

The incident pulses are obtained by subtracting the reflected pulses from the branch voltages

$$
{ }_{\mathbf{k}} \mathbf{V}^{\mathbf{i}}=\mathbf{A}^{\mathbf{T}} \times{ }_{\mathbf{k}} \mathbf{V}^{\mathbf{n}}-{ }_{\mathbf{k}} \mathbf{V}^{\mathbf{r}}
$$

where $\mathbf{A}$ is the modified reduced incidence matrix. The new reflected pulses, which scatter into the ports of $S$ at time $t_{k+1}=(k+1) T$, are given by

$$
k+1 \mathbf{V}^{r}=\mathbf{C} \times{ }_{k} \mathbf{V}^{\mathrm{i}}
$$

where $\mathbf{C}$ is the reflection matrix containing only entries of unity which describes the reflection of pulses.

Suppose that the network under consideration consists of $b$ branches and $N+1$ nodes. We shall label the nodes from 0 to $\mathrm{N}$, with node 0 connected to ground. Branches are labelled from 1 to $b$. The modified node-admittance matrix is a square matrix of minimum order $\mathrm{N}$. If components are entered into the matrix in impedance form, appropriate number of rows and columns have to be added. Suppose $\mathrm{m}$ rows and $\mathrm{m}$ columns have been added to the modified node-admittance matrix $\mathbf{Y}_{\mathrm{n}}$, then its dimension is $(\mathrm{N}+\mathrm{m}) \times(\mathrm{N}+\mathrm{m})$. Table I lists the dimensions of all matrices and vectors that are necessary for the integration routine. 
TABLE I

VECTOR AND MATRIX DIMENSIONS

\begin{tabular}{|cccr|}
\hline vector/matrix & dimension & vector/matrix & dimension \\
\hline $\mathbf{V}^{\mathbf{i}}$ & $\mathrm{b} \times 1$ & $\mathbf{J}^{\mathrm{n}}$ & $(\mathrm{N}+\mathrm{m}) \times 1$ \\
\hline $\mathbf{V}^{\mathbf{r}}$ & $\mathrm{b} \times 1$ & $\mathbf{Y}_{\mathrm{b}}$ & $(\mathrm{N}+\mathrm{m}) \times \mathrm{b}$ \\
\hline $\mathbf{V}^{\mathbf{n}}$ & $(\mathrm{N}+\mathrm{m}) \times 1$ & $\mathbf{Y}_{\mathrm{n}}$ & $(\mathrm{N}+\mathrm{m}) \times(\mathrm{N}+\mathrm{m})$ \\
\hline $\mathbf{J}$ & $(\mathrm{N}+\mathrm{m}) \times 1$ & $\mathbf{A}$ & $(\mathrm{N}+\mathrm{m}) \times \mathrm{b}$ \\
\hline $\mathbf{E}$ & $(\mathrm{N}+\mathrm{m}) \times 1$ & $\mathbf{C}$ & $\mathbf{b} \times \mathrm{b}$ \\
\hline
\end{tabular}

The flow chart in Figure 16 summarizes the TLM integration routine based on the one-graph modified nodal description for a non-switched linear network. It should be noted that switches can be handled by the TLM method. Switches are modelled as shown in Section II.2.5. The modified node-admittance matrix $\mathbf{Y}_{\mathbf{n}}$ is not affected by the switching action. Only the polarity of the unitary entries in the reflection matrix $\mathbf{C}$ have to be changed appropriately when the switch turns ON or OFF.

\section{II.4.2One-graph modified nodal formulation by inspection}

In this section we explain how matrix entries are made using an inductive TLM branch as an example. Tables are given which show how vectors and matrices can be constructed by inspection.

Let us now consider an inductor between the nodes $j$ and $j$ '. The branch number shall be $\mathrm{k}$. The inductor is modelled by a short - circuit transmission line and Figure 17 shows its discrete transmission-line model. 


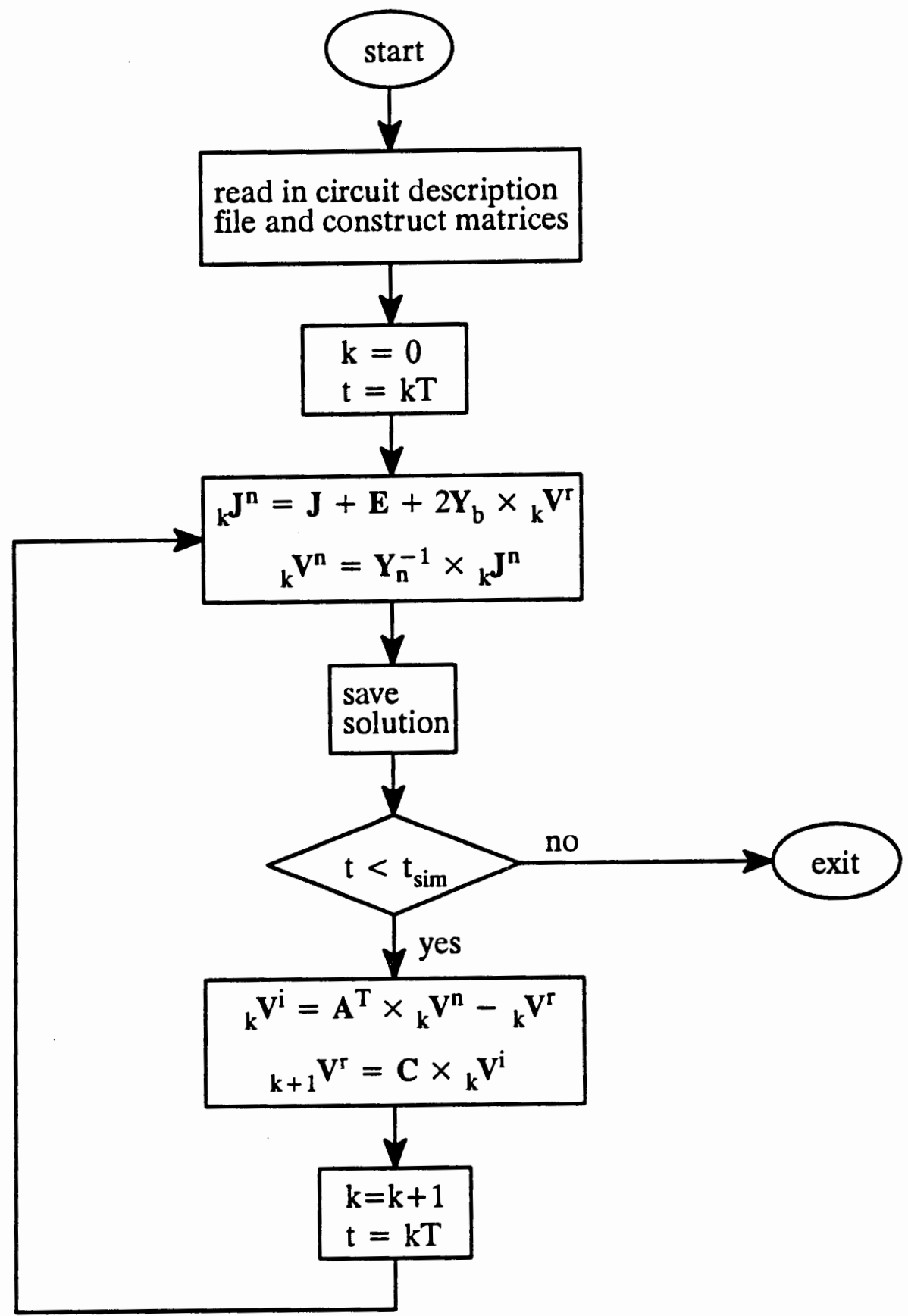

Figure 16. TLM flow chart for non-switched linear network. 


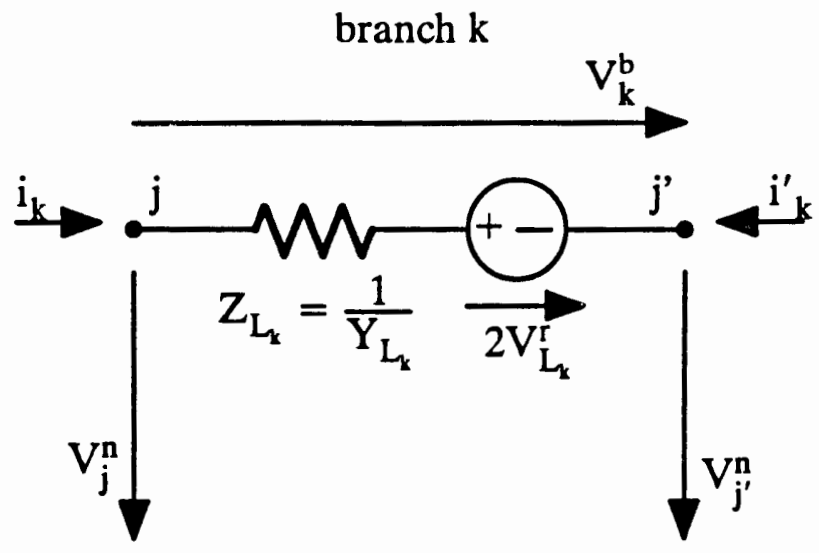

Figure 17 Inductive TLM branch.

According to Kirch hoff's current law the sum of currents at a node equals zero. Therefore we can write the equations

$$
\begin{aligned}
i_{k} & =\left(V_{j}^{n}-V_{j^{\prime}}^{n}-2 V_{L_{k}}^{r}\right) Y_{L_{k}}=0 \\
i_{k}^{\prime} & =-i_{k}=\left(V_{j^{\prime}}^{n}-V_{j}^{n}+2 V_{L_{k}}^{r}\right) Y_{L_{k}}=0
\end{aligned}
$$

Writing (31) and (32) in matrix form results in

$$
j\left[\begin{array}{cc}
j & j^{\prime} \\
Y_{L_{k}} & -Y_{L_{k}} \\
-Y_{L_{k}} & Y_{L_{k}}
\end{array}\right] \times\left[\begin{array}{c}
V_{j}^{n} \\
V_{j^{\prime}}^{n}
\end{array}\right]=\left[\begin{array}{c}
2 Y_{L_{k}} V_{L_{k}}^{r} \\
-2 Y_{L_{k}} V_{L_{k}}^{r}
\end{array}\right]
$$

Clearly equation (33) has the form of (28). We can split up the vector on the right side of equation (33) and we obtain

$$
j\left[\begin{array}{c}
2 Y_{L_{k}} V_{L_{k}}^{r} \\
-2 Y_{L_{k}} V_{L_{k}}^{r}
\end{array}\right]=2 \times\left[\begin{array}{c}
k \\
Y_{L_{k}} \\
-Y_{L_{k}}
\end{array}\right] \times\left[V_{L_{k}}^{r}\right]+[]+[]
$$


which has the form of (27). Since matrix $\mathbf{Y}_{b}$ contains the admittances of the TLM ports of S, we call it the TLM branch admittance matrix. Proceeding in the same way as shown above, we can establish rules for setting up matrix equations by inspection for any component and the results are summarized in the following tables.

We denote the size of the matrix $Y_{n}$ by $n=N$, $n$ being initially the number of ungrounded nodes. The size of the basic matrix is increased whenever we enter an element which does not have an admittance description. After all the elements have been entered, $n$ equals $(\mathrm{N}+\mathrm{m})$; $\mathrm{m}$ being the total number of added rows/columns. The number of rows of the vectors $\mathbf{E}$ and $\mathbf{J}$ have to be adjusted in the same way.

Suppose there are $b$ branches and the scattering zone $S$ contains $p$ ports. Then the vectors $V^{i}$ and $V^{r}$ have $p$ non-zero entries and $(b-p)$ entries equal zero. The number of columns of the TLM branch admittance matrix $\mathbf{Y}_{\mathbf{b}}$ is determined by the number of branches. Only the number of rows has to be increased and equals $(N+m)$. The same is true for the modified reduced incidence matrix A. Details about the matrix A can be found in reference $[1,2] . \mathbf{C}$ is a square matrix of order b. Elements which are not listed in the tables either don't affect matrices and vectors by non-zero entries or can be entered into the matrices as shown in reference [1].

\section{II.5 TLM INTEGRATION METHOD AND TRAPEZOIDAL RULE}

The motivation for the work which is presented in this section has been the fact that a variable step size simulator requires the implementation of two integration routines of different order. Since the difference between the two solutions is taken to be the truncation error of the lower order method, the higher order method is used to monitor the error. Based on the truncation error the step size is varied in order to meet the error criterion. Therefore our goal has been to find out the numerical properties 


\begin{tabular}{|c|c|c|}
\hline ELEMENT & SYMBOL & MATRIX $Y_{n}$ \\
\hline inductor & 音 & $j\left[\begin{array}{cc}j & j^{\prime} \\
Y_{L_{k}} & -Y_{L_{k}} \\
Y_{L_{k}} & -Y_{L_{k}}\end{array}\right.$ \\
\hline capacitor & 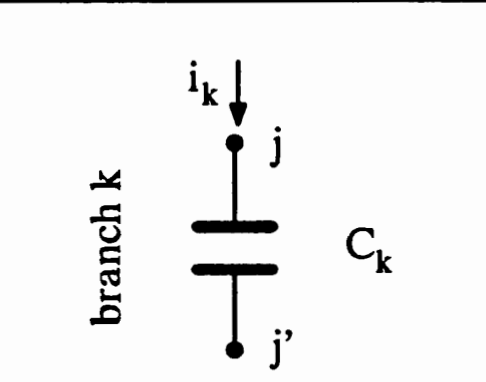 & $j\left[\begin{array}{cc}j & j \\
Y_{C_{k}} & -Y_{C_{k}} \\
Y_{C_{k}} & -Y_{C_{k}}\end{array}\right]$ \\
\hline switch/diode & $\int_{j}^{i_{k}} \int_{j}^{j} s w_{k}$ & $j\left[\begin{array}{cc}j & j \\
Y_{S W_{k}} & -Y_{S W_{k}} \\
Y_{S W_{k}} & -Y_{S W_{k}}\end{array}\right]$ \\
\hline transformer & 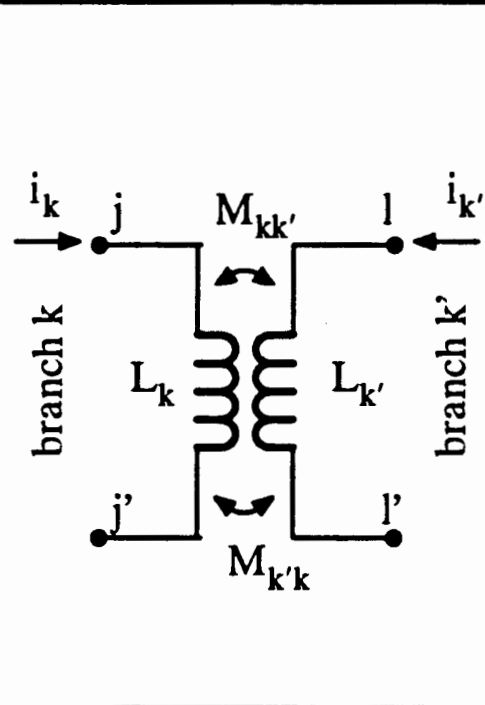 & 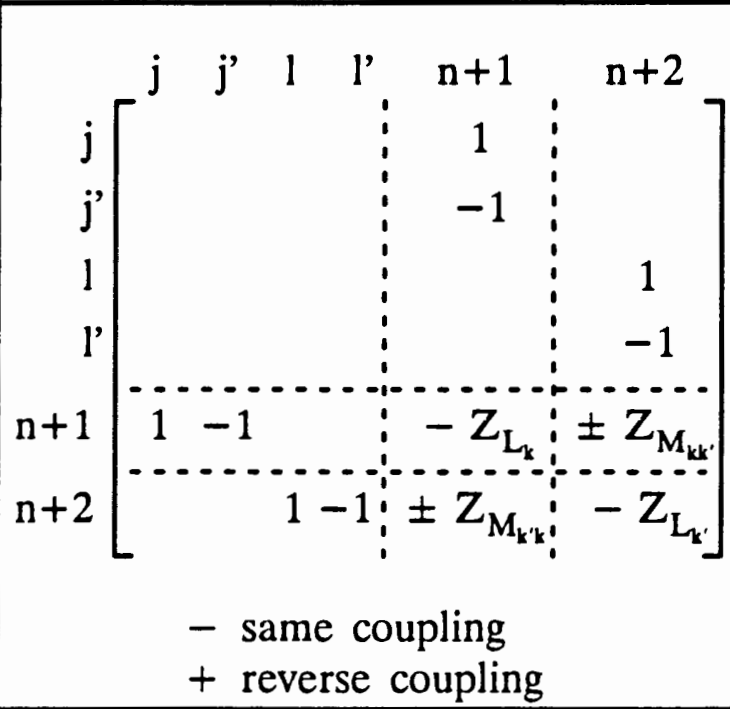 \\
\hline
\end{tabular}

Figure 18. Modified node-admittance matrix $\mathbf{Y}_{\mathbf{n}}$. 


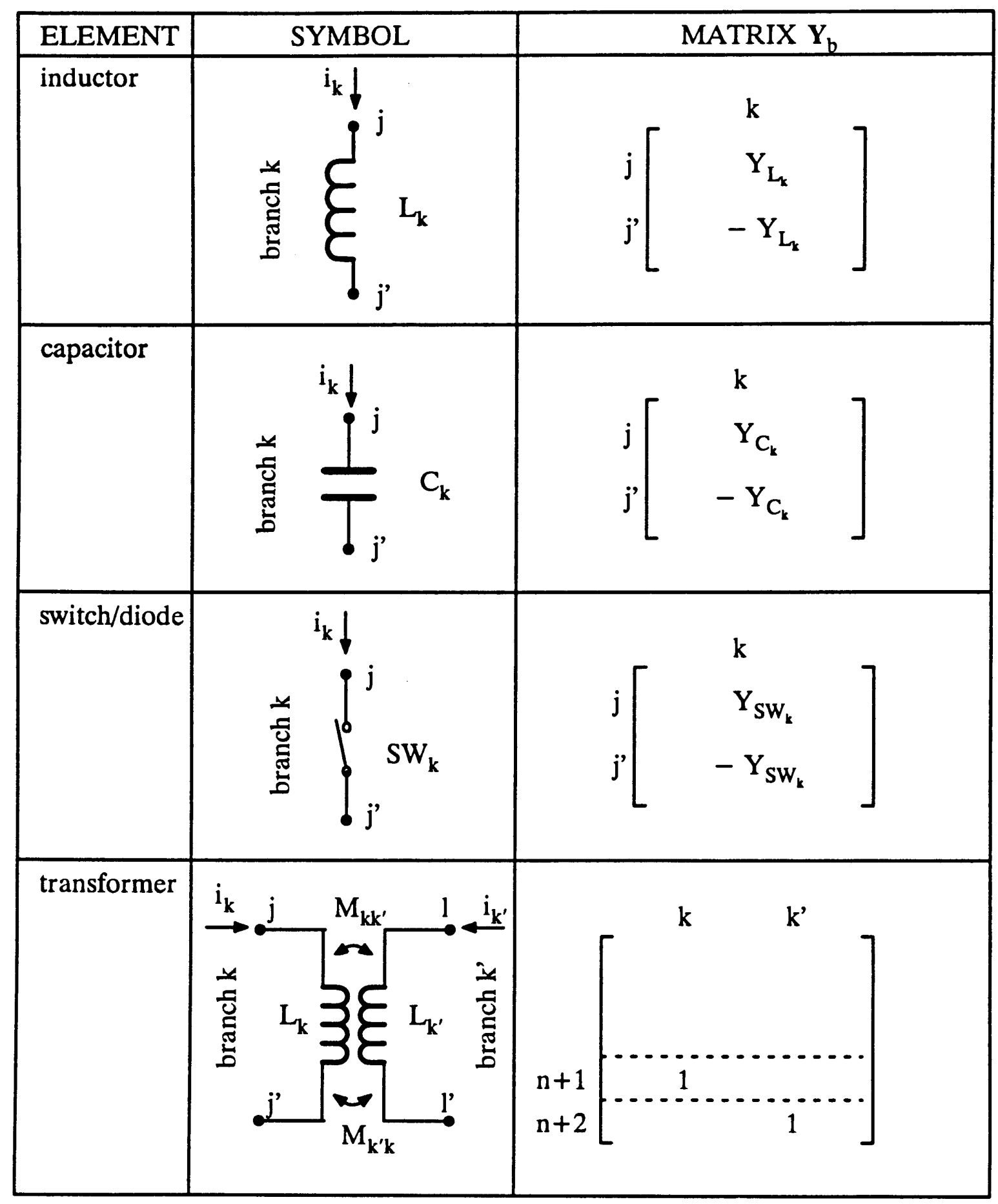

Figure 19. TLM branch admittance matrix $\mathbf{Y}_{\mathrm{b}}$. 


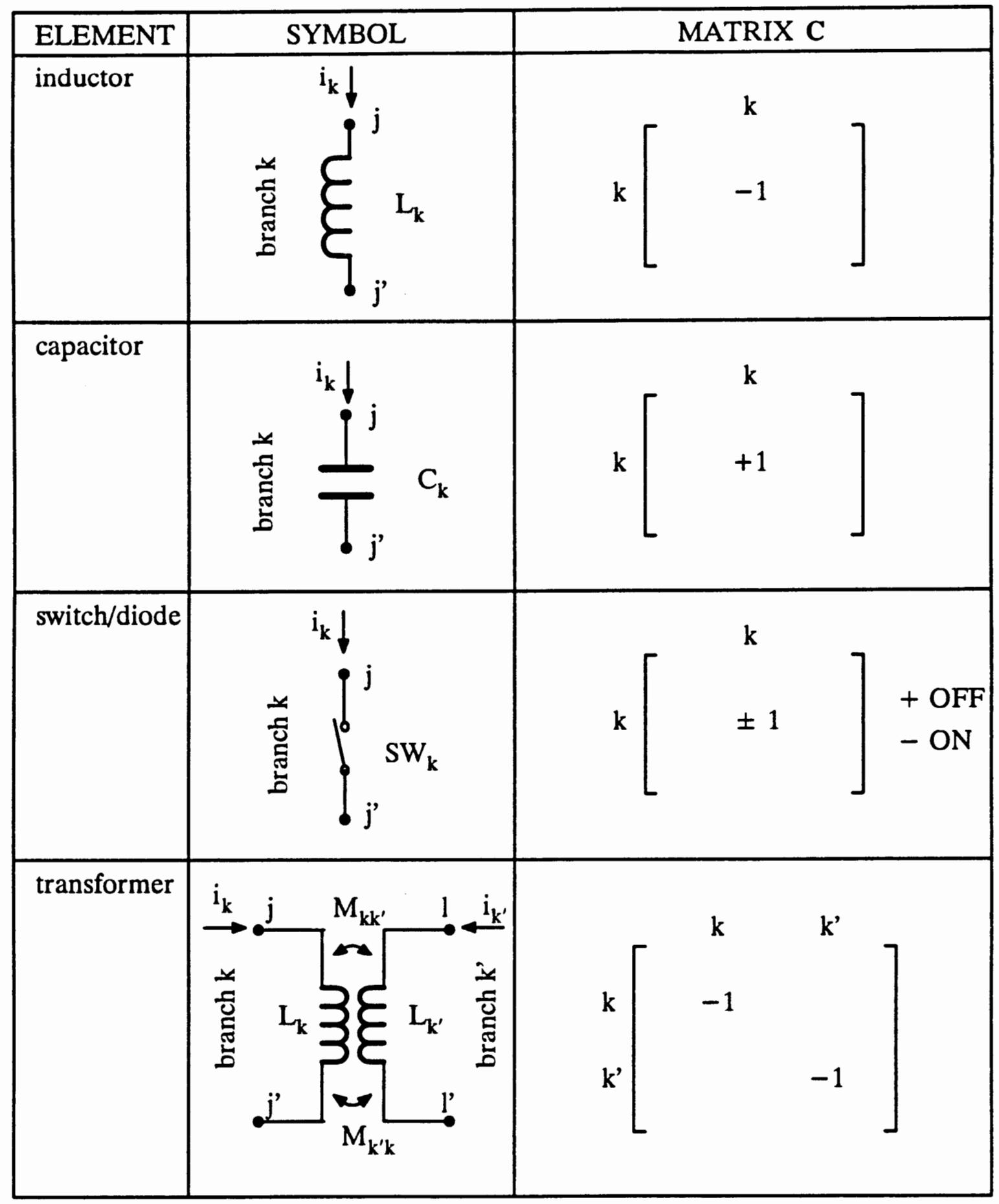

Figure 20, Reflection matrix C. 


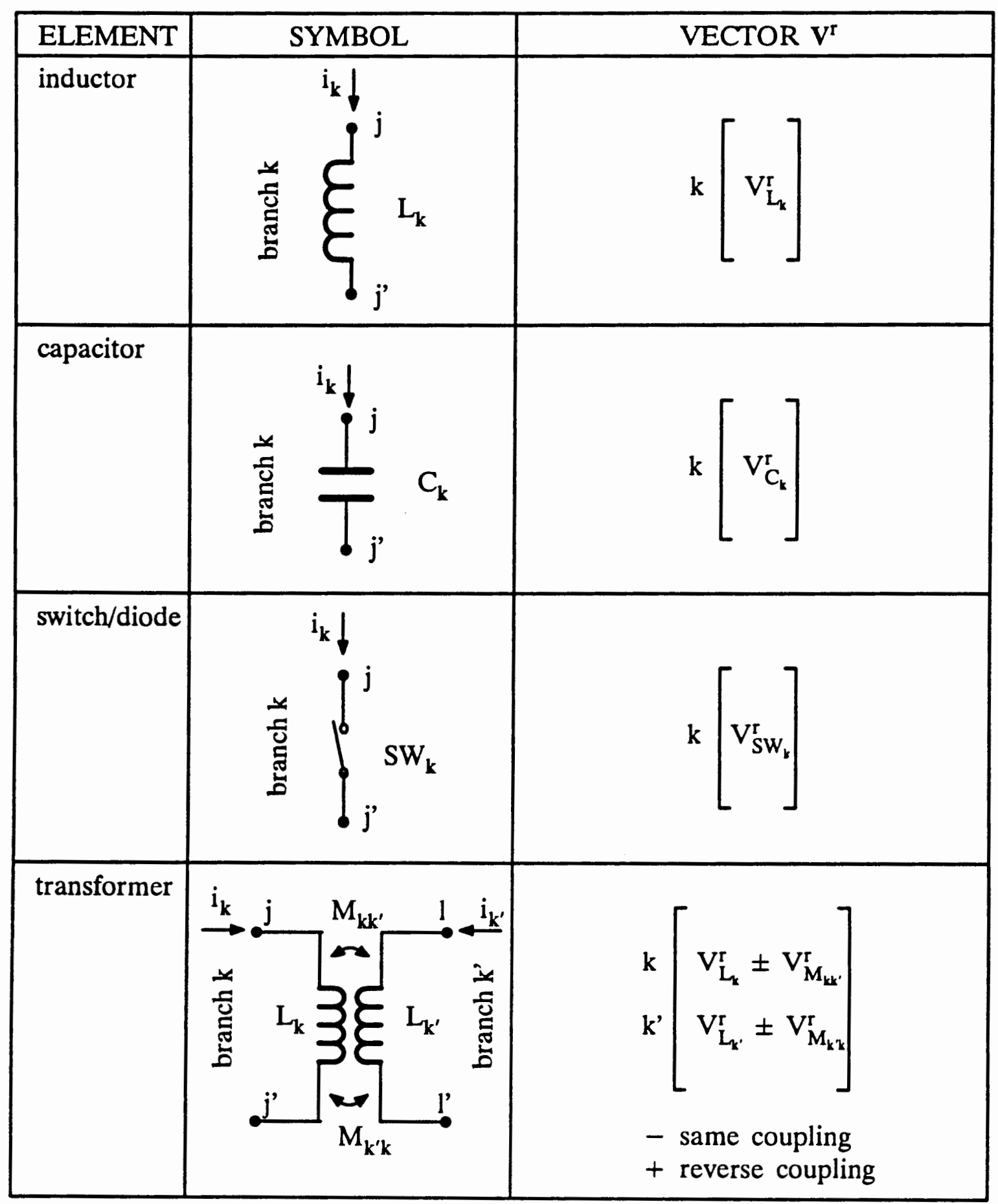

Figure 21. Vector of reflected pulses $\mathbf{V}^{\mathbf{r}}$. 
of the TLM integration method. This question has either not been answered in the current literature or the results of [5] could have been summarized in one sentence: from the numerical point of view TLM integration method and trapezoidal rule are exactly the same. The proof is given next.

The well-known trapezoidal rule $[11,21]$ can be written in the form

$$
\mathrm{x}_{\mathrm{k}}-\mathrm{x}_{\mathrm{k}-1}-\frac{\mathrm{h}}{2}\left(\dot{\mathrm{x}}_{\mathrm{k}}+\dot{\mathrm{x}}_{\mathrm{k}-1}\right)=0
$$

where $\mathrm{k}$ denotes the $\mathrm{k}$ - th time step and $\mathrm{h}$ is the step size. Inductor voltage and inductor current are related in the following equation

$$
\frac{\mathrm{v}}{\mathrm{L}}=\frac{\mathrm{di}}{\mathrm{dt}}
$$

Substituting (36) into (35), we obtain

$$
\mathrm{i}_{\mathrm{k}}-\mathrm{i}_{\mathrm{k}-1}=\frac{\mathrm{h}}{2}\left(\frac{\mathrm{v}_{\mathrm{k}}}{\mathrm{L}}+\frac{\mathrm{v}_{\mathrm{k}-1}}{\mathrm{~L}}\right)
$$

Solving for $\mathrm{i}_{\mathrm{k}}$ results in

$$
i_{k}=i_{k-1}+\frac{T}{2 L}\left(\cdot v_{k}+v_{k-1}\right)
$$

where $\mathrm{h}=\mathrm{T}$ has been used. Using equation (38), we can derive another discrete model for the inductor which is shown in Figure 22.

The discrete transmission-line model of an inductor has been derived in Section II.2.1 and is governed by equation (12). We now consider the $(k-1)$ th and $k-$ th time step of the integration. The reflected voltage pulse $\mathrm{V}_{\mathrm{k}-1}^{\mathrm{r}}$ at time $\mathrm{t}_{\mathrm{k}-1}=(\mathrm{k}-1) \mathrm{T}$ is subtracted from the $(k-1)$ th branch voltage $V_{k-1}$ to find the incident voltage pulse $\mathrm{V}_{\mathrm{k}-1}^{\mathrm{i}}$. After being reflected at the distant termination, the new reflected voltage pulse at the $\mathrm{k}$-th time step becomes

$$
V_{k}^{r}=-V_{k-1}^{i}=-\left(V_{k-1}-V_{k-1}^{r}\right)
$$


Solving equation (12) for the inductor current considering the $k$-th time step results in

$$
\mathrm{i}_{\mathrm{k}}=\frac{\mathrm{T}}{2 \mathrm{~L}}\left(\mathrm{~V}_{\mathrm{k}}-2 \mathrm{~V}_{\mathrm{k}}^{\mathrm{r}}\right)
$$

Substituting (39) into (40) yields equation (41)

$$
\mathrm{i}_{\mathrm{k}}=\frac{\mathrm{T}}{2 \mathrm{~L}}\left(\mathrm{~V}_{\mathrm{k}}+2 \mathrm{~V}_{\mathrm{k}-1}-2 \mathrm{~V}_{\mathrm{k}-1}^{\mathrm{r}}\right)
$$

Finally, we solve equation (12) for 2 times the reflected voltage pulse at the $(k-1)$ th time step and substitute it into (41). The calculation results in

$$
i_{k}=i_{k-1}+\frac{T}{2 L}\left(v_{k}+v_{k-1}\right)
$$

which is obviously the same result as in (38).

Consequently, we can conclude that the TLM integration method and the trapezoidal rule are equivalent numerical integration routines. The reader may refer to $[1,11]$ about its numerical properties (truncation error, region of stability). Equivalent circuit models of an inductor have been shown in Figure 9 and 22.

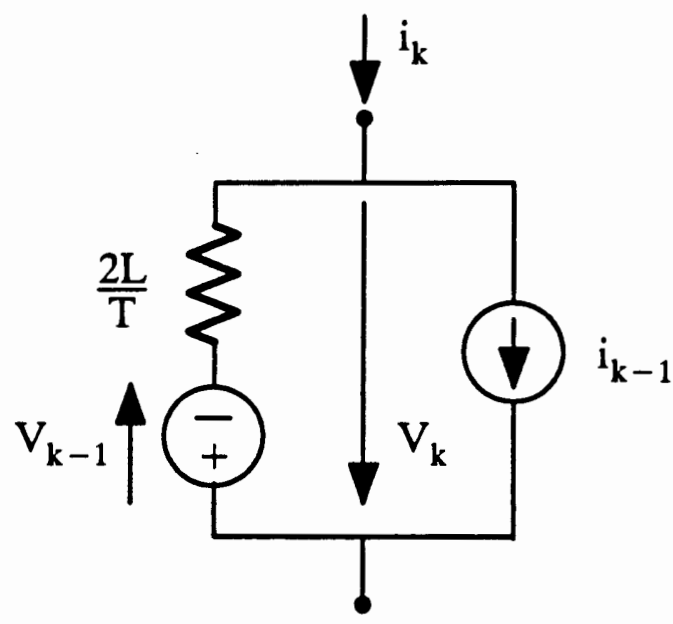

Figure 22. Discrete inductor model. 


\section{II.6 INITIAL CONDITIONS AND EXAMPLE}

In this section we review an example which has been presented in reference [5]. The reader should note the important extension being made: circuit equations are now set up in a general form based on the one-graph modified nodal description. As a result, the equations can be easily implemented in a computer program.

For our example, we consider the circuit as shown in Figure 23. The nodes are labelled from 0 to $\mathrm{N}=5$, with node 0 connected to ground. Branch numbers are enclosed in a box and range from 1 to $b=7$. The elements shall take on the values as shown in Table II. The initial conditions are assumed to be zero. The oriented graph is shown in Figure 24.

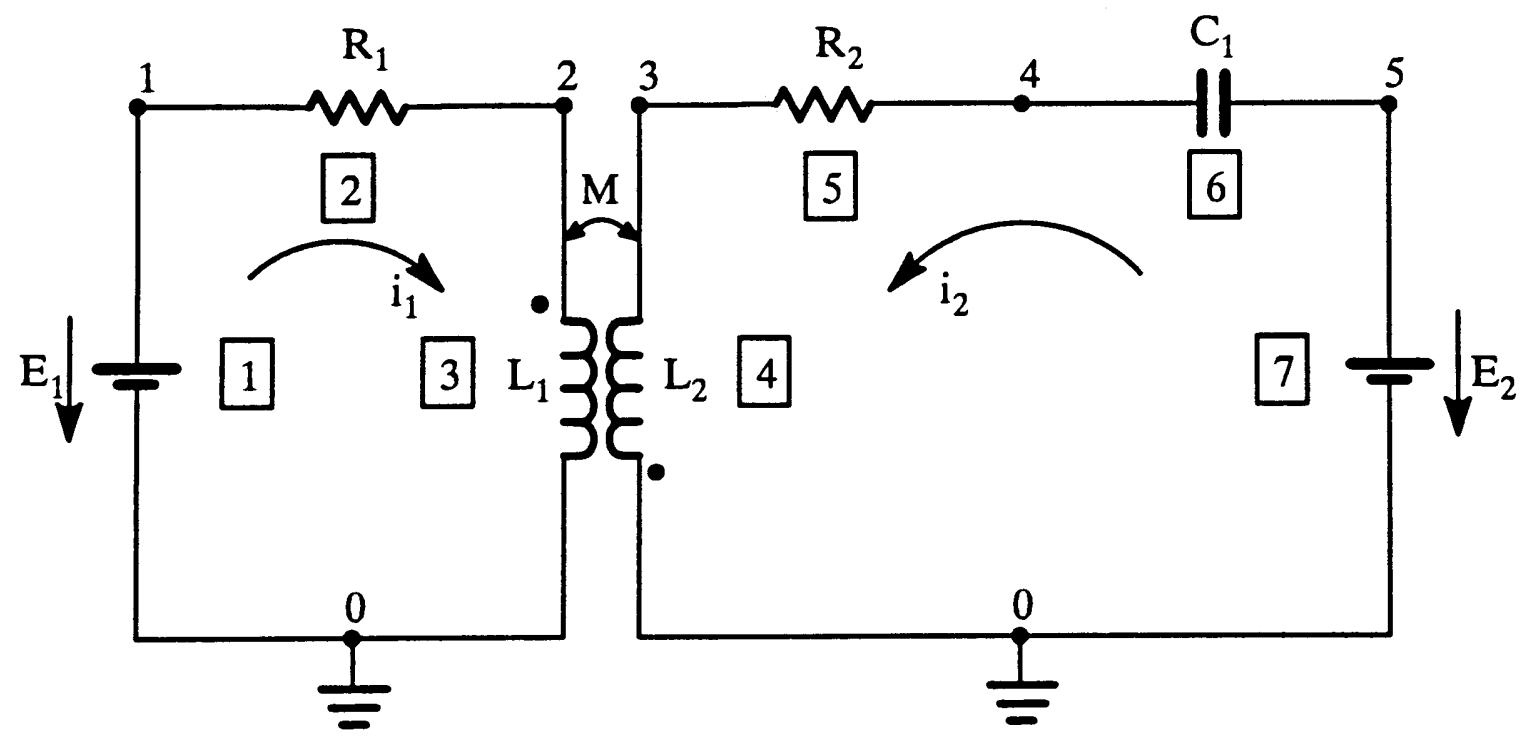

Figure 23, Non-switched linear circuit. 


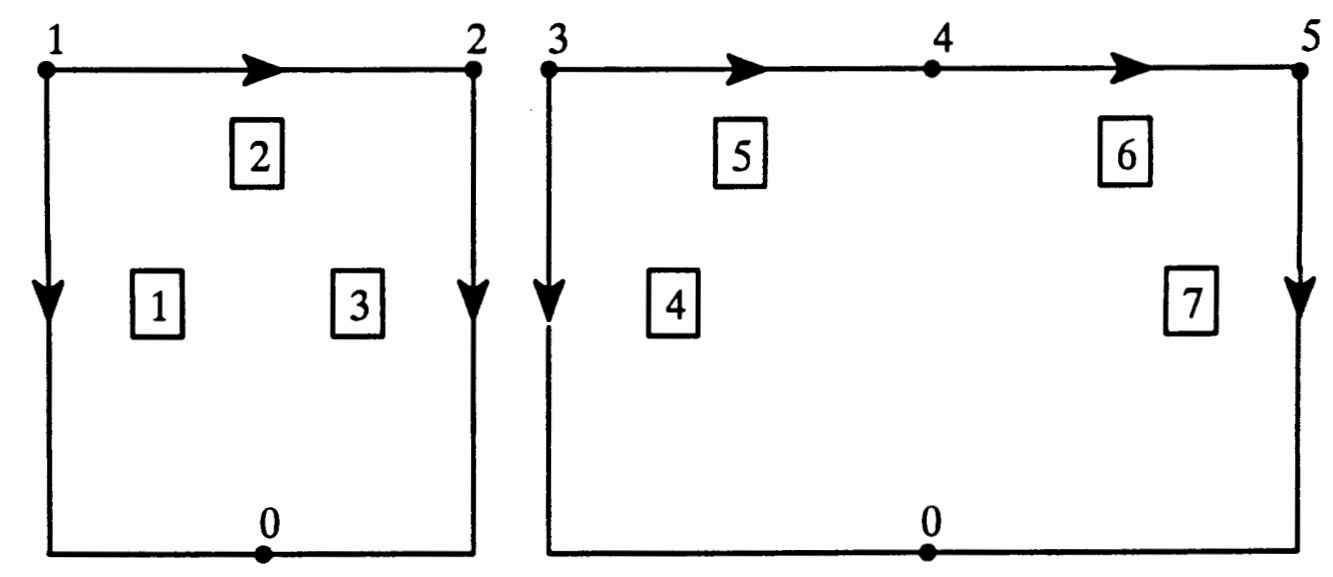

Eigure 24. Oriented graph for the circuit in Figure 23.

TABLE II

COMPONENT VALUES FOR THE CIRCUIT IN FIGURE 23

$$
\begin{array}{ll}
\mathrm{E}_{1}=10 \mathrm{~V} & \mathrm{~L}_{1}=1.0 \mathrm{H} \\
\mathrm{E}_{2}=0 \mathrm{~V} & \mathrm{~L}_{2}=1.0 \mathrm{H} \\
\mathrm{R}_{1}=111 \mathrm{~m} \Omega & \mathrm{M}=\mathrm{M}_{12}=\mathrm{M}_{21}=0.995 \mathrm{H} \\
\mathrm{R}_{2}=987.2 \mathrm{~m} \Omega & \mathrm{V}_{\mathrm{C}_{1}}=0 \mathrm{~V} \\
\mathrm{C}_{1}=111.28 \mathrm{mF} & \mathrm{i}_{1}=\mathrm{i}_{2}=0 \mathrm{~A}
\end{array}
$$


For the reader's convenience, all vectors and matrices used by the TLM integration routine are given next.

$$
\begin{aligned}
& \mathbf{Y}_{\mathbf{b}}=\left[\begin{array}{ccccccc}
0 & 0 & 0 & 0 & 0 & 0 & 0 \\
0 & 0 & 0 & 0 & 0 & 0 & 0 \\
0 & 0 & 0 & 0 & 0 & 0 & 0 \\
0 & 0 & 0 & 0 & 0 & \mathrm{Y}_{\mathrm{C}_{1}} & 0 \\
0 & 0 & 0 & 0 & 0 & -\mathrm{Y}_{\mathrm{C}_{1}} & 0 \\
0 & 0 & 1 & 0 & 0 & 0 & 0 \\
0 & 0 & 0 & 1 & 0 & 0 & 0 \\
0 & 0 & 0 & 0 & 0 & 0 & 0 \\
0 & 0 & 0 & 0 & 0 & 0 & 0
\end{array}\right] \\
& \mathbf{V}^{\mathbf{r}}=\left[\begin{array}{l}
0 \\
0 \\
5 \\
0 \\
0 \\
0 \\
0
\end{array}\right] \\
& \mathbf{E}=\left[\begin{array}{c}
0 \\
0 \\
0 \\
0 \\
0 \\
0 \\
0 \\
10 \\
0
\end{array}\right] \\
& \mathbf{J}=\left[\begin{array}{l}
0 \\
0 \\
0 \\
0 \\
0 \\
0 \\
0 \\
0 \\
0
\end{array}\right] \\
& \mathbf{C}=\left[\begin{array}{ccccccc}
0 & 0 & 0 & 0 & 0 & 0 & 0 \\
0 & 0 & 0 & 0 & 0 & 0 & 0 \\
0 & 0 & -1 & 0 & 0 & 0 & 0 \\
0 & 0 & 0 & -1 & 0 & 0 & 0 \\
0 & 0 & 0 & 0 & 0 & 0 & 0 \\
0 & 0 & 0 & 0 & 0 & 1 & 0 \\
0 & 0 & 0 & 0 & 0 & 0 & 0
\end{array}\right] \\
& {\left[\begin{array}{ccccccc}
1 & 1 & 0 & 0 & 0 & 0 & 0 \\
0 & -1 & 1 & 0 & 0 & 0 & 0 \\
0 & 0 & 0 & 1 & 1 & 0 & 0 \\
0 & 0 & 0 & 0 & -1 & 1 & 0 \\
0 & 0 & 0 & 0 & 0 & -1 & 0
\end{array}\right]} \\
& \mathbf{A}=\left[\begin{array}{ccccccc}
0 & 0 & 0 & 0 & -1 & 1 & 0 \\
0 & 0 & 0 & 0 & 0 & -1 & 0 \\
0 & 0 & 0 & 0 & 0 & 0 & 0 \\
0 & 0 & 0 & 0 & 0 & 0 & 0 \\
0 & 0 & 0 & 0 & 0 & 0 & 0 \\
0 & 0 & 0 & 0 & 0 & 0 & 0
\end{array}\right] \\
& \frac{1}{\mathrm{R}_{1}} \\
& 0 \quad 0 \\
& \text { (1) } \\
& -\frac{1}{\mathrm{R}_{1}} \quad \frac{1}{\mathrm{R}_{1}} \\
& \begin{array}{llllll}
0 & 0 & 1 & 0 & 0 & 0
\end{array} \\
& \begin{array}{ccccccccc}
0 & 0 & \frac{1}{R_{2}} & -\frac{1}{R_{2}} & 0 & 0 & 1 & 0 & 0
\end{array} \mid \\
& \mathbf{Y}_{\mathrm{n}}=\left(\begin{array}{ccccccccr}
0 & 0 & -\frac{1}{\mathrm{R}_{2}} & \frac{1}{\mathrm{R}_{2}}+\mathrm{Y}_{\mathrm{C}_{1}}-\mathrm{Y}_{\mathrm{C}_{1}} & 0 & 0 & 0 & 0 \\
0 & 0 & 0 & -\mathrm{Y}_{\mathrm{C}_{1}} & \mathrm{Y}_{\mathrm{C}_{1}} & 0 & 0 & 0 & 1
\end{array}\right) \\
& \begin{array}{lllllllll}
0 & 1 & 0 & 0 & 0 & -Z_{L_{1}} & Z_{M} & 0 & 0
\end{array} \\
& \begin{array}{lllllllll}
0 & 0 & 1 & 0 & 0 & \mathrm{Z}_{\mathrm{M}} & -\mathrm{Z}_{\mathrm{L}_{2}} & 0 & 0
\end{array} \\
& {\left[\begin{array}{lllllllll}
1 & 0 & 0 & 0 & 0 & 0 & 0 & 0 & 0 \\
0 & 0 & 0 & 0 & 1 & 0 & 0 & 0 & 0
\end{array}\right]}
\end{aligned}
$$


Using the tables of Section II.4.2, we can easily set up the matrices and vectors by inspection. When assigning initial values to the vector of reflected pulses, we have to consider the initial conditions. Since the capacitor current and capacitor voltage are both equal to 0 at time $t=0$, the initial reflected voltage pulse of the capacitor model has to be set to zero in order to satisfy equation (17). If the initial reflected voltage pulses of the $\mathrm{L}_{2}$ inductor model and of the mutual inductance model are assumed to be zero, then the reader may easily verify, that the voltage pulse of the L1 inductor model has to be set to $5 \mathrm{~V}$ in order to satisfy Kirchhoff's voltage law for the left - hand-side loop. Since the circuit response at time $t=0$ is uniquely determined by specifying inductor currents and capacitor voltages, i. e. the energy stored in the circuit, other choices of initial reflected voltage pulses would have been possible as long as initial conditions and Kirchhoff's voltage law are satisfied.

The analytical solution of the current $i_{2}$ is found to be

$\mathrm{i}_{2}=-0.124938 \mathrm{e}^{-0.111153 \mathrm{t}}+10.957517 \mathrm{e}^{-8.899981 t}-10.832579 \mathrm{e}^{-101.0841 \mathrm{t}}$

and is shown in Figure 25.

Figure 26 and 27 show the relative error of the simulated current $i_{2}$ in comparison with the Runge-Kutta second - (RK2) and fourth-order method (RK4) and the fourth-order numerical inverse Laplace transform. The simulation was run with a constant step size of $0.001 \mathrm{~s}$ and $0.01 \mathrm{~s}$.

Application of the Runge-Kutta method [2,4] requires a state space description of the circuit. Using $i_{1}, i_{2}$ and $v_{c}$ as state variables, the state space system equations can thus be shown as follows

$$
\frac{d}{d t}\left[\begin{array}{l}
i_{1} \\
i_{2} \\
v
\end{array}\right]=\left[\begin{array}{ccc}
L_{1} & -M & 0 \\
-M & L_{2} & 0 \\
0 & 0 & C
\end{array}\right]^{-1} \times\left\{\left[\begin{array}{l}
E_{1} \\
E_{2} \\
0
\end{array}\right]-\left[\begin{array}{ccc}
R_{1} & 0 & 0 \\
0 & R_{2} & 1 \\
0 & -1 & 0
\end{array}\right] \times\left[\begin{array}{c}
i_{1} \\
i_{2} \\
v_{c}
\end{array}\right]\right\}
$$


The reader may refer to the given reference for a detailed description of this numerical method. The numerical inverse Laplace transform will be explained in the next chapter.

It has been pointed out in [5] that the TLM method performs better than the Runge-Kutta first and fourth-order method. We have shown that the TLM performance is even better than RK2. This can be expected since TLM (=trapezoidal rule) is known to have the lowest truncation error of all second-order methods. Moreover, there is no theoretical reason for the second-order TLM method to perform better than the fourth-order Runge-Kutta method. This is shown by our simulation results. Finally, we conclude from our plots that the 4th order numerical inverse Laplace transform is even more accurate than RK4. The Runge-Kutta method operates in the time domain and the derivatives of the variables have to be determined before the values of the variables in the next time step can be calculated. Contrarily, the inverse Laplace transform operates in the frequency domain and therefore depends obviously less on the contour of the time-domain response than RK4.

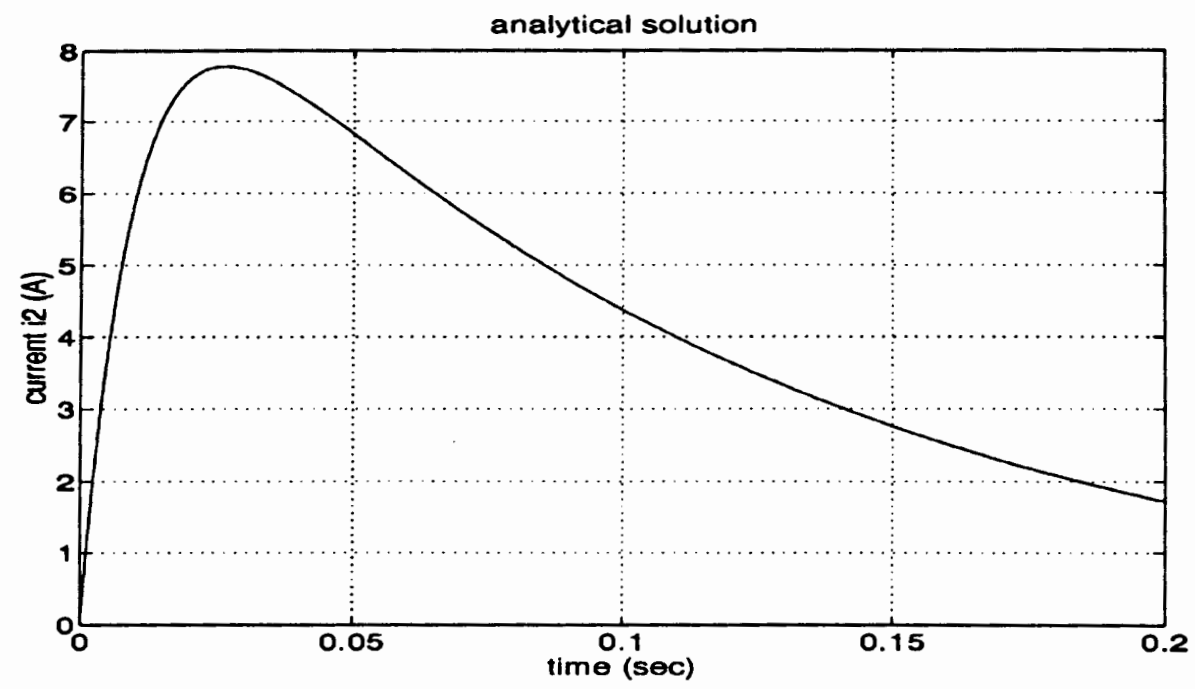

Figure 25. Analytical solution of current i2. 

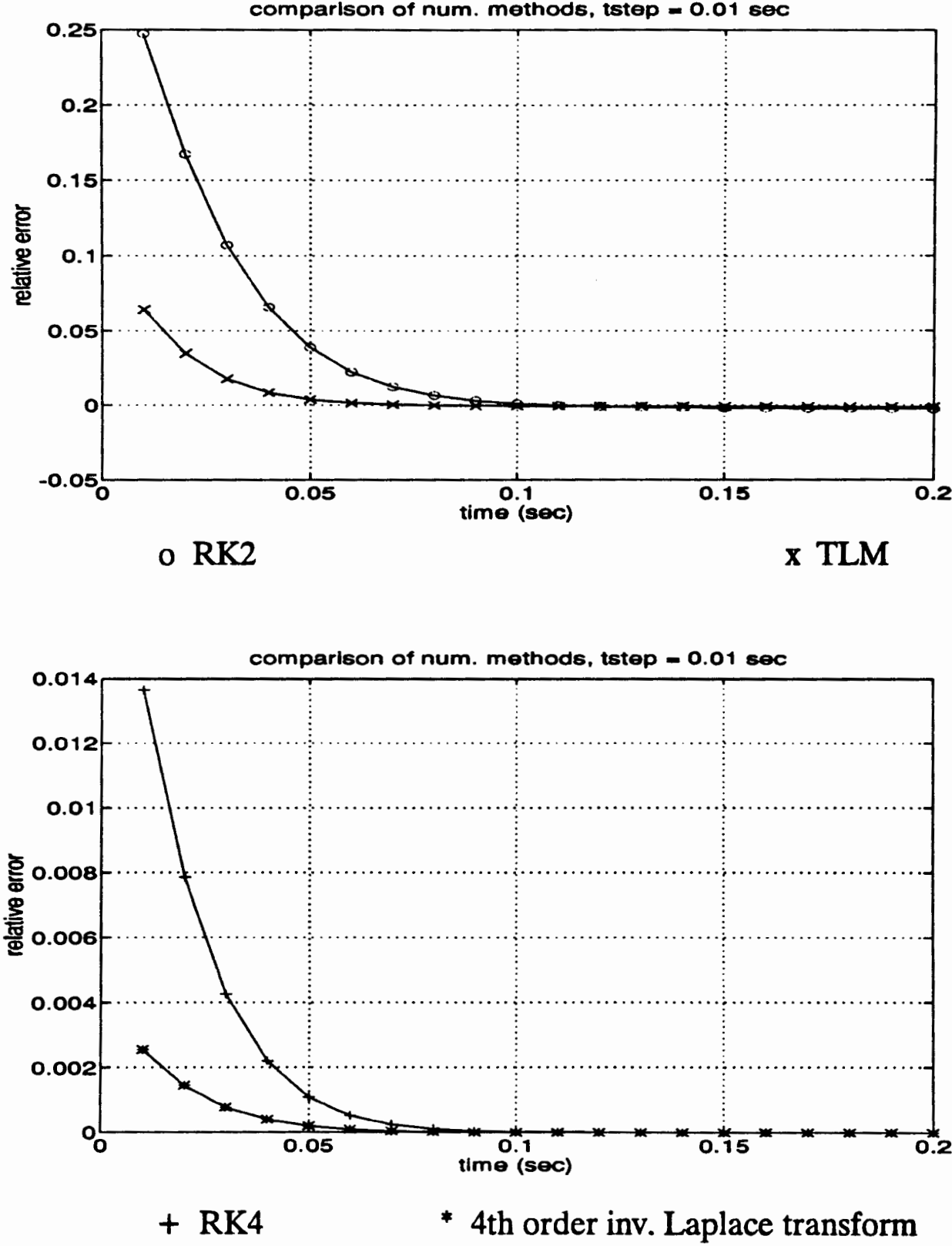

Figure 26. Relative error of simulated current i2, tstep $=0.01 \mathrm{sec}$. 

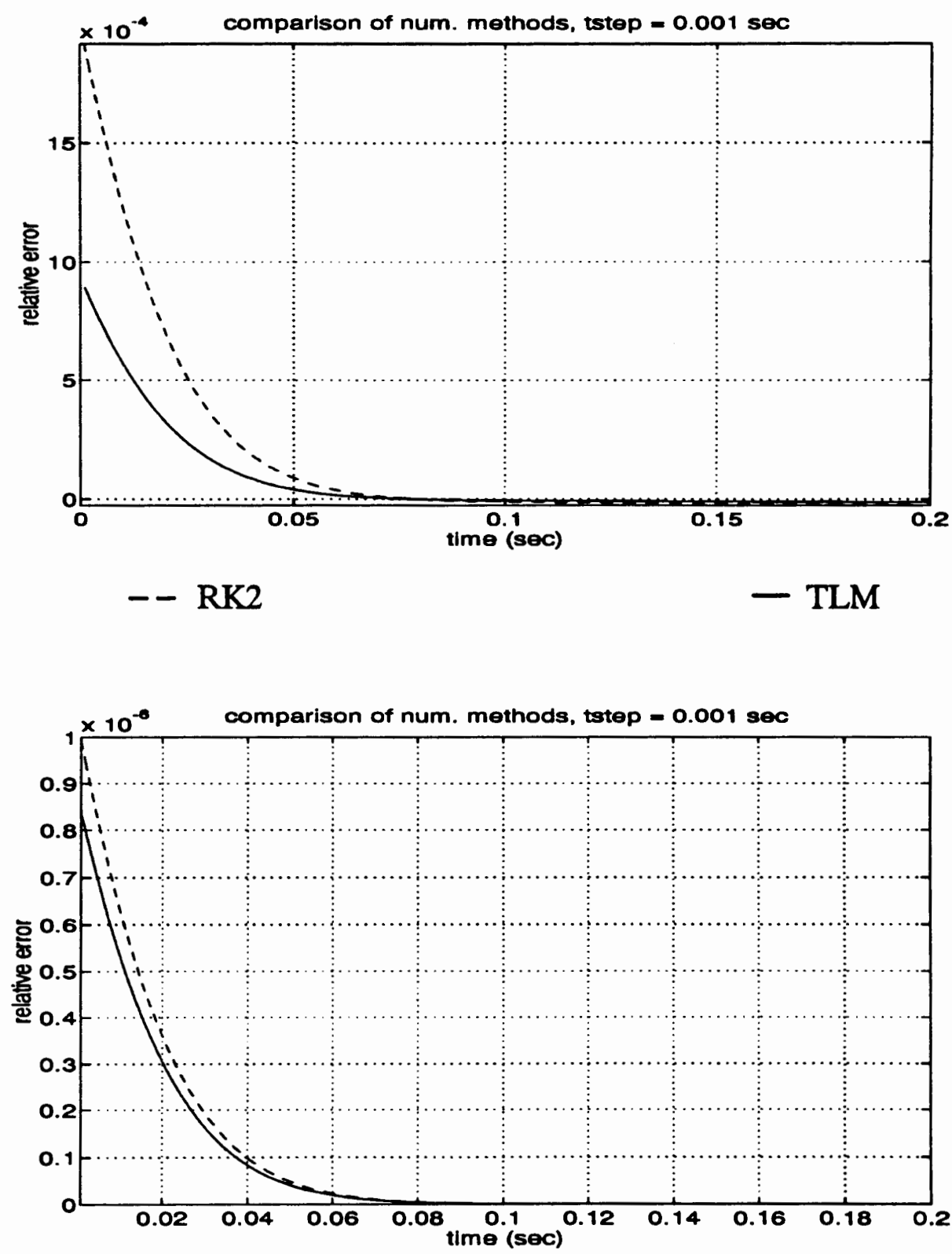

-- RK4

4th order inv. Laplace transform

Figure 27. Relative error of simulated current i2, tstep $=0.001$ sec. 


\section{CHAPTER III}

\section{NUMERICAL INVERSE LAPLACE TRANSFORM}

\section{III.1 INTRODUCTION}

The Laplace transform has been used extensively in the frequency-domain analysis of circuits. Since the inversion requires the computation of the poles and residues of the specific system, its time-domain application has always been limited. This difficulty has been overcome by [14]. Precomputed poles and residues which don't depend on the network function are used to find the time-domain response.

The demand for a simulator which is able to handle switched circuits lead to an intensive restudy of this method $[1,16,19]$. The numerical inverse Laplace transform has been found to be equivalent to a stiffly stable, high order integration of differential equations. Moreover, since all calculations are done in the frequency domain, this method is able to handle inconsistent initial conditions [16] and Dirac impulses [19]. This is a quite crucial consideration, because unlike the approach in Chapter II, we now use an ideal switch model. A short circuit represents the switch when it is ON, whereas an open circuit models the switch in its OFF-state. The switching action of ideal switches quite often results in inconsistent initial conditions and Dirac impulses, and it has been shown in [19] that the Dirac impulses play an important role in the analysis of switched circuits.

In this chapter, the numerical inverse Laplace transform and its properties are reviewed. A two-step method to calculate consistent initial conditions and Dirac impulses is explained. 


\section{III.2 THE INVERSION FORMULA}

Let the network be described by the one-graph modified nodal formulation [1]

$$
(\mathbf{G}+\mathbf{s C}) \mathbf{V}(\mathrm{s})=\mathbf{W}(\mathrm{s})+\mathbf{C v}\left(0^{-}\right)
$$

Conductances and frequency-independent numbers due to dependent sources are stored in matrix G. Matrix C contains capacitor and inductor values which are associated with the frequency variables. V(s) is a frequency transformed vector of node voltages and auxiliary branch currents. Frequency transformed voltage and current sources are stored in $\mathbf{W}(\mathrm{s})$. Initial conditions are described by the product $\mathbf{C v}\left(0^{-}\right)$.

The Laplace inversion formula is given by

$$
v(t)=\frac{1}{2 \pi j} \int_{c-j \infty}^{c+j \infty} V(s) e^{s t} d s
$$

where $s$ is the complex frequency variable. Since the integration path has to enclose the poles $s_{i}$ of $V(s)$, the constant $c$ has to be chosen such that $R e s_{i}<c$. In order to avoid the computational cost-intensive step of finding the poles of $\mathrm{V}(\mathrm{s})$ (note: the poles depend on the network function V(s)), we perform the substitution

$$
\mathrm{z}=\mathrm{st}
$$

This changes (46) into

$$
v(t)=\frac{1}{2 \pi j t} \int_{c^{\prime}-j \infty}^{c^{\prime}+j \infty} V\left(\frac{z}{t}\right) e^{z} d z
$$

The function $\mathrm{e}^{\mathrm{z}}$ can be approximated by a Padé rational function [22] 


$$
\mathrm{e}^{\mathrm{z}} \approx \xi_{\mathrm{N}, \mathrm{M}}(\mathrm{z})=\frac{\mathrm{P}_{\mathrm{N}}(\mathrm{z})}{\mathrm{Q}_{\mathrm{M}}(\mathrm{z})}=\frac{\sum_{\mathrm{i}=0}^{\mathrm{N}} \mathrm{p}_{\mathrm{i}} \mathrm{z}^{\mathrm{i}}}{1+\sum_{\mathrm{i}=1}^{\mathrm{M}} \mathrm{q}_{\mathrm{i}} \mathrm{z}^{\mathrm{i}}}
$$

where $P_{N}(z)$ and $Q_{M}(z)$ are polynomials of order $N$ and $M$, respectively. It has been shown in [14] that if we choose the coefficients $p_{i}$ and $q_{i}$ of the Padé approximation such that the first $\mathrm{M}+\mathrm{N}+1$ terms of its Taylor series expansion match exactly the first $M+N+1$ terms of the Taylor expansion of $e^{z}$ and if $M>N$, the Padé approximation becomes

$$
\xi_{N, M}(z)=\sum_{i=1}^{M} \frac{K_{i}}{z-z_{i}}
$$

$\mathrm{K}_{\mathrm{i}}$ are the residues and $\mathrm{z}_{\mathrm{i}}$ are the poles of $\xi_{\mathrm{N}, \mathrm{M}}(\mathrm{z})$. Inserting (50) into (48) and we obtain

$$
\mathbf{v}(t) \approx \hat{v}(t)=\frac{1}{2 \pi j t} \sum_{i=1}^{M} \int_{c^{\prime}-j \infty}^{c^{\prime}+j \infty} \frac{K_{i}}{z-z_{i}} v\left(\frac{z}{t}\right) d z
$$

Recall that a complex integral can be evaluated by residue calculus

$$
\oint F(z) d z= \pm 2 \pi j \sum \text { (residue at poles inside the closed path) }
$$

where the plus sign refers to a counterclockwise integration and the minus sign applies to the other case. Note that (52) can only be used if the integration along the infinite arc doesn't contribute to the integral itself. This is accomplished by choosing $M \geqq N+2$ and the proof can be found in [1]. Applying (52) to (51) yields the basic inversion formula

$$
\hat{\mathbf{v}}(\mathrm{t})=-\frac{1}{t} \sum_{i=1}^{M} K_{i} V\left(\frac{z_{i}}{t}\right)
$$


The reader should note that the integration path has been closed in the right half plane (minus sign!). This is due to the fact that if $\mathrm{M}$ and $\mathrm{N}$ don't differ considerably from each other, the poles $\mathrm{z}_{\mathrm{i}}$ of $\xi_{\mathrm{N}, \mathrm{M}}$ lie in the right half plane. The poles of a real system clearly lie in the left half plane, but (53) has become independent of the specific system poles. If $\mathrm{M}$ is even, the computation time can be reduced by half due to that only the upper half plane poles are needed for the evaluation of real time functions. The final inversion formula becomes

$$
\hat{v}(t)=-\frac{1}{t} \sum_{i=1}^{M^{\prime}} \operatorname{Re}\left[K_{i}^{\prime} V\left(\frac{z_{i}}{t}\right)\right]
$$

where $M^{\prime}=M / 2$ and $K_{i}^{\prime}=2 K_{i}$. It has been proven in [14] that

$$
V(s)=\frac{1}{s^{m}} \text { for } \quad N+2-M \leqq m \leqq N+M+1
$$

is inverted exactly by equation (53) and the result is

$$
v(t)=\frac{t^{m-1}}{(m-1) !}
$$

Using this result, it can be shown that the order of integration is $p=N+M$. If $N$ and $M$ are chosen appropriately, $m$ in equation (55) may be negative and the method can handle Dirac impulses and even its derivatives.

Next we consider an arbitrary function $v(t)$. Its Taylor series expansion may be written in the form

$$
v(t)=\sum_{i=0}^{M+N} c_{i} t^{i}+\sum_{i=M+N+1}^{\infty} c_{i} t^{i}
$$

Since the order of integration is $\mathrm{p}=\mathrm{N}+\mathrm{M}$, the numerical inverse Laplace transform inverts exactly the first $\mathrm{M}+\mathrm{N}+1$ terms in (57). Equation (57) is a Taylor expansion around $t=0$ and therefore the more $t$ increases during the simulation, the less the first $\mathrm{M}+\mathrm{N}+1$ terms in (57) will approximate $\mathrm{v}(\mathrm{t})$. This problem can be 
overcome by shifting the time axis as shown in Figure 28. The shifting is accomplished in the following way. The solution $v\left(t_{1}\right)$ at time $t=t_{1}$ is used to reset the initial conditions. Inductor currents and capacitor voltages are taken as the new initial conditions and the analysis proceeds with time step $t_{2}$. Without resetting a much bigger time step $t_{3}$ would have been necessary to solve for $v\left(t_{3}\right)$. Establishing the new initial conditions is easily done. According equation (45) matrix $\mathrm{C}$ is simply multiplied by the solution vector $\mathbf{v}\left(0^{-}\right)$.

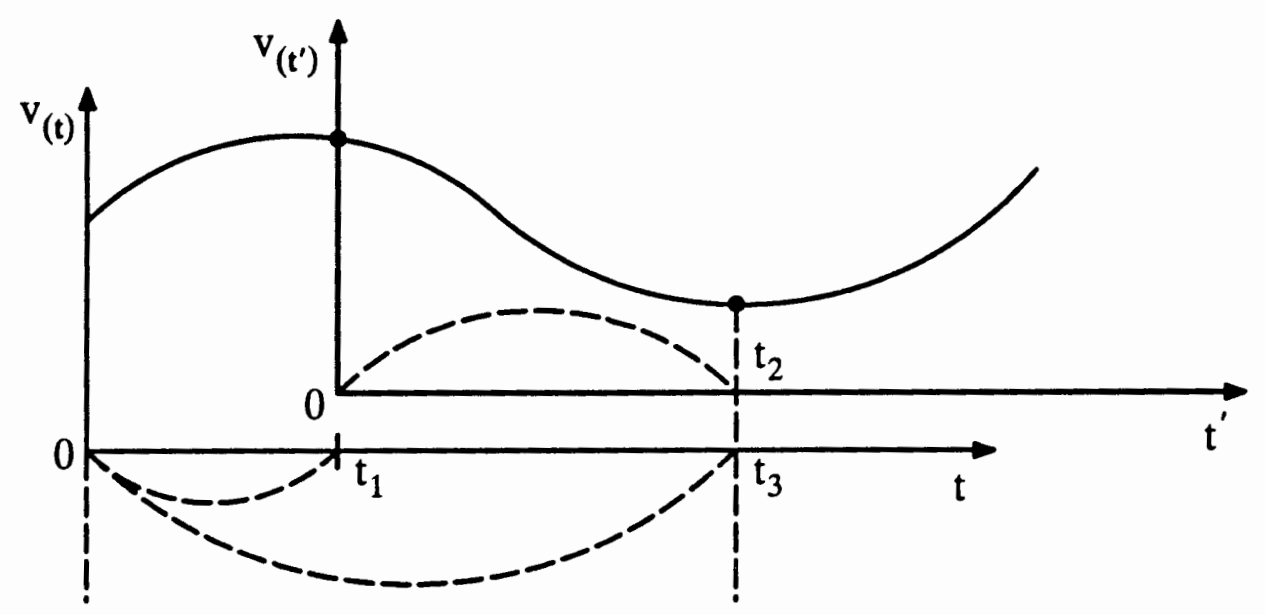

Figure 28. Shifting of the time axis.

For our simulator, we chose the $\xi_{0,4}$ Padé approximation. Hence, the order of integration is $p=0+4=4$. The condition $M \geqq N+2$ is fulfilled and the contour integral along the integration path is zero. According to equation (55) $\mathrm{m}$ ranges between -2 and 5. This allows for the correct inversion of the Dirac impulse and its first and second derivatives. The implementation of error control in a simulation program requires the use of a higher order method. We chose the $\xi_{1,4}$ Padé approximation, i.e. a fifth-order integration. The reader may refer to Section IV.8 for the implementation of variable step size and automatic error control in our simulation program. The corresponding values of the residues $K_{i}^{\prime}$ and the poles $z_{i}$ are given in Table III and IV. 
TABLE III

POLES AND RESIDUES FOR $\xi_{0,4}$

$z_{1}=1.729444231067705+j 0.8889743761218658$

$z_{2}=0.2705557689322945+j 2.504775904362434$

$K_{1}^{\prime}=-1.082826696858315-j 3.177718364446557$

$\mathrm{K}_{2}^{\prime}=1.082826696858315+\mathrm{j} 0.4971250417322381$

TABLE IV

POLES AND RESIDUES FOR $\xi_{1,4}$

$\mathrm{z}_{1}=2.764346415715100+\mathrm{j} 1.162323629283275$

$z_{2}=1.235653584284900+j 3.437652493671051$

$\mathrm{K}_{1}^{\prime}=-1.486485011597801-\mathrm{j} 12.10916705674577$

$\mathrm{K}_{2}^{\prime}=1.486485011597801+\mathrm{j} 3.433270826956831$ 


\section{III.3 CONSISTENT INITIAL CONDITIONS AND DIRAC IMPULSES}

The problem which we address in this section is fundamental in networks with ideal switches. Suppose the solution $\mathbf{v}^{-}\left(0^{-}\right)$is given immediately before switching and we want to calculate the solution $\mathbf{v}\left(0^{+}\right)$immediately after switching. The time axis has been shifted such that the switching action occurs at $t=0$. In general, it can't be assumed that the network variables are constant across the switching boundaries. Moreover, Dirac impulses will always be present whenever inductor currents and capacitor voltages are discontinuous at a switching instant. In this section, we review a method $[16,19]$ to calculate consistent initial conditions and Dirac impulses (more detailed: the area of a Dirac impulse) of a switched linear network. Its application (especially the role of the Dirac impulse) in the network analysis is discussed in Section IV.7.

We consider the following circuit as shown in Figure 29. The components shall take on the values and initial conditions as listed in Table V. A simple calculation results in the analytical solution of the current $\mathrm{i}_{\mathrm{C}_{2}}$ and the capacitor voltage $\mathrm{v}_{\mathrm{C}}$

$$
\begin{aligned}
& { }^{i} C_{2}=2 \delta(t)+1.5 e^{-0.5 t} \\
& v_{C}(t)=6-3 e^{-0.5 t}
\end{aligned}
$$

The capacitor voltage response at time $\mathrm{t}=0$ is discontinuous. At time $\mathrm{t}=0^{-} \mathrm{Cl}$ is charged to $5 \mathrm{~V}$, whereas $\mathrm{C} 2$ is charged to $1 \mathrm{~V}$. At time $\mathrm{t}=0$ the switch is closed and the capacitor charge is redistributed instantaneously by a Dirac impulse of current. At time $\mathrm{t}=0^{+}$both capacitors are charged to $3 \mathrm{~V}$.

Since equation (54) can't be divided by zero, the question arises of how can we solve for the circuit response at time $t=0^{+}$. An obvious possibility would be to approximate the solution using a very small time step. This has not been recommended by [16]. If a time step is chosen too close to an impulsive circuit response (see equation 


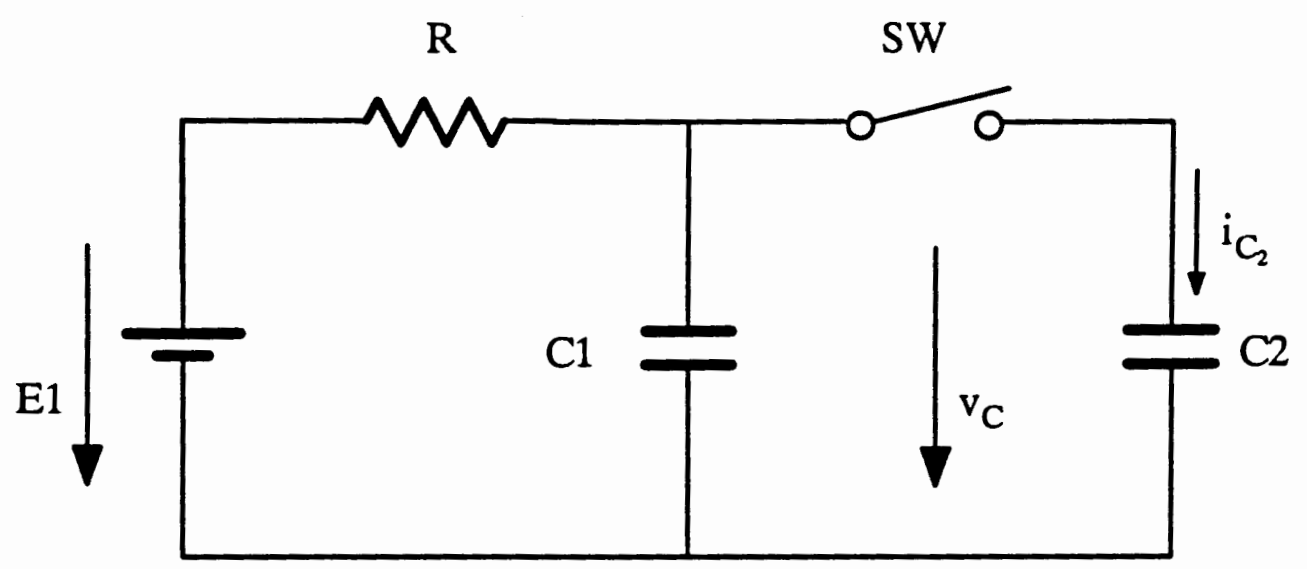

Eigure 29 RC-network with inconsistent initial conditions.

TABLE V

COMPONENT VALUES FOR THE CIRCUIT IN FIGURE 29
$\mathrm{E} 1=6 \mathrm{~V}$
$\mathrm{R}=1 \Omega$
$\mathrm{C} 1=1 \mathrm{~F}$
$\mathrm{v}_{\mathrm{C}_{1}}\left(0^{-}\right)=5 \mathrm{~V}$
$\mathrm{C} 2=1 \mathrm{~F}$
$\mathrm{v}_{\mathrm{C}_{2}}\left(0^{-}\right)=1 \mathrm{~V}$ 
(58)), then the Dirac impulse might dominate over the non-impulsive time-domain response and a wrong simulation result would be obtained.

Instead, [16] suggests a two-step approach. First, a sufficiently large forward step $t_{F}$ is taken and possible Dirac impulses are inverted to zero according to equation (55) and (56). The initial conditions are reset (note that the initial conditions are now consistent) and the same integration step is taken backwards $\left(t_{B}=-t_{F}\right)$, which results in the solution at time $\mathrm{t}=0^{+}$.

In Section III.2, it has been shown that the numerical inverse Laplace transform is able to handle Dirac impulses provided the order of the Padé polynomials are chosen appropriately. We recall the definition of a Dirac impulse in equation (60) and (61). The Dirac impulse can't be represented on a computer because it takes on an infinite value at $\mathrm{t}=\mathrm{t}_{0}$. Instead, the area under the Dirac impulse is finite and can be handled by the computer.

$$
\begin{gathered}
\delta_{\left(t-t_{0}\right)}=0 \quad \text { for } t \neq t_{0} \\
\int_{-\infty}^{+\infty} k \delta_{\left(t-t_{0}\right)} d t=k
\end{gathered}
$$

To calculate the area under the Dirac impulse an integration step is taken. Since an integration in the time domain corresponds to $1 / \mathrm{s}$ in the Laplace domain, the integration formula becomes

$$
\int_{0^{-}}^{t} \hat{v}(\tau) d \tau=-\frac{1}{t} \sum_{i=1}^{M}\left(\frac{z_{i}}{t}\right)^{-1} K_{i} V\left(\frac{z_{i}}{t}\right)
$$

Note that the integral calculated with equation (62) includes the area of any Dirac impulse at time $\mathrm{t}=0$. Clearly, Dirac impulses can only occur at the switching instants. Suppose that the time axis has been shifted such that the switching instant occurs at $t=0$. 
This enables us to split up the circuit response at time $t=0$ into an impulsive and a non-impulsive part (compare with (58))

$$
\mathbf{v}(0)=\mathbf{v}_{\delta}(0) \delta(t)+\mathbf{v}\left(0^{+}\right)
$$

The impulse multiplier can be calculated with the same two-step method as it has been used in the calculation of consistent initial conditions.

$$
v_{\delta}(0)=\int_{0^{-}}^{t_{F}} v(\tau) d \tau+\int_{t_{F}}^{0^{+}} v(\tau) d \tau
$$

The first integral in equation (64) represents the forward step and includes the area of any possible Dirac impulses and the area of the non-impulsive part in equation (63). Before the backward step is taken, the initial conditions are reset. Therefore the second integral in equation (64) only includes the area of the non-impulsive circuit response, but now with a minus sign indicating the backward integration. The sum of both integrals leaves the area of the Dirac impulses, i.e. the impulse multiplier $v_{\delta}(0)$.

It is quite obvious, that an arbitrary large forward step can't guarantee accurate results. The error of the forward step needs to be monitored by a higher order method. The reader should refer to Section IV.6, where a flow chart of the error-controlled two-step method is given. For simplicity, the forward step in our example has been fixed to $t_{F}=0.001 \mathrm{sec}$. Table VI summarizes the calculated results obtained by our simulator. The relative error of the calculated consistent initial conditions and Dirac impulses is very small and is in the range of $10^{-12}$ to $10^{-16}$. Although equation (59) doesn't contain any Dirac impulse, the reader should note that the sum of the forward and backward integral for the capacitor voltage $\mathrm{v}_{C}$ is not exactly zero. The number is very small, but still it might have an effect in the analysis of switched circuits and will be discussed in Section IV.7. 
TABLE VI

CALCULATED INITIAL CONDITIONS AND DIRAC IMPULSE AREA

\begin{tabular}{|c|c|c|c|}
\hline & & Calculated value & Relative error \\
\hline \multirow[t]{2}{*}{$\begin{array}{l}\text { Initial } \\
\text { conditions }\end{array}$} & $\begin{array}{l}\text { forward } \\
\text { step } \\
\left(0^{-} \rightarrow 1 \mathrm{~ms}\right)\end{array}$ & $\begin{array}{l}\mathrm{i}_{\mathrm{C}_{2}}(1 \mathrm{~ms})=1.49251872 \mathrm{~A} \\
\mathrm{v}_{\mathrm{C}}(1 \mathrm{~ms})=3.01496256 \mathrm{~V}\end{array}$ & $\begin{array}{l}9.89 \times 10^{-14} \\
2.50 \times 10^{-14}\end{array}$ \\
\hline & $\begin{array}{l}\text { backward } \\
\text { step } \\
\left(1 \mathrm{~ms} \rightarrow 0^{+}\right)\end{array}$ & $\begin{array}{l}\mathrm{i}_{\mathrm{C}_{2}}\left(0^{+}\right)=1.50000000 \mathrm{~A} \\
\mathrm{v}_{\mathrm{C}}\left(0^{+}\right)=3.00000000 \mathrm{~V}\end{array}$ & $\begin{array}{l}1.09 \times 10^{-14} \\
1.20 \times 10^{-15}\end{array}$ \\
\hline \multirow[t]{4}{*}{$\begin{array}{l}\text { Dirac } \\
\text { impulse } \\
\text { area }\end{array}$} & $\begin{array}{l}\text { forward } \\
\text { step }\end{array}$ & $\begin{array}{l}\int_{0^{-}}^{1 \mathrm{~ms}} \mathrm{i}_{\mathrm{C}_{2}}(\tau) \mathrm{d} \tau=2.01496256 \mathrm{As} \\
\int_{0^{-}}^{1 \mathrm{~ms}} \mathrm{v}_{\mathrm{C}}(\tau) \mathrm{d} \tau=0.03007488 \mathrm{Vs}\end{array}$ & $\begin{array}{l}3.81 \times 10^{-15} \\
5.17 \times 10^{-12}\end{array}$ \\
\hline & $\begin{array}{l}\text { backward } \\
\text { step }\end{array}$ & $\begin{array}{l}\int_{1 \mathrm{~ms}}^{0^{+}} \mathrm{i}_{\mathrm{C}_{2}}(\tau) \mathrm{d} \tau=-0.01496256 \mathrm{As} \\
\int_{1 \mathrm{~ms}}^{0^{+}} \mathrm{v}_{\mathrm{C}}(\tau) \mathrm{d} \tau=-0.03007488 \mathrm{Vs}\end{array}$ & $\begin{array}{l}5.19 \times 10^{-12} \\
5.21 \times 10^{-12}\end{array}$ \\
\hline & $\int_{0^{-}}^{1 \mathrm{~ms}} \mathrm{i}_{\mathrm{C}_{2}}(\tau) \mathrm{d} \tau+$ & $\mathrm{i}_{\mathrm{C}_{2}}(\tau) \mathrm{d} \tau=2.00000000 \mathrm{As}$ & $4.50 \times 10^{-16}$ \\
\hline & $\int_{0-}^{1 \mathrm{~ms}} \mathrm{v}_{\mathrm{C}}(\tau) \mathrm{d} \tau+$ & $\mathrm{v}_{\mathrm{C}}(\tau) \mathrm{d} \tau=-1.3184 \times 10^{-15} \mathrm{Vs}$ & \\
\hline
\end{tabular}




\section{CHAPTER IV}

\section{DEVELOPMENT OF A SIMULATOR FOR SWITCHED LINEAR NETWORKS BASED ON THE NUMERICAL INVERSE LAPLACE TRANSFORM}

\section{IV.1 INTRODUCTION TO TIME-DOMAIN ANALYSIS}

When developing a simulator for switched linear networks, several problems have to be overcome. When designing a simulator one of the first decisions which needs to be made is the form in which the circuit equations should appear. We chose the popular one-graph modified nodal formulation [1], which allows the construction of circuit equations by inspection. The contribution of each circuit component can be added easily to the set of modified nodal equations when reading a netlist of the circuit.

Switches are non-linear elements and they need to be modelled in order to keep a set of linear circuit equations. We decided to use an ideal switch model as it has been proposed in [19]. When the switch is ON, it is modelled as a short circuit, whereas an open circuit represents the switch in its OFF-state. Further modification of the model is possible. For example, if the user wants to take into account the ON-resistance of a diode, he may put a resistor in series with the ideal switch.

Once the matrices are built up, the analysis can progress in time using equation (54) until one or several circumstances cause one or several switches to change state. For example, a diode current has become negative indicating that the diode should be turned OFF. At this time the present topology is no longer valid and the simulation must backtrack to the exact switching time and the topology is updated. 
Determining the switching time is equivalent to finding a root of a scalar function in a given interval. Therefore any standard root finding method can be applied. We chose Newton's first method [11], since it requires a minimum of computational cost.

The switching action might cause other switches to change state and the correct topology needs to be determined immediately after switching. Clearly, this is no longer a trivial problem. Suppose there are $\mathrm{n}$ switches, then the simulator has to find out the correct topology out of $2^{\mathrm{n}}$ possible topologies. This problem has been overcome by [19]. It uses Dirac impulses, which may occur in switched networks with ideal switches, to determine the correct topology immediately after switching. A method to calculate Dirac impulses has been given in Section III.3. Section IV.7 discusses the determination of a correct topology using the method of Dirac impulses.

After the right topology has been found, consistent initial conditions are calculated (refer to Section III.3) and the simulation can progress in time.

In order to reduce computation time, a variable step size algorithm can be implemented. The step size is varied based on the truncation error of the calculated network solution. The algorithm increases the step size (i.e. reduces the number of necessary calculations in a simulation) as long as the specified error criterion is met. The implementation of variable step size and automatic error control is discussed in Section IV.8.

\section{IV.2 FORMULATION OF CIRCUIT EQUATIONS WITH IDEAL SWITCHES}

The formulation of circuit equations is based on the one-graph modified nodal description, which is easily implemented on a computer.

Suppose a data file 'netlist' which is read by the computer contains necessary information about the network. Let the basic structure of the circuit be described in 


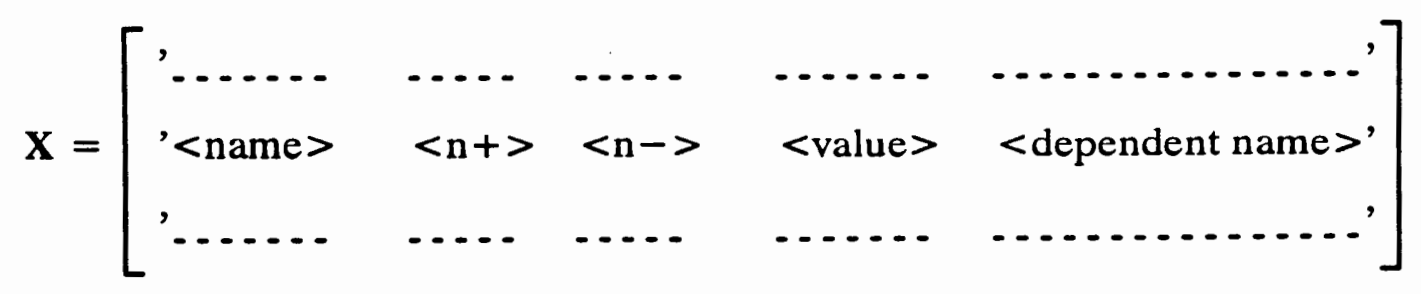

A circuit component is identified by <name $>$. It is connected between the nodes $\langle\mathrm{n}+\rangle$ and $\langle\mathrm{n}-\rangle$. The component value is given by $\langle$ value $\rangle$. Two-port elements have to specify its dependent branch in $<$ dependent name $>$.

Initial conditions may be described in a column vector $\mathbf{x} 0$. Suppose there are $\mathrm{n}_{\mathbf{C}}$ capacitors and $n_{L}$ inductors in $X$. Then $x 0$ is of dimension $\left(n_{C}+n_{L}\right) \times 1$ and its entries describe initial capacitor voltages and inductor currents.

Using this information, the contribution of any element in $\mathbf{X}$ to the set of nodal equations can be added to the appropriate matrices as it has been shown in [1]. Moreover, the formulation method even allows the incorporation of ideal switches. Suppose the ith ideal switch in $\mathbf{X}$ is connected between nodes $\mathbf{j}$ and $\mathbf{j}^{\prime}$ and the current matrix size of $\mathbf{G}$ (see equation (45)) is $(\mathrm{m} \times \mathrm{m})$, then its entries into matrix $\mathbf{G}$ become

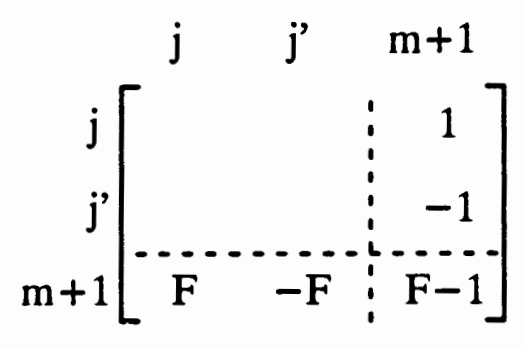

The value for $F$ depends on the state of the switch. If the switch is closed (short circuit), $\mathrm{F}$ equals 1 . If the switch opens up (open circuit), $\mathrm{F}$ equals 0 . The matrix size of $\mathbf{G}$ is consequently not affected by the switching action, i.e. completely reformulating the circuit equations at every switching instant is not necessary. Only the proper value for $\mathrm{F}$ is inserted in (66). This reduces considerably the computation time.

Initial values for $\mathrm{F}$ are specified in the data file 'netlist' by a row vector 


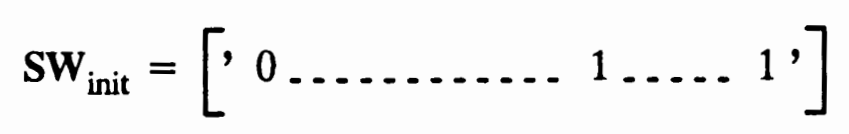

where the entry in the ith column refers to the ith switch as they appear in $\mathbf{X}$. It is quite obvious, that the corresponding matrix indices for $F$ have to be stored. Supposing the final matrix dimension of $\mathbf{G}$ is $(\mathrm{N} \times \mathrm{N})$ and single indexing is possible, it is convenient to store the single matrix indices for the ith switch in the ith row of $\mathbf{S} \mathbf{W}_{\text {indices }}$ as it is shown in equation (68)

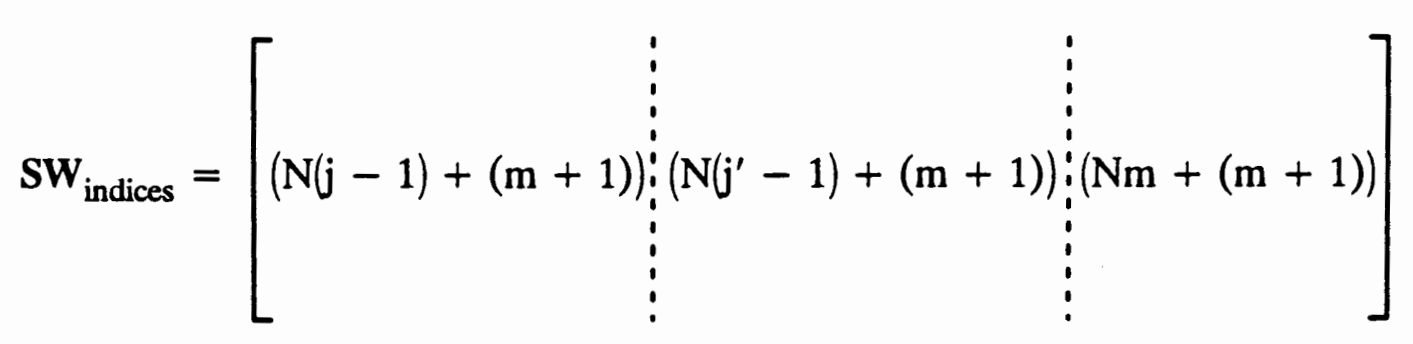

SW $W_{\text {indices }}$ is a $\left(n_{s} \times 3\right)$ matrix, where $n_{s}$ is the number of switches. If the ith switch changes its state, we can insert the proper value for $F$ in $\mathbf{G}$ using single indexing

$$
\mathbf{G}\left(\mathbf{S} \mathbf{W}_{\text {indices }}(i, j)\right), \text { for } \mathrm{j}=1,2,3
$$

\section{IV.3 CLASSIFICATION OF SWITCHES AND SWITCHING VARIABLES}

We distinguish between externally and internally controlled switches. The switching of externally controlled switches is determined by an external clock. Its switching times are already known at the beginning of the simulation.

Internally controlled switches (e.g. diode) are controlled by voltages and/or currents that need to be determined as the analysis progresses. Therefore its switching times are not known at the beginning of the simulation and need to be calculated precisely.

The state of a switch is monitored by switching variables. Every switch has at least two switching variables: one for monitoring its $\mathrm{ON}$-state and another one which 
monitors its $\mathrm{OFF}$-state. The switching variables are checked after each integration step and if a negative value is encountered then (by definition) the present topology is no longer valid and the simulation must backtrack to the time when the particular switching variable was zero and the corresponding switch is turned ON/OFF.

IV.3.1 Switching variables for externally controlled switches and stepping sources

Suppose the data file 'netlist' provides information about externally controlled switches and stepping sources in the following form

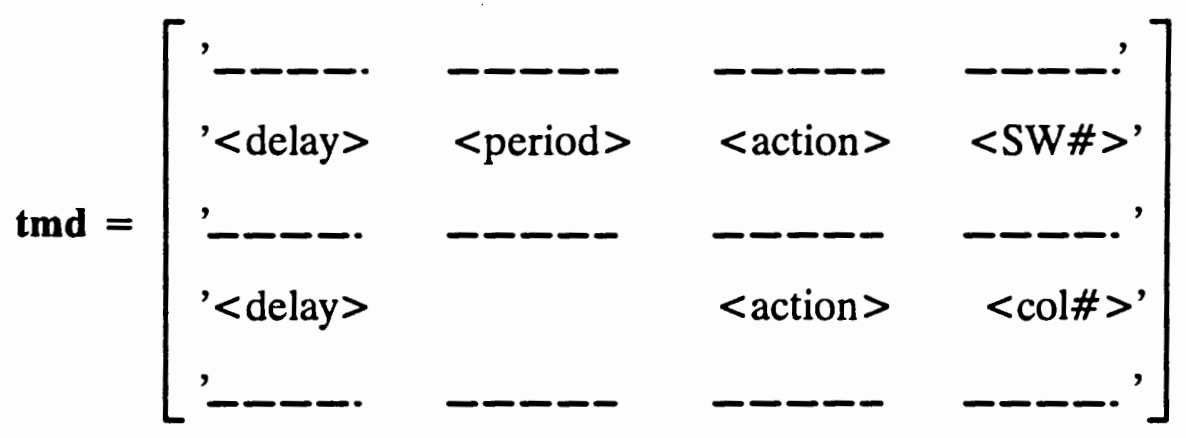

Externally controlled switches are turned $\mathrm{ON}$ and/or OFF periodically (as specified in $<$ period>) after a certain <delay $>-$ time measured from the beginning of the simulation. The switching action is described in <action $>(1=\mathrm{ON}, 0=\mathrm{OFF})$. The corresponding switch number (as they appear in $\mathrm{X}$ ) is given in $\langle\mathrm{SW \# \rangle}\rangle$.

The switching variable for the ith externally controlled switch becomes

$$
\mathrm{p}_{\text {ext, } \mathrm{i}}=\left(\text { delay }_{\mathrm{i}}+\mathrm{n}_{\mathrm{i}} \times \text { period }_{\mathrm{i}}\right)-\mathrm{t}_{\mathrm{sim}}
$$

where $t_{\text {sim }}$ is the current simulation time and $n_{i}$ is a positive integer, which is incremented by 1 whenever a switch violation (i.e. $p_{\text {ext, }, i} \leqq 0$ ) has occurred.

Our simulator has been designed to consider stepping input sources. This is accomplished in the following way. The entry <action > in matrix tmd may take on the value 2 . This indicates that there is a stepping of the input sources after a certain $<$ delay $>-$ time measured from the beginning of the simulation. $<$ col\# $>$ contains the 
column number of a matrix vgs, where the new voltage and current source values have been stored in the same order as the independent sources appear in X. Using this information, vector $W$ in equation (45) can be easily modified.

The switching variable for stepping sources considering the ith step becomes

$$
\mathrm{p}_{\text {source, } \mathrm{i}}=\text { delay }_{\mathrm{i}}-\mathrm{t}_{\text {sim }}
$$

and the topology is no longer valid if $p_{\text {source, } i} \leqq 0$. If $n_{i}$ in equation (71) is fixed to zero, equation (72) is obtained. Therefore, equation (71) will further be used for simplicity.

In order to avoid an excessively small time step when integrating to the exact switching time, equation (71) can be modified in the following way

$$
\mathrm{p}_{\text {ext }, \mathrm{i}}=\left(\text { delay }_{\mathrm{i}}+\mathrm{n}_{\mathrm{i}} \times \text { period }_{\mathrm{i}}\right)-\mathrm{t}_{\mathrm{sim}}-\text { minstep }
$$

where minstep is the desired minimum integration time step specified by the user. This modification requires the storage of the previous calculated solution $\mathbf{v}_{\mathrm{p}}$ at time $t_{\mathrm{psim}}$. Suppose at time $t_{\text {sim }}$ a switch violation has been detected by (73). Starting with the initial condition $\mathbf{C v}_{\mathrm{p}}$ at time $t_{\mathrm{psim}}$, an integration step tstepext,i is taken to the exact switching time of the externally controlled switch

$$
\operatorname{tstep}_{\text {ext }, i}=\left(\text { delay }_{i}+n_{i} \times \text { period }_{i}\right)-t_{p s i m}
$$

where tstep ext, $\mathrm{i} \geqq$ minstep is always guaranteed.

\section{IV.3.2 Switching variables for internally controlled switches}

As it has been first published in [20], switching variables for internally controlled switches are described by the following inequality

$$
C_{y} \times y+C_{t} \times t+C_{c} \leqq 0
$$

where $y$ and $t$ are output and time-counter vectors, respectively. $C_{y}, C_{t}, C_{c}$ are matrices of appropriate size. (75) makes up a set of scalar equations or switching 
variables $p_{\text {int }, j}$, which need to be checked after each integration step. If $p_{i n t, j} \leqq 0$ then a topology is no longer valid. The $j$ th switching variable $p_{\text {int,j }}$ or the $j$ th condition in (75) is related to the switching action (ON or OFF) of the ith switch. The reader should note the generality of the previous statement. The jth condition is not necessarily related to the switching action of the jth switch. Moreover, the jth condition may be related to several switches. The time-counter vector $t$ is given by

$$
t=\left[\begin{array}{l}
t_{\text {sim }} \\
t_{\text {cycle }} \\
t_{\text {topo }} \\
\text { sw }_{\text {ontime }}(i)
\end{array}\right]
$$

The current simulation time is $t_{\text {sim }} \cdot t_{\text {cycle }}$ measures the cycle time of the initial switch configuration and is reset to zero whenever a valid topology with the initial switch configuration occurs. The "lifetime" of a topology is $t_{\text {topo }}$. It is reset to zero whenever a valid topology has been found. $\mathbf{S} \mathbf{W}_{\text {ontime }}$ is a column vector with as many rows as there are switches. The ith row refers to the ith switch and measures its $\mathrm{ON}$-time. If the ith switch is turned OFF, $\mathbf{S W}_{\text {ontime }}(\mathrm{i})$ is reset to zero. For generality purpose, we even allow the $\mathrm{ON}$-time of the kth switch to be inserted into (76) when checking the jth condition of (75). This may be related to the switching action of the ith switch.

Equation (75) is in a general form and allows the user to implement several control laws for power electronic circuits and threshold conditions for internally controlled switches.

The most common internally controlled switch is the diode:

DIODE: $\left\{\begin{array}{l}\text { ON if } i_{D}>0 \text {, then } v_{D}=0 \\ \text { OFF if } v_{D}<0 \text {, then } i_{D}=0\end{array}\right.$ 
and its switching variables written in the form of (75) become

$$
\left[\begin{array}{cc}
1 & 0 \\
0 & -1
\end{array}\right] \times\left[\begin{array}{l}
\mathrm{i}_{D} \\
\mathrm{v}_{\mathrm{D}}
\end{array}\right]+\left[\begin{array}{lllll}
0 & 0 & 0 & 0 & 0 \\
0 & 0 & 0 & 0 & 0
\end{array}\right] \times \mathbf{t}+\left[\begin{array}{l}
0 \\
0
\end{array}\right] \leqq 0
$$

where the first condition is used to monitor the $\mathrm{ON}-$ state of the diode and the second condition monitors its $\mathrm{OFF}-$ state.

Due to numerical inaccuracy, it is recommended to modify (75). A threshold eps unequal to zero is used and (75) changes into

$$
\mathbf{C}_{\mathbf{y}} \times \mathbf{y}+\mathbf{C}_{\mathbf{t}} \times \mathbf{t}+\mathbf{C}_{\mathrm{c}} \leqq- \text { eps }
$$

The problem of assigning a value to the threshold eps is discussed in section IV.7.

\section{IV.4 DETERMINING THE SWITCHING TIME OF INTERNALLY CONTROLLED SWITCHES}

Since the switching times of internally controlled switches are not known at the beginning of the simulation, they have to be determined precisely. Suppose at time $t=t_{1}$ equation (75) indicates a valid topology. After an integration step has been taken, one or several conditions in (75) might now indicate a switch violation at time $t_{2}=t_{1}+t_{\text {step }}$. The conditions are treated one at a time to determine the switching time(s) of the corresponding internally controlled switch(es). The problem reduces to the problem of finding the root of a scalar function in a given interval $\left[t_{1} ; t_{2}\right]$ which is illustrated in Figure 30.

The reader should note that $\mathrm{p}_{\mathrm{int}, \mathrm{j}}$ indicates a switch violation $\left(\mathrm{p}_{\mathrm{int}, \mathrm{j}}\left(\mathrm{t}_{2}\right) \leqq 0\right)$, but no switching has taken place yet. Therefore $\mathrm{p}_{\mathrm{int}, \mathrm{j}}(\mathrm{t})$ is a continuous function in time and according Bolzano's theorem [11], there must be a $t^{*} \in\left[t_{1} ; t_{2}\right]$ such that $p_{i n t, j}\left(t^{*}\right)=0$. Any standard root finding method can be applied to solve for $t^{*}$. Our simulator uses Newton's first method [11], which is the following iteration formula 


$$
t_{k+1}=t_{k}-\frac{p_{\text {int }, j}\left(t_{k}\right)}{p_{\text {int }, j}^{\prime}\left(t_{k}\right)}
$$

Substituting (75) into (80) results in

$$
t_{k+1}=t_{k}-\frac{\left[C_{y} \times y\left(t_{k}\right)+C_{t} \times t\left(t_{k}\right)+C_{c}\right]_{j}}{\left[C_{y} \times y^{\prime}\left(t_{k}\right)+C_{t}\right]_{j}}
$$

where the subscript $\mathrm{j}$ reminds us of the $\mathrm{jth}$ scalar equation in (75).

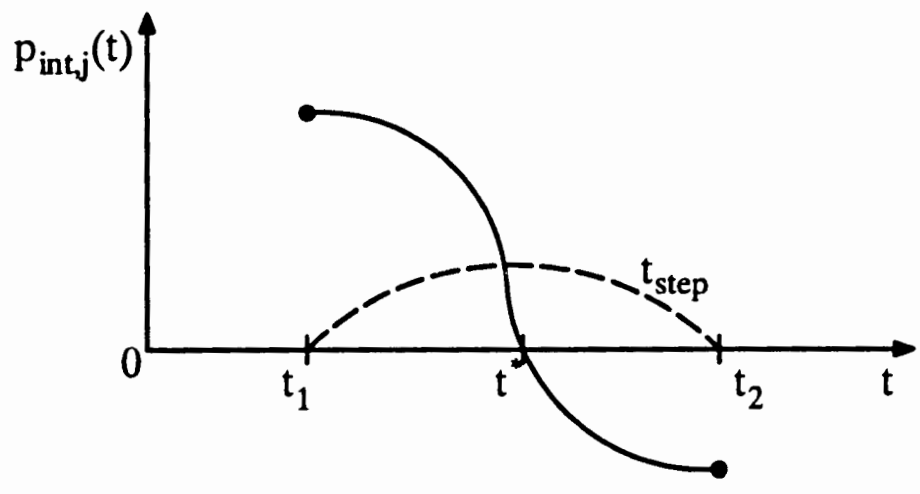

Figure 30 . Switching variable $p_{\text {int, }}(t)$ in a given interval $\left[t_{1} ; t_{2}\right]$.

Equation (81) requires the calculation of the derivative of the output vector $y$. Since a derivative in the time domain corresponds to a multiplication with $s$ in the frequency domain, the inversion formula for a derivative becomes (compare to (54) and (62))

$$
\frac{\mathrm{d} \hat{\mathbf{v}}(\mathrm{t})}{\mathrm{dt}}=-\frac{1}{\mathrm{t}} \sum_{\mathrm{i}=1}^{\mathrm{M}^{\prime}} \operatorname{Re}\left[\left(\frac{z_{i}}{\mathrm{t}}\right) \mathrm{K}_{\mathrm{i}}^{\prime} \mathbf{V}\left(\frac{z_{i}}{\mathrm{t}}\right)\right]
$$

The output vector $\mathbf{y}$ and its derivative are generated from the solution vector $\mathbf{v}$ and its derivative, respectively. This is done by a suitable matrix multiplication

$$
\begin{aligned}
& \mathbf{y}=\text { OUT } \times \mathbf{v} \\
& \mathbf{y}^{\prime}=\text { OUT } \times \mathbf{v}^{\prime}
\end{aligned}
$$


To prevent divergence of the method, we maintain an interval on the root and if $t_{k+1}$ leaves the current interval, then a bisection step is taken instead. The algorithm stops when the convergence criterion is met. The convergence criterion is the absolute error of the calculated root and is typically chosen in the range $10^{-10}$ to $10^{-12} \mathrm{sec}$.

To demonstrate the algorithm's performance, we consider the circuit as shown in Figure 31. The components shall take on the values as listed in Table VII. The switches $S W_{1}$ and $S W_{2}$ operate in antiphase to regulate the inductor current in the desired range. When $S W_{1}$ is closed ( $S W_{2}$ is open) the inductor current rises exponentially. When it becomes $1 \mathrm{~A}$, the current regulator turns $\mathrm{SW}_{1} \mathrm{OFF}$ and $\mathrm{SW}_{2} \mathrm{ON}$ and the inductor current decreases exponentially until the start of the next cycle.

The steady-state solution for the loading cycle is

$$
i_{L}(t)=\frac{E_{0}}{R_{0}+R_{1}}\left(1-e^{-\frac{1}{r_{1}}}\right)+i_{L}(0) e^{-\frac{l}{r_{1}}}
$$

where $i_{L}(0)=0.5 \mathrm{~A}$ is the inductor current at the start of the cycle and $\tau_{1}$ is the time constant

$$
\tau_{1}=\frac{L_{1}}{\left(R_{0}+R_{1}\right)}
$$

At time $t=t_{1}, S W_{1}$ is opened ( $S W_{2}$ is closed) and the analytical solution for the disloading cycle is

$$
i_{L}(t)=i_{L}\left(t_{1}\right) e^{-\frac{t-t_{1}}{i_{2}}}
$$

where $i_{L}\left(t_{1}\right)=1 \mathrm{~A}$ and the corresponding time constant $\tau_{2}$ is

$$
\tau_{2}=\frac{L_{1}}{R_{1}}
$$

Figure 32 shows the simulated inductor current and its relative error is shown in Figure 33. The switching times are calculated with a relative error in the range of $10^{-13}$ to $10^{-11}$. 


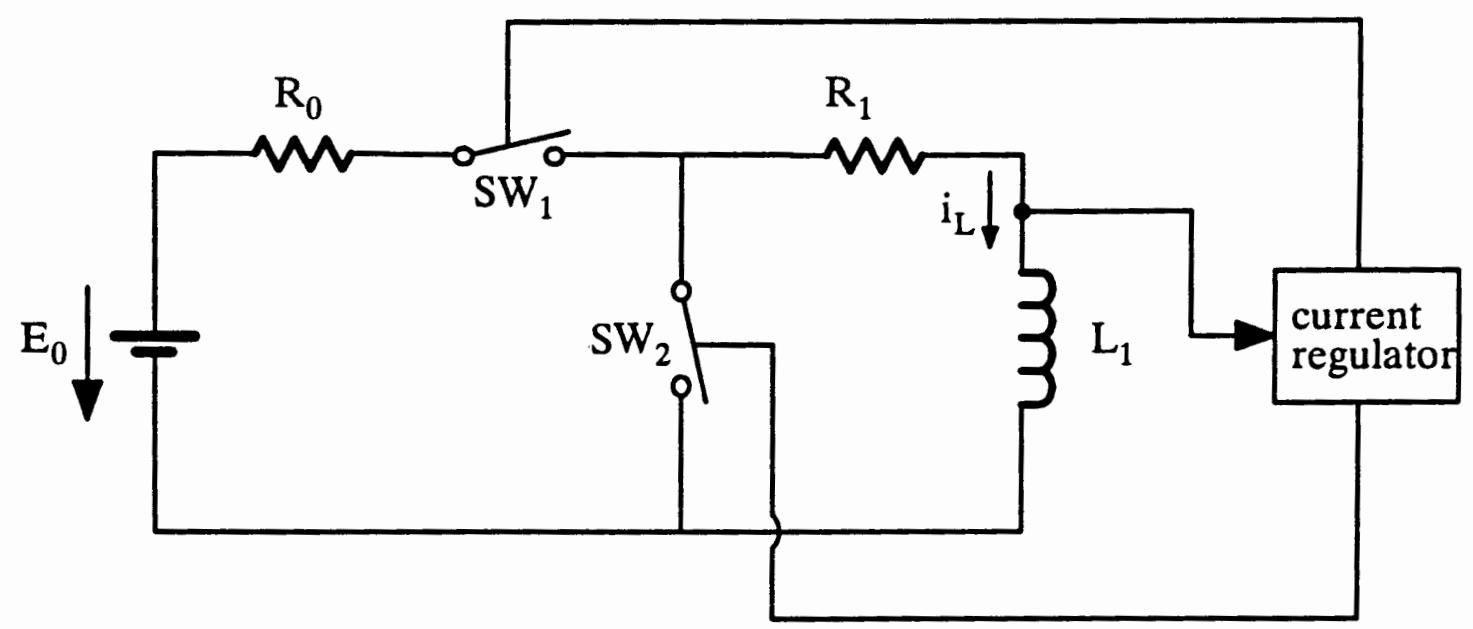

Eigure 31 Switched RL-network, $S W_{1}$ and $S W_{2}$ operate in antiphase.

\section{TABLE VII}

COMPONENT VALUES FOR THE CIRCUIT IN FIGURE 31

$$
\begin{array}{lc}
\mathrm{E}_{0}=220 \mathrm{~V} & \mathrm{~L}_{1}=1 \mathrm{H} \\
\mathrm{R}_{0}=10 \Omega & \mathrm{i}_{\mathrm{L}}(0)=0.5 \mathrm{~A} \\
\mathrm{R}_{1}=100 \Omega & 0.5 \mathrm{~A} \leqq \mathrm{i}_{\mathrm{L}} \leqq 1 \mathrm{~A}
\end{array}
$$




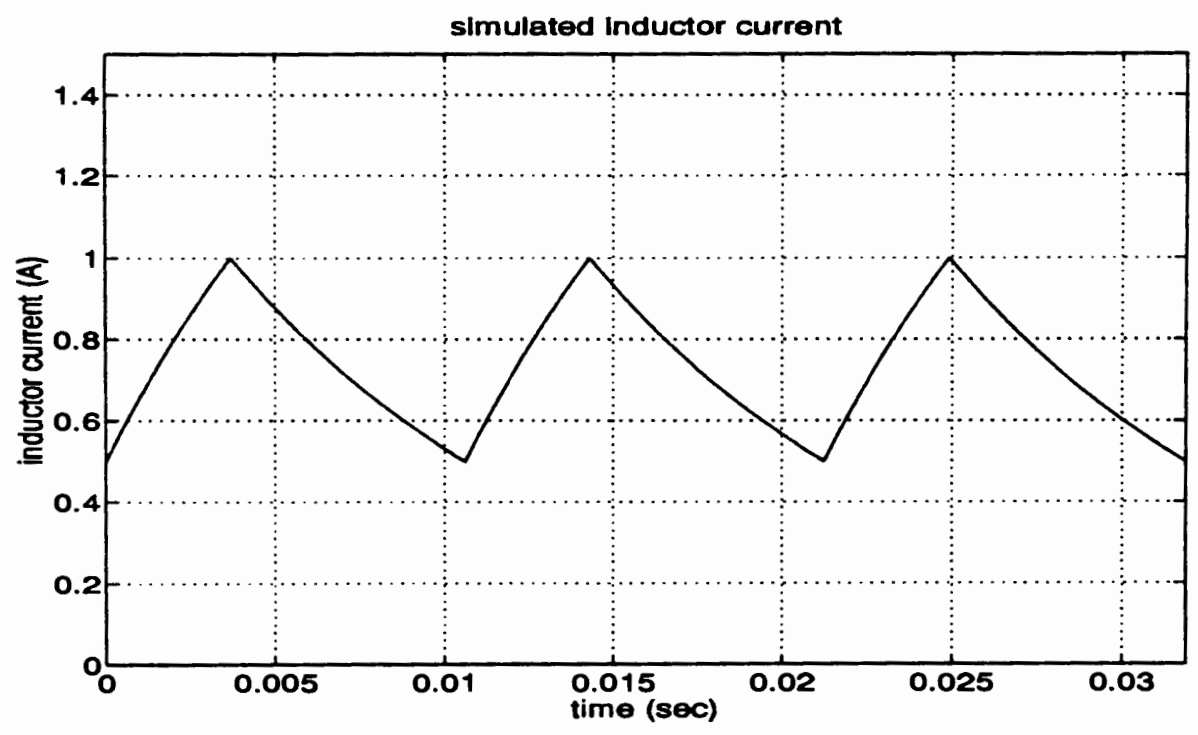

Figure 32. Simulated inductor current for the circuit in Figure 31.

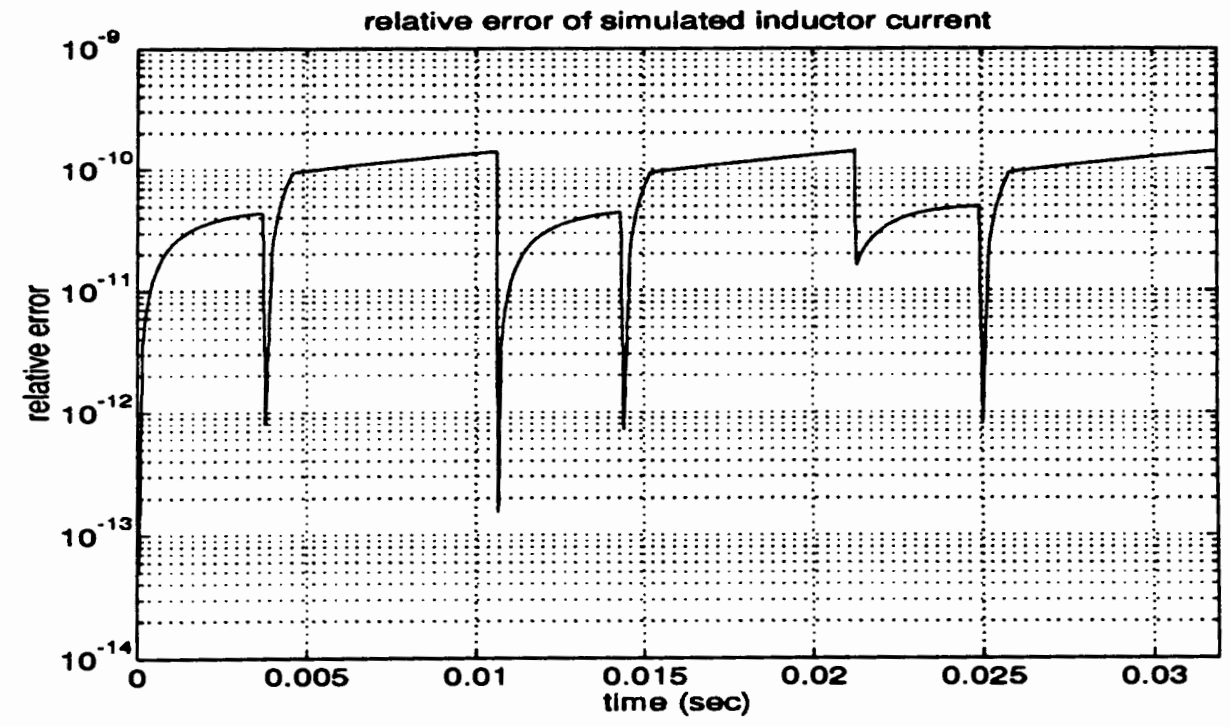

Figure 33. Relative error of inductor current. 


\section{IV.5 HANDLING OF SWITCHING VARIABLES AND DETERMINATION OF THE NETWORK SOLUTION IMMEDIATELY BEFORE SWITCHING}

In Section IV.3 switching variables have been introduced which monitor the state of each externally and/or internally controlled switch. If a switching variable takes on a negative value, then the corresponding switch(es) are no longer in a valid state. Obviously, the simulator has to determine a subset of switches which changes its state first in a given interval. Since the topology is updated after an integration step is taken to the first switching time, all other switching violations happening further in time can be discarded.

Suppose we found the network solution $\mathbf{v}_{1}$ at time $t=t_{1}$ and an integration step is taken forward in time to solve for $v_{2}$ at time $t=t_{2}$. The solution vector $v_{2}$ and the time variable $t=t_{2}$ are used to find out if the present topology is still valid. At time $t=t_{2}$, each switch is in a particular state (either ON or OFF). Let $n_{s}$ be the number of switches then the present switch configuration may be described in a $\left(n_{s} \times 1\right)$ column vector $\mathbf{S W}_{\text {pos}}$, where the ith row refers to the ith switch $(1=\mathrm{ON}, 0=\mathrm{OFF})$.

In general, a switch may be both externally and internally controlled and may have several switching variables related to its $\mathrm{ON}$ - and $\mathrm{OFF}$ - state.

Internally controlled switches have been discussed in Section IV.3.2 and its switching variables are described by (75). Suppose (75) describes $n_{p, i n t}$ switching variables which are collected in the set

$$
P_{\text {int }}=\left\{p_{\text {int }, j} \mid 1 \leqq j \leqq n_{p, i n t}\right\}
$$

We denote the set of internal switching variables monitoring the $\mathrm{ON}-$ state of the ith switch as 


$$
P_{\text {int }, i}^{O N}=\left\{p_{\text {int }, j} \mid j \in\left\{1, \ldots, n_{p, i n t}\right\} \wedge n\left(P_{\text {int,i }}^{\text {ON }}\right)=N_{\text {int }, i}\right\}
$$

where $\mathrm{N}_{\mathrm{int}, \mathrm{i}}$ is the number of switching variables in the set. Similarly, the set of switching variables monitoring the OFF-state of the ith switch is defined as

$$
\mathrm{P}_{\text {int,i }}^{\text {OFF }}=\left\{\mathrm{p}_{\text {int }, j} \mid j \in\left\{1, \ldots, n_{p, i n t}\right\} \wedge n\left(P_{\text {int }, i}^{\text {OFF }}\right)=M_{\text {int }, i}\right\}
$$

where $M_{\text {int, }, i}$ is the set size of $P_{i n t, i}^{O F F}$. The switching variables in $P_{\text {int }}$ are checked using the following set of threshold conditions

$$
\begin{aligned}
& \mathrm{P}_{\mathrm{int}, \mathrm{j}}>\text { eps } \rightarrow \quad \text { no switch violation } \\
& \mathrm{p}_{\text {int } \mathrm{j}}<- \text { eps } \rightarrow \text { switching time } \mathrm{t}_{\mathrm{int}, \mathrm{j}}^{*} \text { is } \\
& \text { in the interval }\left[t_{1} ; t_{2}\right] \\
& \text { and is calculated by } \\
& \text { Newton-Raphson iteration } \\
& \left|p_{\text {int } j}\right| \leq \text { eps } \quad \rightarrow \quad \text { switching time is } t_{\text {int, } j}^{*}=t_{2}
\end{aligned}
$$

The threshold eps is typically chosen about $10^{-10}$ to make the algorithm more insensitive for numerical errors. Clearly, if $S W_{\text {pos }}(i, 1)=1\left(S_{\text {pos }}(i, 1)=0\right)$ then we only need to check the corresponding switching variables in the set $P_{\text {int, } i}^{O N}\left(P_{\text {int }, i}^{\text {OFF }}\right)$. Applying (92) to the set $P_{\text {int }}$, results in a set of switching times $t_{\text {int,j }}^{*}$ and its corresponding time steps are

$$
\text { tstep }_{\text {int, }}=t_{\text {int, } j}^{*}-t_{1}
$$

Externally controlled switches and its switching variables have been discussed in Section IV.3.1. A switch which is controlled by an external clock is turned $O N$ and/or OFF at a fixed frequency. Therefore an externally controlled switch has at most 2 switching variables.

We define the sets of external switching variables 


$$
\begin{aligned}
& P_{\text {ext }}^{O N}=\left\{p_{\text {ext,i }}^{O N} \mid i \in\left\{1, \ldots, n_{s}\right\} \wedge n\left(P_{\text {ext }}^{O N}\right)=N_{\text {ext }}\right\} \\
& P_{\text {ext }}^{\text {OFF }}=\left\{p_{\text {ext }, i}^{\text {OFF }} \mid i \in\left\{1, \ldots, n_{s}\right\} \wedge n\left(P_{\text {ext }}^{O F F}\right)=M_{\text {ext }}\right\}
\end{aligned}
$$

where $p_{\text {ext, }}$ refers to the ith switch, $n_{s}$ is the number of switches and the set size of $P_{\text {ext }}^{O N}$ and $\mathrm{P}_{\text {ext }}^{\mathrm{OFF}}$ is $\mathrm{N}_{\text {ext }}$ and $\mathrm{M}_{\text {ext }}$, respectively. Each switching variable is checked using equation (73) and if a negative value is encountered, the corresponding time step tstep $p_{\text {ext, } i}$ to the switching time of the ith switch is obtained by (74).

The stepping of input sources is also controlled by an external clock and its switching variables have the form of (72). We collect them in a set

$$
\mathrm{P}_{\text {source }}=\left\{\mathrm{p}_{\text {source, } \mathrm{i}} \mid \mathrm{n}_{\text {step }}<\mathrm{i} \leqq \mathrm{n}_{\mathrm{p}, \text { source }}\right\}
$$

where $i$ refers to the ith step and $n_{p, s o u r c e}$ is the number of switching variables $p_{\text {source, } i}$ in the set. It is assumed that $n_{\text {step }}$ steps of input sources have occurred and therefore its corresponding switching variables are no longer a member of the set. Checking each switching variable in $\mathrm{P}_{\text {source }}$ results in time steps tstepsource, corresponding to the switching variables $\mathrm{p}_{\text {source, }, \text {. }}$

Let the minimum of all calculated time steps be

$$
\text { tstep }=\operatorname{MIN}\left\{\text { tstep }_{\text {int,j, }}, \text { tstep }_{\text {ext,i, }}, \text { tstep }_{\text {source, } i}\right\}
$$

Some of the calculated switching times of externally and/or internally controlled switches (including the stepping of input sources) might be too close together such that it is not necessary to treat them separately. If the following inequalities

$$
\begin{aligned}
& \text { tstep }_{\text {int }, \mathrm{j}}-\text { tstep }<\text { eps } \\
& \text { tstep }_{\text {ext, } \mathrm{i}}-\text { tstep }<\text { eps } \\
& \text { tstep }_{\text {source, }}-\text { tstep }<\text { eps }
\end{aligned}
$$


hold then we assume that the corresponding switching actions happen at the same time $t=t_{1}+$ tstep. All other switching actions not satisfying (98), (99) or (100) are ignored. Consequently, the sets (89), (94), (95) and (96) change into

$$
\begin{aligned}
& P_{\text {int }}^{*}=\left\{p_{\text {int }, j} \mid j \in\left\{1, \ldots, n_{\text {p,int }}\right\} \wedge n\left(P_{\text {int }}^{*}\right)=n_{p, \text { int }}^{*}\right\} \\
& P_{\text {ext }}^{\text {ON, }}=\left\{p_{\text {ext,i }}^{\text {ON }} \mid i \in\left\{1, \ldots, n_{s}\right\} \wedge n\left(P_{\text {ext }}^{\text {ON, }}\right)=N_{\text {ext }}^{*}\right\} \\
& P_{\text {ext }}^{\text {OFF, }}=\left\{p_{\text {ext,i }}^{\text {OFF }} \mid i \in\left\{1, \ldots, n_{s}\right\} \wedge n\left(P_{\text {ext }}^{\text {OFF, }}\right)=M_{\text {ext }}^{*}\right\} \\
& P_{\text {source }}^{*}=\left\{p_{\text {source, } i} \mid i \in\left\{n_{\text {step }}, \ldots, n_{\text {p,source }}\right\} \wedge n\left(P_{\text {source }}^{*}\right)=n_{\text {p,source }}^{*}\right\}
\end{aligned}
$$

The sets (101), (102), (103) and (104) are subsets of (89), (94), (95), (96) and we can write

$$
\begin{aligned}
& \mathrm{P}_{\text {int }}^{*} \subseteq \mathrm{P}_{\text {int }} \\
& \mathrm{P}_{\text {ext }}^{\text {ON, }} \subseteq \mathrm{P}_{\text {ext }}^{\text {ON }} \\
& \mathrm{P}_{\text {ext }}^{\text {OFF, }} \subseteq \mathrm{P}_{\text {ext }}^{\text {OFF }} \\
& \mathrm{P}_{\text {source }}^{*} \subseteq \mathrm{P}_{\text {source }}
\end{aligned}
$$

Clearly, if no switch violation has been detected then $\mathrm{P}_{\mathrm{int}}^{*} \mathrm{P}_{\mathrm{ext}}^{\mathrm{ON}, *}, \mathrm{P}_{\mathrm{ext}}^{\mathrm{OFF},}, \mathrm{P}_{\text {source }}^{*}$ are empty sets $\left(n_{\mathrm{p}, \text { int }}^{*}=\mathrm{N}_{\mathrm{ext}}^{*}=\mathrm{M}_{\mathrm{ext}}^{*}=\mathrm{n}_{\mathrm{p} \text {,source }}^{*}=0\right)$ and the solution $\mathrm{v}_{2}\left(\mathrm{t}_{2}\right)$ is saved to a file. If the above sets are non-empty and tstep $=t_{2}-t_{1}$, then $v_{2}$ is the solution immediately before switching and is also saved to a file. If tstep $<t_{2}-t_{1}$, then $v_{2}$ is discarded and we solve for $v_{2}^{*}$ immediately before switching at time $t=t_{1}+$ tstep using $\mathbf{C v}_{1}$ as initial conditions and save the solution to a file. The reader should note that we shift the time axis after each integration step (see Section III.2). Therefore, the obtained solution becomes the solution $\mathrm{v}\left(0^{-}\right)$immediately before the switching action 
and is used in the error-controlled two-step method which is presented in the next section. Finally the topology is updated based on the information contained in the sets $\mathrm{P}_{\text {int }}^{*}, \mathrm{P}_{\mathrm{ext}}^{\mathrm{ON}, *}, \mathrm{P}_{\mathrm{ext}}^{\mathrm{OFF}, *}, \mathrm{P}_{\text {source }}^{*}$.

$$
\begin{aligned}
& \text { if }\left(P_{e x t}^{O N * *} \neq \emptyset\right) \text { then } \\
& \text { if }\left(p_{e x, i}^{O N} \in P_{e x t}^{O N, *}\right) \text { then turn ON ith switch; } \\
& \text { if }\left(P_{\text {ext }}^{O F F^{*}} \neq \emptyset\right) \text { then } \\
& \text { if }\left(p_{e x t, i}^{\text {OFF }} \in P_{\text {ext }}^{\text {OFF* }}\right) \text { then turn OFF ith switch; } \\
& \text { if }\left(P_{\text {source }}^{*} \neq \emptyset\right) \text { then } \\
& \text { if }\left(p_{\text {source, },} \in P_{\text {source }}^{*}\right) \text { then update } W \text { using the values for the ith step; } \\
& \text { if }\left(P_{i n t}^{*} \neq \emptyset\right) \text { then } \\
& \{ \\
& \text { if }\left(p_{\text {int } j} \in P_{\text {int }}^{*}\right) \text { then } \\
& \{ \\
& \text { if }\left(p_{\text {int }, j} \in P_{i n t, i}^{O N}\right) \text { then turn OFF ith switch; } \\
& \text { if }\left(p_{\text {int } j} \in P_{i n t, i}^{O F F}\right) \text { then turn ON ith switch; } \\
& \text { \} } \\
& \text { \} }
\end{aligned}
$$

In this section, we assumed that a solution to the network equations exists. This assumption is necessary; otherwise a unique topology can't be derived from the various sets of switching variables. Since the switching action can cause other switches to change state, the updated topology might still not be a valid one. Determining the final correct topology at a switching instant is described in Section IV.7. 


\section{IV.6 ERROR - CONTROLLED TWO-STEP METHOD}

In Section III. 3 we demonstrated the calculation of consistent initial conditions and Dirac impulses at the switching instant using the two-step method. Suppose the time axis has been shifted again such that the switching action occurs at $t=0$. Since an arbitrary large forward step can't guarantee accurate results, we would like to have the solution of the forward integration step at time $t=t_{F}$ to meet a certain error criterion.

Let $v_{p}\left(t_{F}\right)$ and $v_{p+1}\left(t_{F}\right)$ denote the network solution at time $t=t_{F}$ obtained by the pth and $(p+1)$ th order numerical inverse Laplace transform, respectively. The absolute difference between the two solutions is taken to be the truncation error of the lower order method [15]. Suppose $\mathbf{v}_{\mathrm{p}}$ and $\mathbf{v}_{\mathrm{p}+1}$ are $(\mathrm{N} \times 1)$ vectors, then we check

$$
\left|v_{p+1}(j, 1)-v_{p}(j, 1)\right| \leqq \text { ERRMAX for } j=1, \ldots, N
$$

for every component, where ERRMAX is the specified maximum error. Only if the error criterion is met, the backward integration step $t_{B}=-t_{F}$ is taken to solve for $v_{p}\left(0^{+}\right), v_{p+1}\left(0^{+}\right), v_{p, d i r a c}(0)$. Otherwise we half the forward step and the procedure is repeated. The initial value for $t_{F}$ in the first forward step may be the desired maximum integration step MAXSTEP as specified by the user. From our practical experience, we recommend to specify as well a minimum integration step MINSTEP $\left(10^{-10}\right.$ to $10^{-12}$ sec.). If the specified maximum error is too tight for a particular application (large matrices and/or large current/voltage derivatives in the time domain), then the error criterion might not be met even for fairly small time steps and the algorithm would keep on halving the forward step. Following [16], we have to avoid excessively small time steps due to numerical round-off errors. In the simulation of switched linear networks consistent initial conditions and Dirac impulses have to be calculated at every switching instant. Therefore, it is convenient to implement the algorithm in a function. Its flow chart is given in Figure 34. 


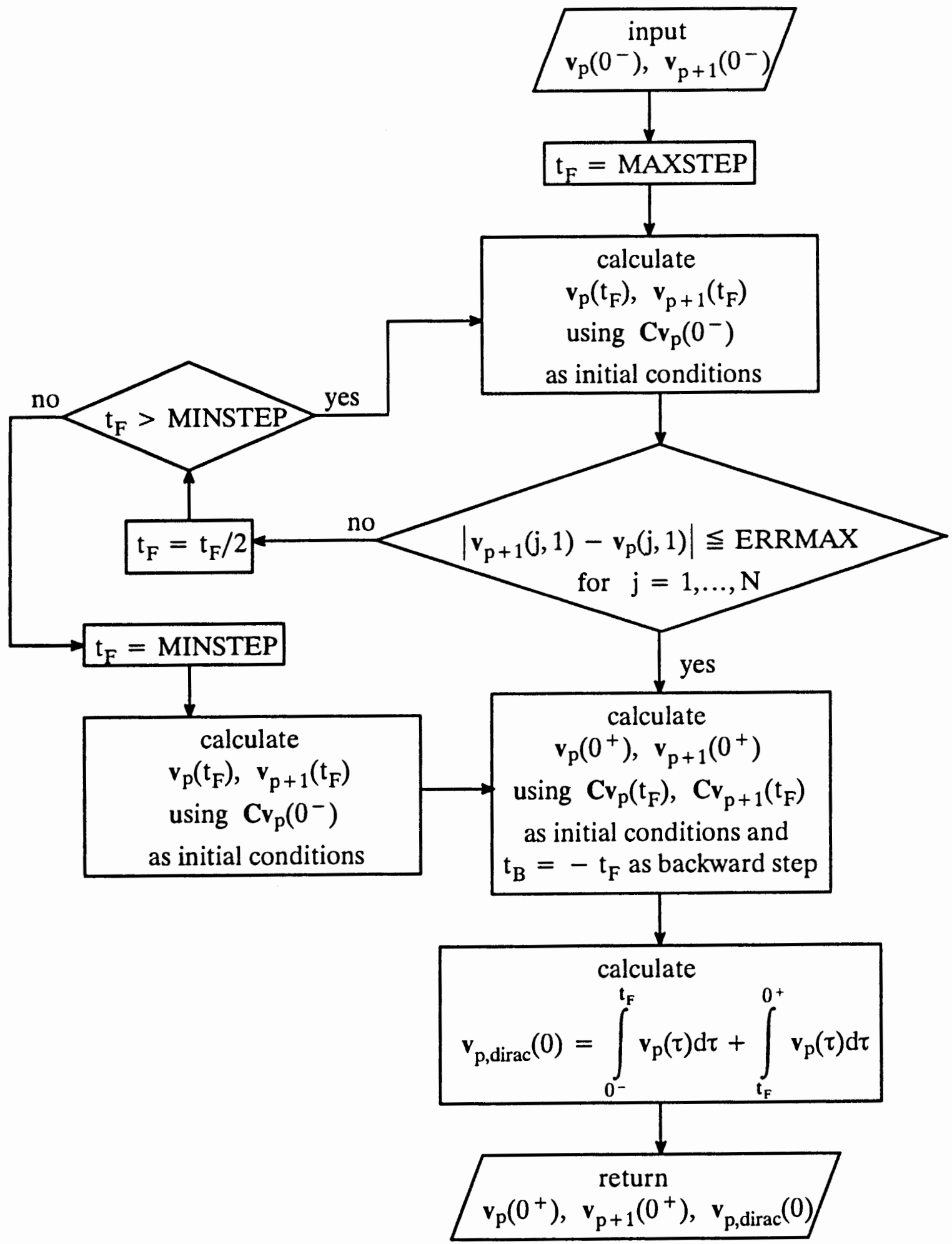

Figure 34. Flow chart of the error-controlled two-step method. 


\section{IV.7 DETERMINATION OF A CORRECT TOPOLOGY IMMEDIATELY AFTER SWITCHING}

\section{IV.7.1 Review of the method of Dirac impulses}

In Section IV.5 we demonstrated how the network solution $\mathbf{v}\left(0^{-}\right)$can be obtained immediately before switching. In this section we discuss the problem of determining a valid topology immediately after switching. We hereby review the method of Dirac impulses [19].

To introduce the problem, it is supposed that the simulator has to deal with $n_{s}$ switches and consequently there will be $2^{\mathrm{n}_{\mathrm{s}}}$ different topologies. Nevertheless, only one topology is valid immediately after switching. We denote the topology immediately before switching as $\mathrm{T}\left(0^{-}\right)$. If we assume that a solution to the network equations exists then there will be a uniquely determined topology $\mathrm{T}\left(0^{+}\right)$immediately after switching. In Section IV.5 it has been shown that after having found the network solution $\mathbf{v}\left(0^{-}\right)$, the topology is updated based on the switching variables in the various sets. The resulting topology is $\mathrm{T} 1\left(0^{+}\right)$and in general it does not equal topology $\mathrm{T}\left(0^{+}\right)$since the switching action can cause further switch violations. Therefore, the analysis has to check several intermediate topologies $\mathrm{T} 1\left(0^{+}\right), \mathrm{T} 2\left(0^{+}\right), \mathrm{T} 3\left(0^{+}\right), \ldots$ at the switching instant until the valid topology $\mathrm{T}\left(0^{+}\right)$is found. Once topology $\mathrm{T} 1\left(0^{+}\right)$is found, all further topology changes are due to the switching of internally controlled switches.

As it has been mentioned in Section III.3, the switching action of ideal switches may cause inconsistent initial conditions (e.g. a capacitor is switched in parallel to another capacitor charged to a different voltage). Therefore Dirac impulses of current and voltage may be present at the switching instant to redistribute charge and flux respectively. Although the Dirac impulses are only present at intermediate steps of the analysis (i.e. Dirac impulses may occur in $\mathrm{T} 1\left(0^{+}\right), \mathrm{T} 2\left(0^{+}\right), \mathrm{T} 3\left(0^{+}\right), \ldots$, but they are not 
present in the valid topology $\mathrm{T}\left(0^{+}\right)$), they indicate switch violations of internally controlled switches.

In Section IV.5, the set of internal switching variables $P_{\text {int }}$, the set of internal switching variables $\mathrm{P}_{\text {int, } \mathrm{O}}^{\mathrm{ON}}$ and $\mathrm{P}_{\text {int, } \mathrm{i}}^{\mathrm{OFF}}$ monitoring the $\mathrm{ON}-$ and $\mathrm{OFF}-$ state of the ith switch, respectively, have been defined by (89), (90) and (91). The circuit response at the switching instant consists of an impulsive and a non-impulsive part (refer to equation (63)). The impulse-multiplier vector $\mathbf{v}_{\delta}(0)$ and the solution vector $\mathbf{v}\left(0^{+}\right)$are calculated by the two-step method presented in Section IV.6.

The method of Dirac impulses operates as follows. At every switching instant we calculate $v_{\delta}(0)$ and $v\left(0^{+}\right)$using the initial conditions $\operatorname{Cv}\left(0^{-}\right)$immediately before switching. The switching variables in the set $P_{\text {int }}$ are checked both with the impulse-multiplier vector $\mathbf{v}_{\delta}(0)$ and the solution vector $\mathbf{v}\left(0^{+}\right)$. Note that if the ith switch is $\mathrm{ON}\left(\mathrm{SW}_{\mathrm{pos}}(\mathrm{i}, 1)=1\right)$ then we only need to check the switching variables in the set $P_{\text {inti }}^{\text {ON }}$ If $S W_{\text {pos }}(i, 1)=0$, then we check the switching variables in the set $P_{\text {int, } i}^{\text {OFF }}$. We hereby use the threshold condition

$$
\mathrm{p}_{\text {int } \mathrm{j}}<- \text { eps }
$$

The sets $\mathrm{P}_{\text {int }}^{\mathrm{D}, *}$ and $\mathrm{P}_{\text {int }}^{*}$ collect internal switching variables in violation when being checked with $\mathbf{v}_{\delta}(0)$ and $\mathbf{v}\left(0^{+}\right)$, respectively.

$$
\begin{aligned}
& P_{\text {int }}^{D, *}=\left\{p_{\text {int }, j} \mid j \in\left\{1, \ldots, n_{p, i n t}\right\} \wedge n\left(P_{\text {int }}^{D, *}\right)=n_{p, \text { int }}^{D, *}\right\} \\
& P_{\text {int }}^{*}=\left\{p_{\text {int } j} \mid j \in\left\{1, \ldots, n_{p, \text { int }}\right\} \wedge n\left(P_{\text {int }}^{*}\right)=n_{p, \text { int }}^{*}\right\}
\end{aligned}
$$

where $n_{p, i n t}$ is the number of internal switching variables. Clearly, (111) and (112) are subsets of (89) and we can write 


$$
\begin{aligned}
& \mathrm{P}_{\mathrm{int}}^{\mathrm{D}}, \subseteq \mathrm{P}_{\mathrm{int}} \\
& \mathrm{P}_{\mathrm{int}}^{*} \subseteq \mathrm{P}_{\mathrm{int}}
\end{aligned}
$$

Finally, the topology is updated using the information of the sets (111) and (112).

$$
\begin{aligned}
& \text { if }\left(\left(P_{\text {int }}^{D^{*}} \neq \emptyset\right) \|\left(P_{\text {int }}^{*} \neq \emptyset\right)\right) \text { then } \\
& \{ \\
& \text { if }\left(\left(p_{i n t, j} \in P_{\text {int }}^{D, *}\right) \|\left(p_{i n t, j} \in P_{\text {int }}^{*}\right)\right) \text { then } \\
& \text { \{ } \\
& \text { if }\left(p_{i n t, j} \in P_{i n t, i}^{O N}\right) \text { then turn OFF ith switch; } \\
& \text { if }\left(p_{\text {int } j} \in P_{i n t, i}^{O F F}\right) \text { then turn ON ith switch; } \\
& \text { \} } \\
& \text { \} }
\end{aligned}
$$

The reader should note that a switching action can be caused either by a Dirac impulse or the non-impulsive solution vector $\mathbf{v}\left(0^{+}\right)$. Moreover, a Dirac impulse will always swamp the non-impulsive component regardless of its value (notice the OR condition in the above algorithm for updating a topology). The new resulting topology is checked again by calculating the corresponding non-impulsive and impulse-multiplier components using the saved initial conditions $\operatorname{Cv}\left(0^{-}\right)$. The procedure is repeated until all switching variables are satisfied.

\section{IV.7.2 Problems and limitations of the method of Dirac impulses}

We consider an ideal buck converter as shown in Figure 35. Both switches (SW1 and D1) are assumed ideal. The switch SW1 is controlled by an external clock with a fixed duty cycle, whereas the diode D1 is an internally controlled switch. 


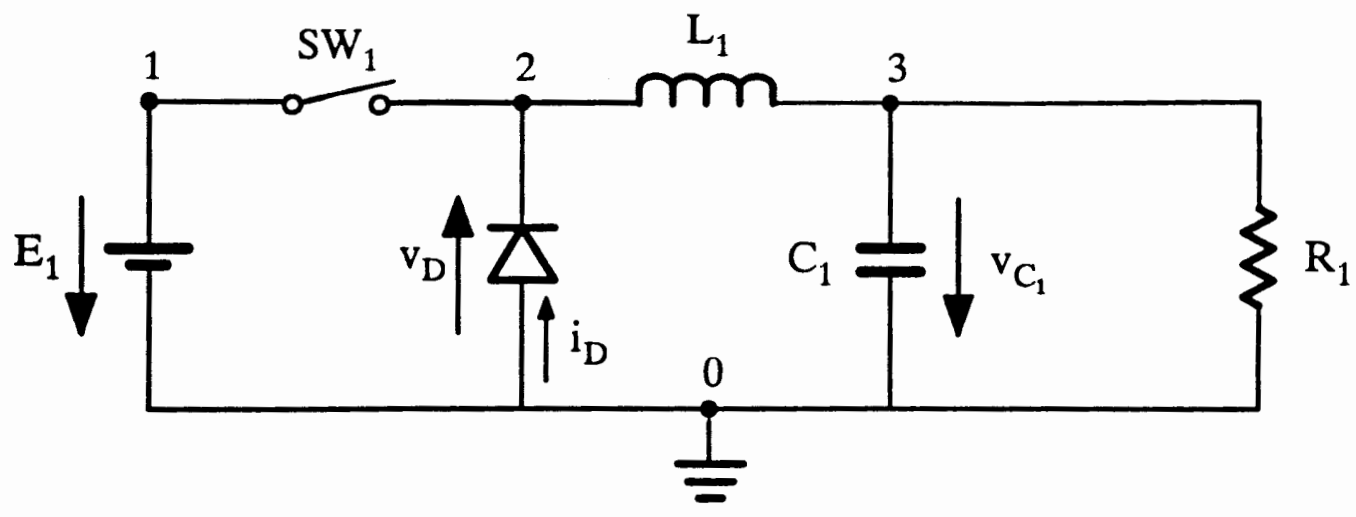

Figure 35. Ideal buck converter.

During the time when SW1 is ON and D1 is OFF, the inductor current increases linearly and the voltage across the diode is

$$
\mathrm{v}_{\mathrm{D}}=-\mathrm{E}_{1}
$$

indicating that the diode is in its correct state. Since the inductor current flows uninterrupted in continuous conduction mode, D1 is supposed to turn ON immediately when SW1 is turned OFF by an external clock. The analysis which determines the correct topology $\mathrm{T}\left(0^{+}\right)$immediately after switching goes as follows. The simulator integrates until the exact switching time of SW1 and turns SW1 OFF. The solution $v\left(0^{-}\right)$ is saved to a file. The solution vector $\mathbf{v}\left(0^{+}\right)$and the impulse-multiplier vector $\mathbf{v}_{\delta}(0)$ corresponding to the topology $\mathrm{T} 1\left(0^{+}\right)$(both switches are OFF) are calculated by using the two-step method and the initial conditions $\mathrm{Cv}\left(0^{-}\right)$. The diode voltage at the switching instant written in the form of (63) becomes

$$
\mathrm{v}_{\mathrm{D}}(0)=\mathrm{Li}_{\mathrm{L}_{1}}\left(0^{-}\right) \delta(0)-\mathrm{v}_{\mathrm{C}_{1}}
$$

indicating that the diode should be turned $\mathrm{ON}$. We clearly like to point out that the impulse multiplier $\mathrm{Li}_{L_{1}}\left(0^{-}\right)$is only present in the intermediate topology $\mathrm{T} 1\left(0^{+}\right)$where both switches are OFF. The inductor current can only fall to zero instantaneously if a negative Dirac impulse of voltage $-\mathrm{Li}_{\mathrm{L}_{1}}\left(0^{-}\right)$occurs at node 2 . Therefore, it is quite 
important that topology $\mathrm{T} 1(0+)$ is part of the analysis and that we first have to turn OFF switch SW1 before the correct state of the diode can be determined. After D1 has been turned $\mathrm{ON}$, the corresponding non-impulsive and impulse-multiplier components of topology $\mathrm{T} 2(0+)(\mathrm{SW} 1$ is $\mathrm{OFF}, \mathrm{D} 1$ is $\mathrm{ON})$ have to be calculated again using the saved

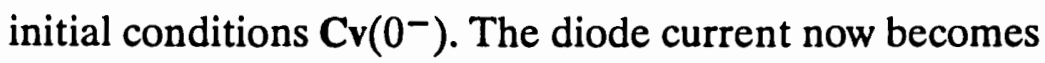

$$
\mathrm{i}_{D}(0)=0 \delta(0)+\mathrm{i}_{\mathrm{L}_{1}}\left(0^{-}\right)
$$

indicating that the correct topology $\mathrm{T}\left(0^{+}\right)=\mathrm{T} 2(0+)$ has been found. If the inductor current does not drop to zero before the input voltage is applied to the circuit again then the buck converter operates in continuous conduction mode. The external clock determines the time when SW1 is turned ON. Again the simulator integrates until the switching time at which it saves the solution $\mathbf{v}\left(0^{-}\right)$to a file and updates the topology by turning ON SW1. In the resulting topology $\mathrm{T} 1(0+)$ both switches are now $\mathrm{ON}$, and the next step in the analysis would be to calculate $v_{\delta}(0)$ and $\mathbf{v}\left(0^{+}\right)$. At this point the analysis fails, which is explained next.

Without loss of generality, the nodes are labelled as indicated in Figure 35. The determinant of the node-admittance matrix becomes

$$
\left.\operatorname{det}(\mathbf{G}+\mathrm{sC})=\operatorname{det}\left(\begin{array}{ccccccc}
0 & 0 & 0 & 0 & 0 & 1 & 1 \\
0 & 0 & 0 & 1 & 1 & -1 & 0 \\
0 & 0 & \frac{1}{\mathrm{R}_{1}}+\mathrm{sC}_{1} & -1 & 0 & 0 & 0 \\
0 & 1 & -1 & -\mathrm{sL}_{1} & 0 & 0 & 0 \\
0 & 1 & 0 & 0 & 0 & 0 & 0 \\
1 & -1 & 0 & 0 & 0 & 0 & 0 \\
1 & 0 & 0 & 0 & 0 & 0 & 0
\end{array}\right]\right)=0
$$

The reader may easily verify that $\operatorname{det}(\mathbf{G}+\mathrm{s} \mathbf{C})=0$ and an inversion of the matrix $(\mathbf{G}+\mathrm{sC})$ is not possible. Clearly, this must be the case because the input voltage $\mathrm{E} 1$ is shortened in topology $\mathrm{T} 1\left(0^{+}\right)$. 
It is interesting to note that discontinuous conduction mode of an ideal buck converter can be handled by the algorithm. The inductor current falls to zero before E1 is applied to the circuit. Therefore, diode D1 is turned OFF before switch SW1 is turned $\mathrm{ON}$ again and the input voltage $\mathrm{E} 1$ is not shortened.

Since a general analysis method can't assume any relation between switches (e.g. treating SW1 and D1 as a single complementary switch), intermediate topologies have to be considered at the switching instant. Therefore, we must conclude that the method of Dirac impulses is limited to circuits where the determinant of $(\mathbf{G}+\mathbf{s} \mathbf{C})$ for any intermediate topology does not equal zero.

The problem of the ideal buck converter can simply be overcome by putting a small resistor in series with the diode D1. The reader may refer to Section IV.9 where a simulation result of a regulated buck converter is given.

Further problems arise when assigning a value to the threshold eps in (110). If a current or a node voltage is non-impulsive at the switching instant then exactly zero is theoretically expected in the corresponding entries of the impulse-multiplier vector. Because of numerical errors this is clearly not the case in practice. The reader should refer to the example in Section III. 3 in which the small number $-1.3184 \times 10^{-15}$ Vs has been calculated by the algorithm instead of zero. In an arbitrary electrical circuit a Dirac impulse of current through branch $k$ is the weighted sum of all other Dirac impulses of current occurring at the same switching instant

$$
\delta_{\mathrm{l}, \mathrm{k}}(0)=\sum_{j=1}^{\mathrm{n}_{\mathrm{c}}} \mathrm{A}_{\mathrm{j}, \mathrm{k}} \mathrm{C}_{\mathrm{j}} \mathrm{v}_{\mathrm{C}_{\mathrm{j}}}\left(0^{-}\right)
$$

where $\mathrm{n}_{C}$ is the number of capacitors in the circuit. Similarly, a Dirac impulse of voltage at node $\mathrm{n}$ is the linear combination of all other Dirac impulses of voltage at the same switching instant 


$$
\delta_{V, n}(0)=\sum_{j=1}^{n_{L}} B_{j, n} L_{j} i_{L_{j}}\left(0^{-}\right)
$$

where $\mathrm{n}_{\mathrm{L}}$ is the number of inductors in the network.

It is quite obvious that $\delta_{I, k}(0)$ or $\delta_{V, n}(0)$ can be a very small number in the general case. The question arises of how can we separate a "real" Dirac impulse from the numerical errors. If eps is chosen too small, numerical errors might cause a switch violation by mistake. As it has been mentioned in the previous section, any Dirac impulse (regardless of the value of the impulse multiplier) always dominates over the non-impulsive circuit response. As a result, the corresponding switch(es) of the switching variables in violation may be turned $O N / O F F$ by mistake. If eps is chosen too large, all "real" Dirac impulses smaller in value than eps are ignored and a wrong topology might be derived.

For our simulator we chose eps $=10^{-10}$, and satisfactory simulation results were obtained (refer to Section IV.9 for numerical examples).

\section{IV.8 IMPLEMENTATION OF VARIABLE STEP SIZE}

Since every practically applicable simulation program must have a built-in error control check, we now discuss the implementation of a variable step size and automatic error control algorithm. The algorithm is supposed to monitor the truncation error of the calculated solution and to vary the integration step size such that a certain error criterion is met. This requires to solve the network equations for a selected step size twice: once with order $p$, and once with the order $p+1$. We denote the pth and $(p+1)$ th order solution with $v_{p}$ and $v_{p+1}$, respectively. Since the error criterion must be met for every component in the solution vector $v_{p}$, the truncation error of the pth order solution is taken to be 


$$
\varepsilon_{p+1}=\operatorname{MAX}\left\{\left|v_{p+1}(j, 1)-v_{p}(j, 1)\right|\right\} \text { for } j=1, \ldots, N
$$

where it is assumed that $\mathrm{v}_{\mathrm{p}}$ and $\mathrm{v}_{\mathrm{p}+1}$ are $(\mathrm{N} \times 1)$ vectors. The maximum allowable error is specified by the user and is denoted as $\varepsilon_{\max }$ and the error-control algorithm has to vary the step size such that

$$
\varepsilon_{\mathrm{p}+1} \leq \varepsilon_{\max }
$$

A possible way to determine an integration step size which satisfies the inequality (122) has been suggested in [15] and the formula is given next

$$
h_{e}=h \sqrt[p]{\frac{\varepsilon_{\max } h}{\varepsilon_{p+1}}}
$$

where $h$ is the previous selected step size and $h_{e}$ is referred to as the estimated step size for the next integration step. The reader should note that $h_{e}$ is indeed an estimated step size, since the corresponding solution to the selected time step $h_{e}$ is not subject to further error control and is saved to a file provided all switching variables are satisfied. The integration time step $h_{e}$ determined by (123) already satisfies (122). The approach will further be referred to as the step size estimation method.

An alternative way to implement a variable step size algorithm would be to check the truncation error of a calculated solution. If the error is small enough relative to $\varepsilon_{\max }$ then the step size is increased. If (122) is not satisfied, the solution is discarded and the simulation backtracks in time to find a more accurate solution by selecting a smaller integration step $h_{c}$ to correct for the error. This clearly requires the storage of the previous calculated solution. We call this approach the error-correction method. A flow chart of the algorithm is given in Figure 36, where it is assumed that $v_{p}\left(t_{n}\right)$ is the current calculated solution at time $t=t_{n}$ and $v_{p}\left(t_{n-1}\right)$ is the previous obtained solution at time $t=t_{n-1}$. Furthermore, it is assumed that no switch violation has been detected in the interval $\left[t_{n-1} ; t_{n}\right]$. Similarly to the error-controlled two-step method (refer to 


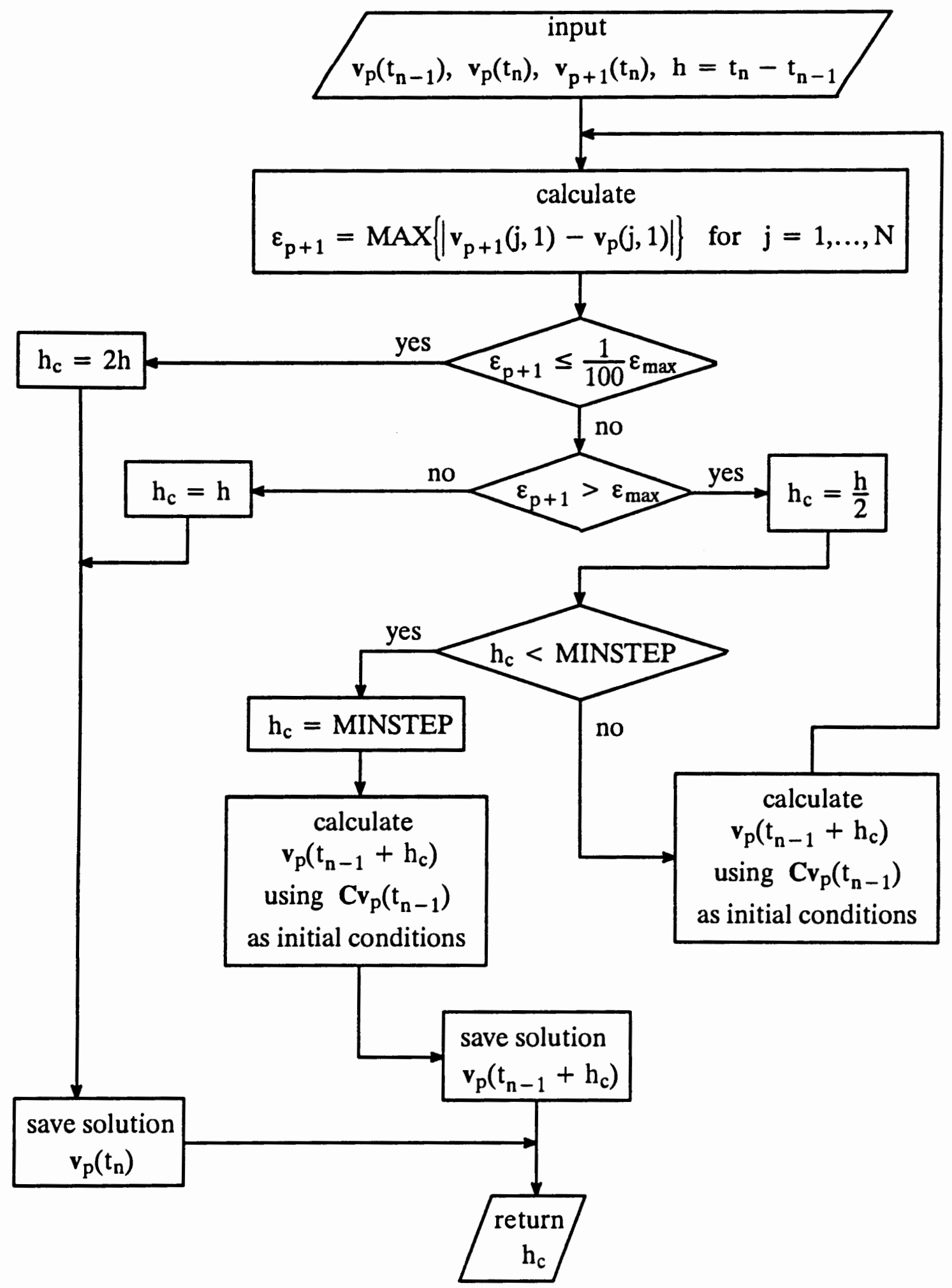

Figure 36. Flow chart of the error-correction method. 
Section IV.6), it is necessary to specify a minimum integration step size.

To compare the performance of both approaches, we consider the circuit in Figure 37. The component values and initial conditions are given in Table VIII. The simulated variable has been taken to be the output voltage across the load resistance $R_{L}$ and is shown in Figure 38. To examine the error of the simulation, a set of state and output equations [4] has been used. Its standard form are

$$
\begin{aligned}
& \dot{x}=A x+B u \\
& y=C x+D u
\end{aligned}
$$

and the exact solution of the state vector is obtained by

$$
x(t)=e^{A t} x(0)+A^{-1}\left(e^{A t}-I\right) B u
$$

where a constant input $u$ has been assumed. Substituting (126) into (125) yields the desired output. The simulation was run with different error specifications $\varepsilon_{\max }$ and without setting a lower limit to the integration step size. The results are shown in the figures $39-42$.

The error-correction method is performing well for all specified $\varepsilon_{\max }$. The step size $h_{c}$ is selected such that the specified maximum error criterion is always met.

Contrarily, the step size estimation method fails completely. Although the error criterion is met, the step size is successively decreased. This is due to the fact that $h_{e}$ in equation (123) is not only a function of the truncation error $\varepsilon_{\mathrm{p}+1}$ and the maximum permissible error $\varepsilon_{\max }$ but a function of the previous selected step size $\mathrm{h}$ as well. Suppose we would like to have the estimated step size to be

$$
h_{e}=k h \quad \text {, for } k \geq 1
$$

Inserting (127) into (123) and solving for the truncation error results in

$$
\varepsilon_{\mathrm{p}+1}=\frac{\varepsilon_{\max }}{\mathrm{k}^{\mathrm{p}} \mathrm{h}}
$$




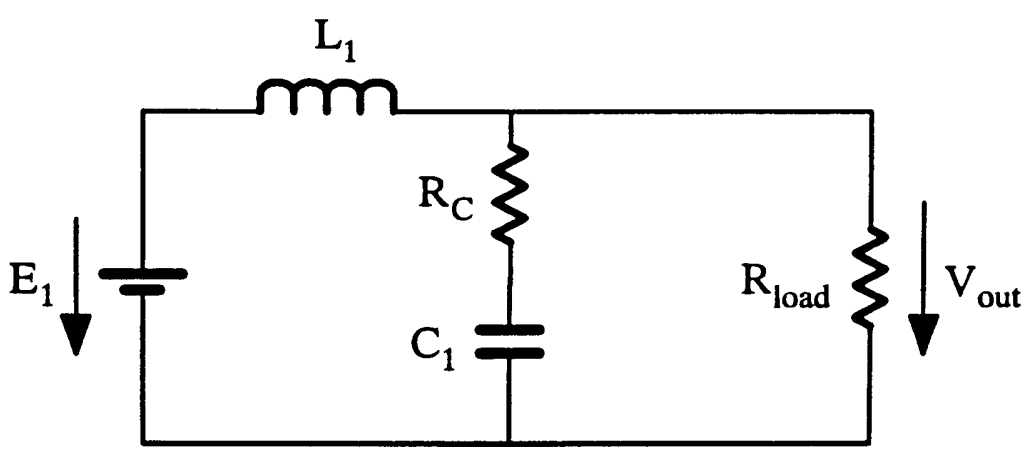

Figure 37 RLC-network for variable step size performance test.

TABLE VIII

COMPONENT VALUES FOR THE CIRCUIT IN FIGURE 37

$$
\begin{array}{lll}
\mathrm{E}_{1}=15 \mathrm{~V} & \mathrm{~L}_{1}=1 \mathrm{mH} & \mathrm{i}_{\mathrm{L}_{1}}(0)=0.1 \mathrm{~A} \\
\mathrm{R}_{\mathrm{C}}=0.1 \Omega & \mathrm{C}_{1}=5 \mu \mathrm{F} & \mathrm{V}_{\mathrm{C}_{1}}(0)=1 \mathrm{~V} \\
\mathrm{R}_{\text {load }}=20 \Omega & &
\end{array}
$$

simulated output voltage Vout

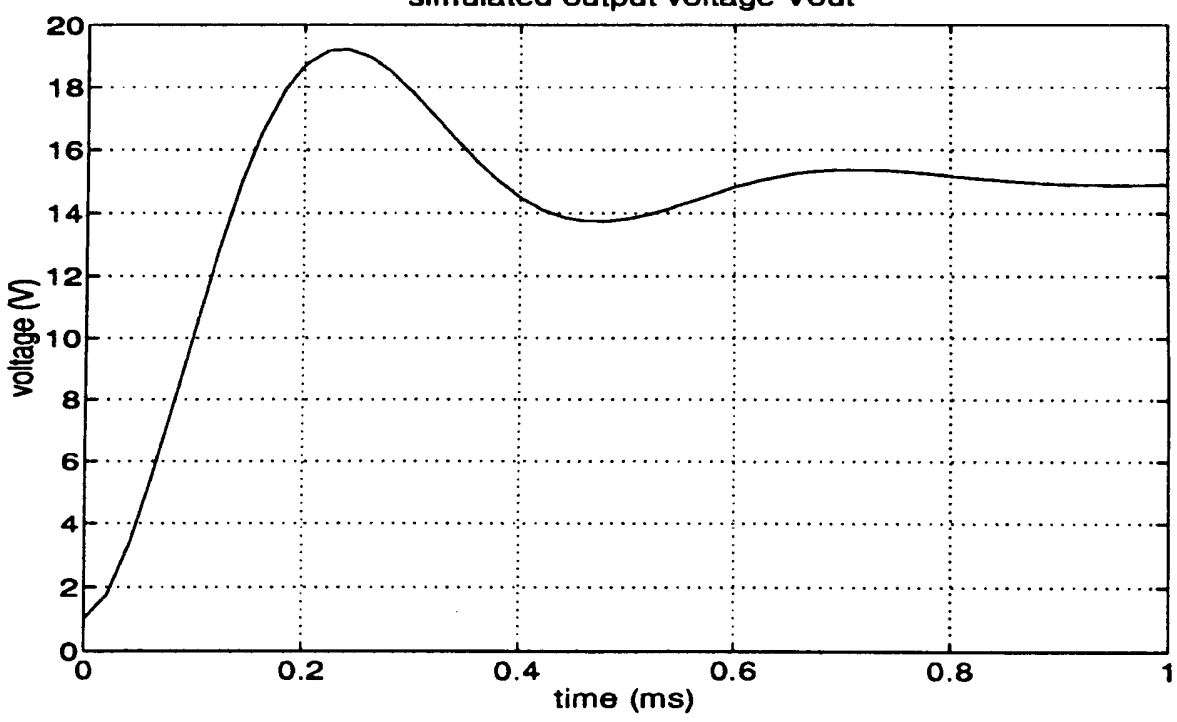

Figure 38. Simulated output voltage $\mathrm{V}_{\text {out }}$. 


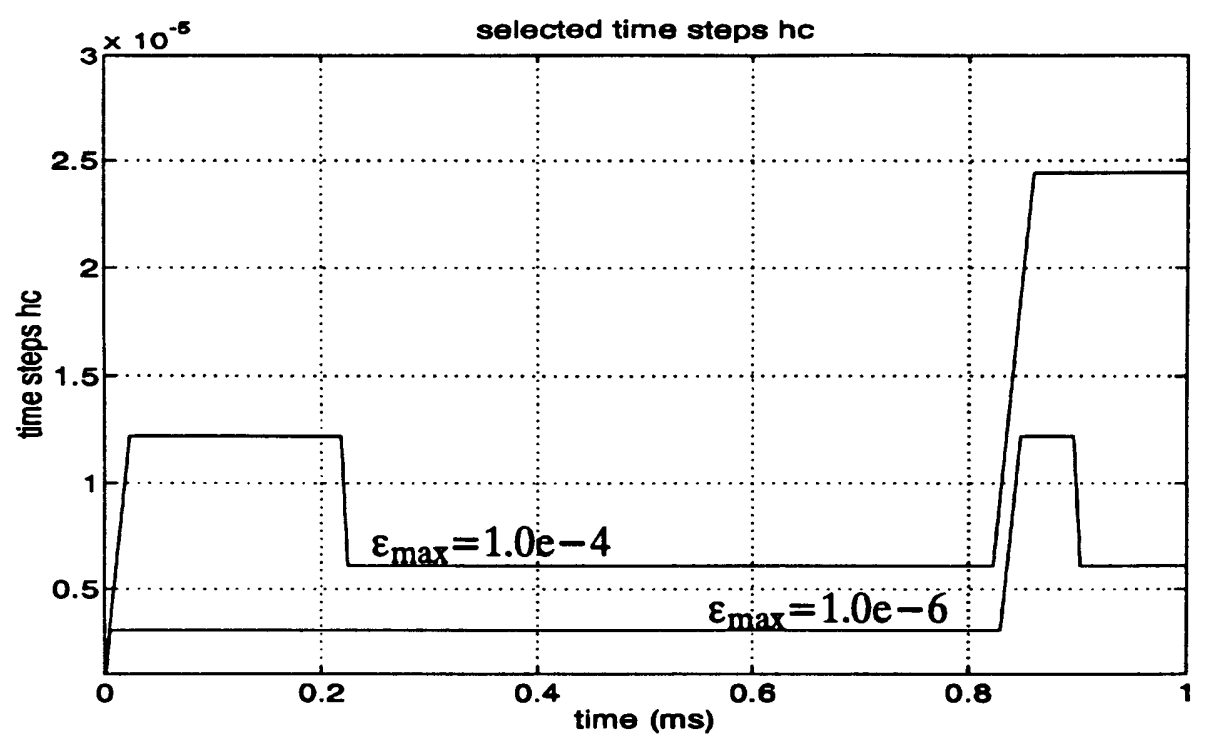

Figure 39. Selected time steps $h_{c}$.

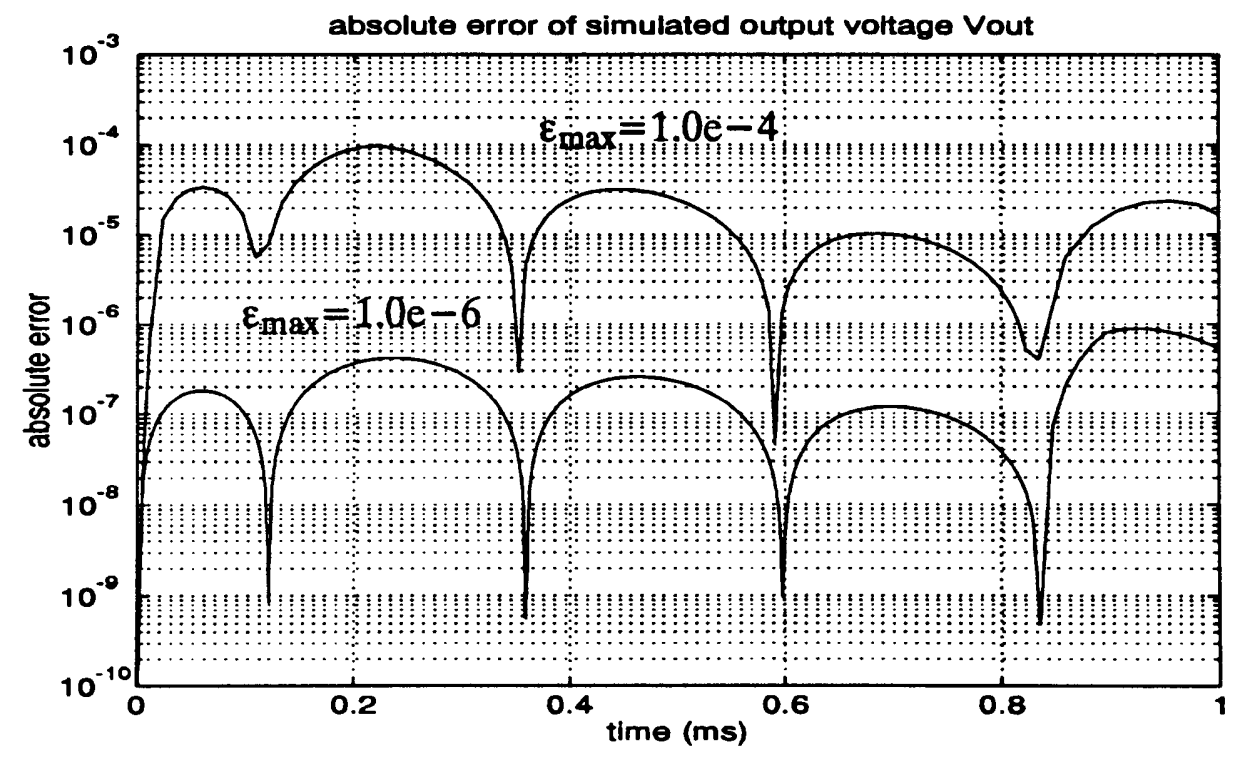

Figure 40. Absolute error of simulated output voltage $V_{\text {out }}$ using the error-correction method. 


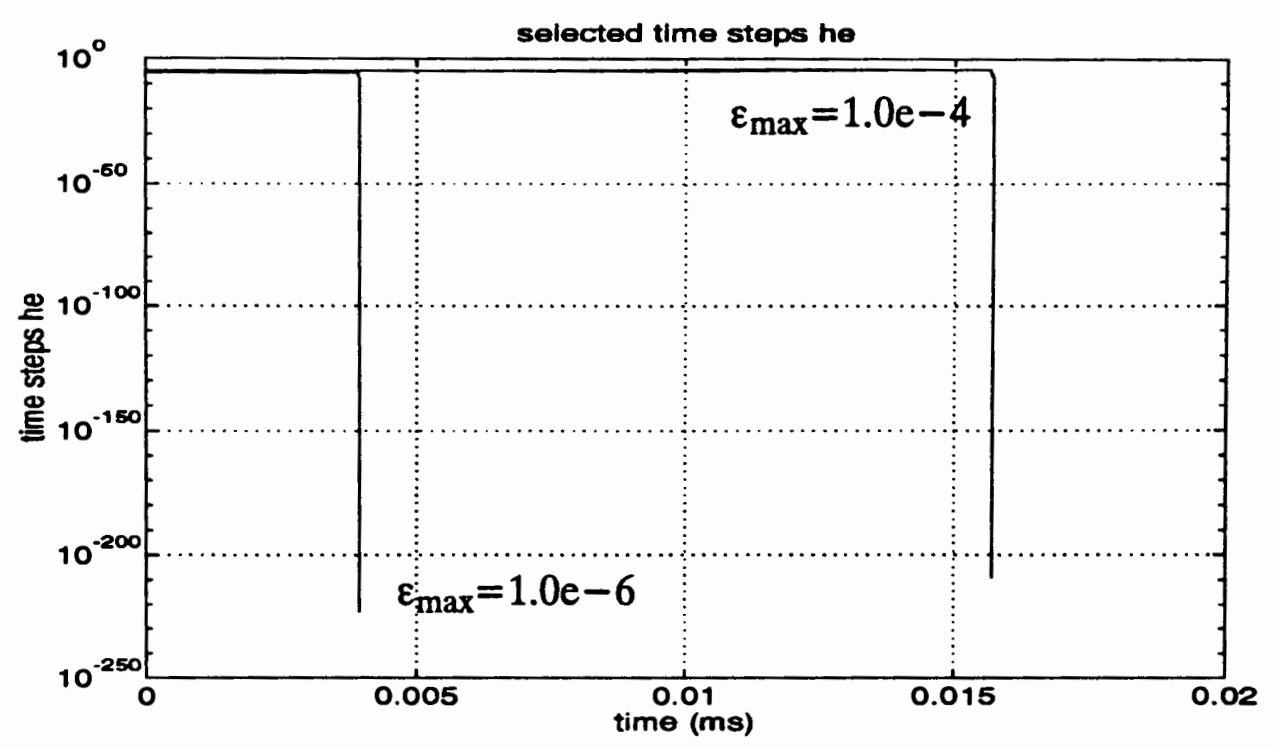

Figure 41. Selected time steps $h_{e}$.

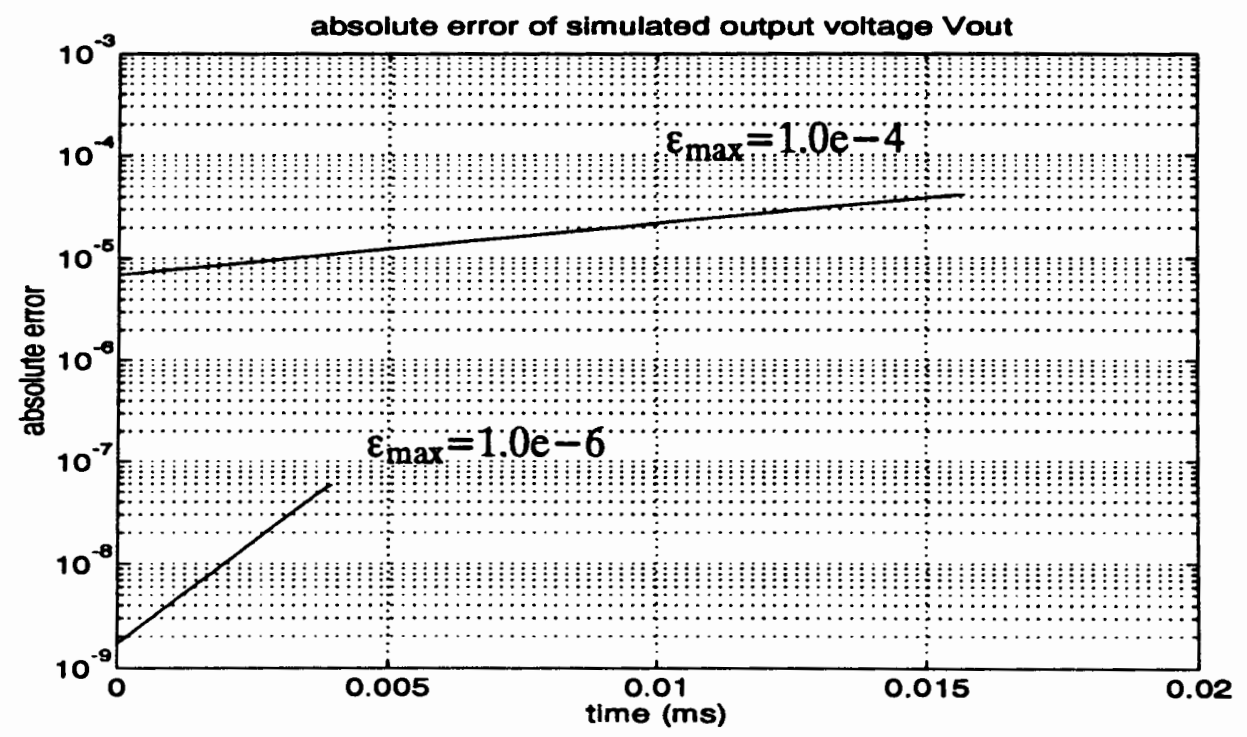

Figure 42. Absolute error of simulated output voltage $V_{\text {out }}$ using the step size estimation method. 
Equation (128) has been plotted for $\varepsilon_{\max }=10^{-6}, p=4$ and $k=1$, 2. The plot is shown in Figure 43.

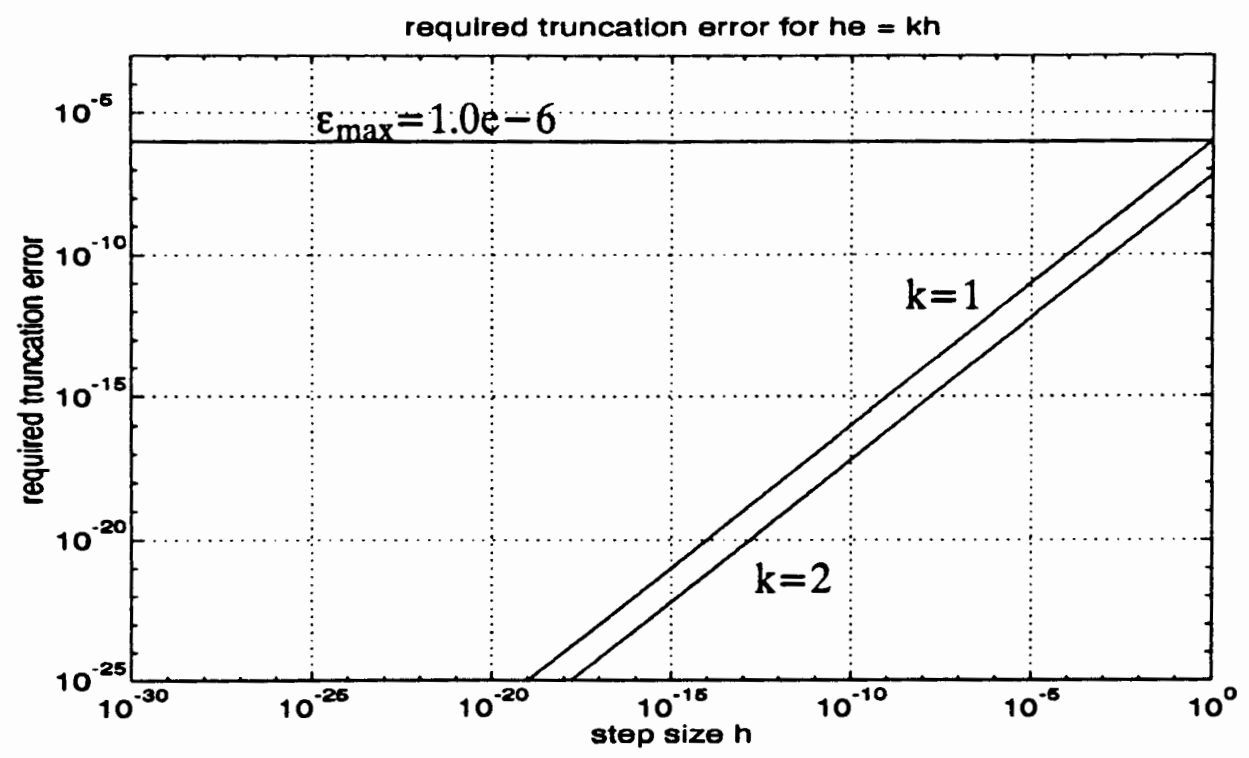

Figure 43. Required truncation error $\varepsilon_{p+1}$ for $h_{e}=k h$.

We immediately conclude that the algorithm must fail in practice. Suppose that for a previous selected time step $h$ the actual truncation error is bigger than the corresponding required truncation error in Figure 43 , but still smaller than $\varepsilon_{\max }$. Instead of at least maintaining the same step size, the algorithm decreases the step size. For a smaller time step an even smaller truncation error is required to increase the step size again. If a minimum step size is not specified, the algorithm decreases the step size successively until the program is interrupted by underflow. This has been shown in Figure 41 and 42 . Suppose we would have set a lower limit for the integration step size (typically MINSTEP $=10^{-12}$ ) the algorithm would already use the minimum step size after a couple of integrations (see Figure 41) and about $10^{9}$ integration steps would be necessary to simulate the circuit in Figure 37 for $1 \mathrm{~ms}$. The step size estimation method can only increase the step size again, if the truncation error takes on an excessively small 
value (e.g. for $\varepsilon_{\max }=10^{-6}, \mathrm{p}=4, \mathrm{~h}=\mathrm{MINSTEP}=10^{-12}$ a truncation error of $6.25 \times 10^{-20}$ is required to double the step size). This is clearly not possible due to numerical round-off errors and the machine precision.

\section{IV.9 SIMULATION EXAMPLES}

To demonstrate the capabilities of the developed simulator, the following simulation results are given.

\section{IV.9.1 Example 1}

We consider the circuit as shown in Figure 44. The component values are given in Table IX. Transistor $T_{1}$ operates at a fixed switching frequency $f_{s}$ and controls the load current. To avoid destruction of $T_{1}$, several protection elements are used. Basically $L_{2}$ slows the current rise when $T_{1}$ turns $O N$ and $C_{2}$ prevents the transistor collector voltage from rising too quickly. The simulation does not require an advance knowledge of the circuit's operation. Every switch is treated as a single element and the switching is handled automatically by the algorithm. The reader should convince himself from the difficulty of determining in advance the switching relation of the three protection diodes and the transistor. The simulated transistor collector voltage and the load current are given in Figure 45 and 46, respectively.

\section{IV.9.2 Example 2}

Figure 47 shows the schematic diagram of a regulated buck dc-to-dc converter. The converter operates with a fixed switching frequency $f_{s}=20 \mathrm{kHz}$. The control circuitry provides over-current protection of the switch $T_{1}$ of $4 \mathrm{~A}$, maximum duty ratio limiting of $\mathrm{D} \leq 0.85$, and a soft-start mechanism preventing the output voltage $V_{\text {out }}$ from rising too quickly when power is first applied. Figure 48 shows the 


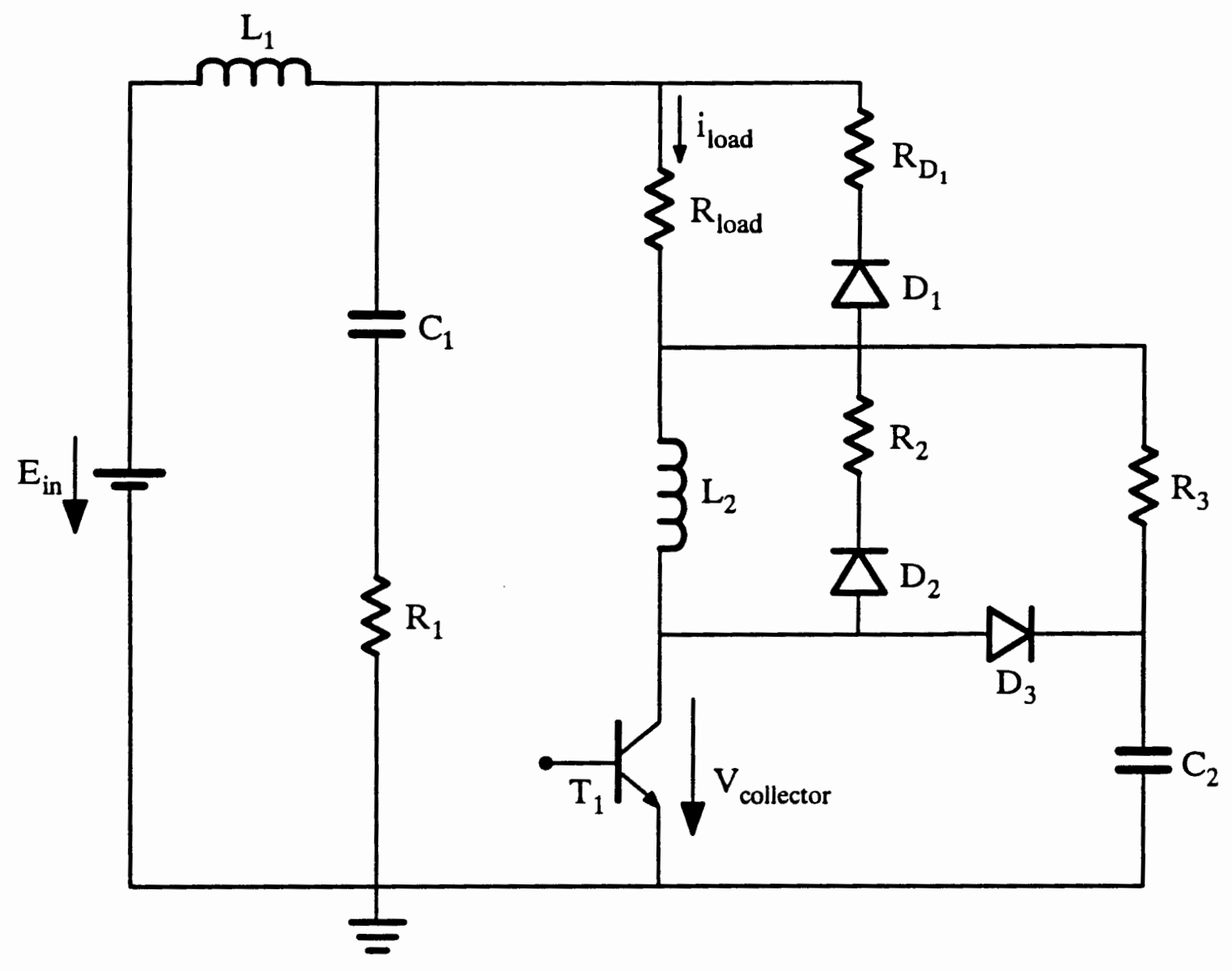

Figure 44. Transistor circuit with protection elements.

TABLE IX

COMPONENT VALUES FOR THE CIRCUIT IN FIGURE 44

$$
\begin{array}{lll}
\mathrm{E}_{\mathrm{in}}=120 \mathrm{~V} & \mathrm{C}_{1}=1 \mu \mathrm{F} & \mathrm{f}_{\mathrm{s}}=20 \mathrm{kHz} \\
\mathrm{R}_{\mathrm{D}_{1}}=1 \Omega & \mathrm{C}_{2}=68 \mathrm{nF} \\
\mathrm{R}_{1}=0.05 \Omega & \mathrm{L}_{1}=1 \mu \mathrm{H} \\
\mathrm{R}_{2}=5 \Omega & \mathrm{L}_{2}=20 \mu \mathrm{H} \\
\mathrm{R}_{3}=50 \Omega & \mathrm{R}_{\text {load }}=24 \Omega+1 \mathrm{mH}
\end{array}
$$




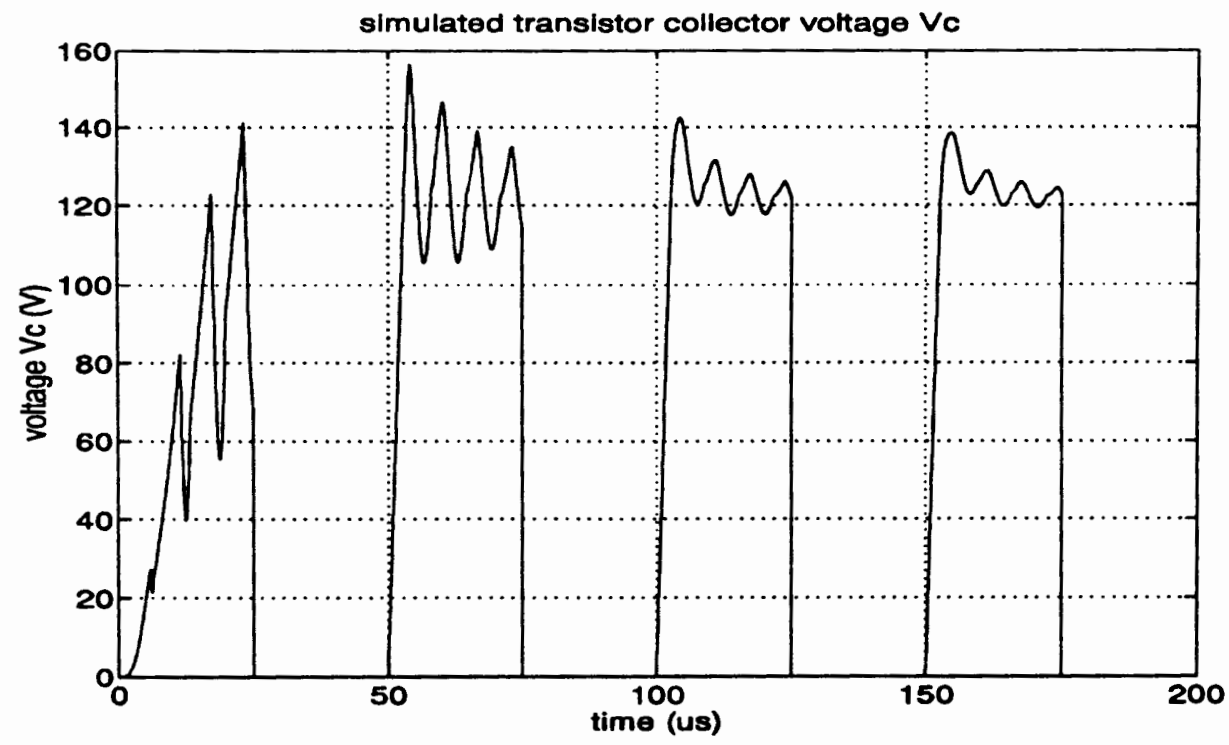

Figure 45. Simulated transistor collector voltage for the circuit in Figure 44.

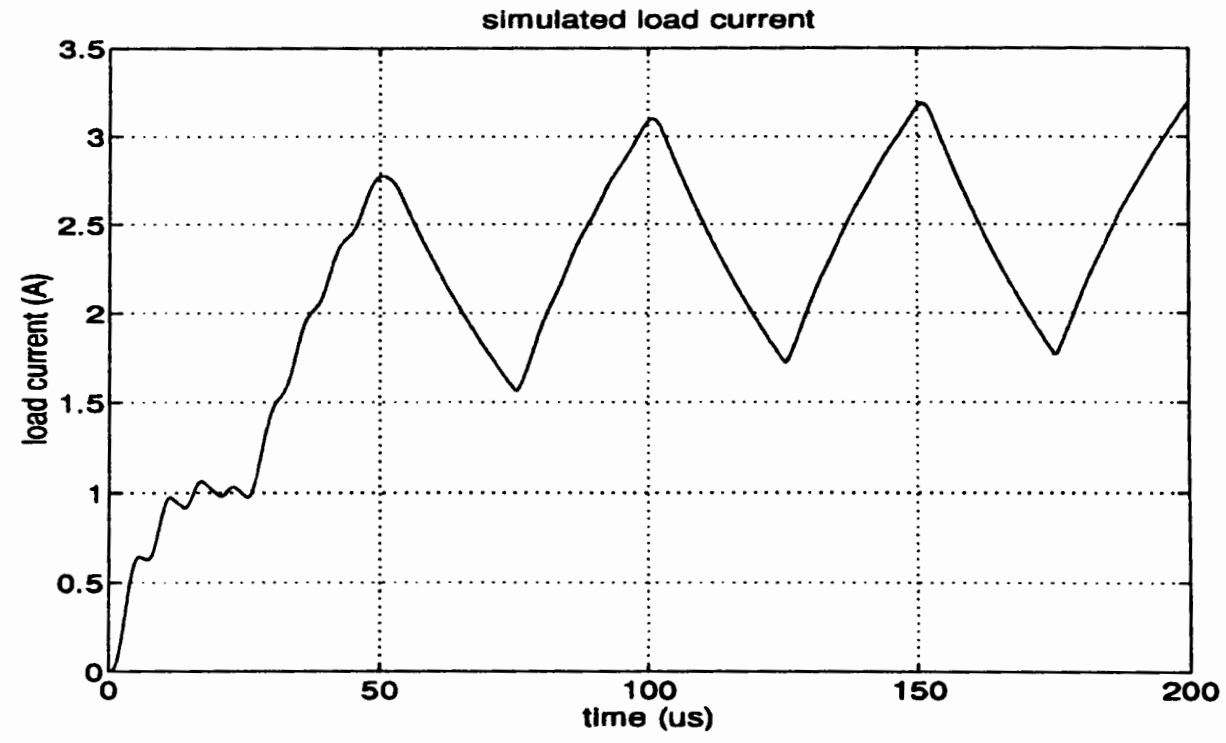

Figure 46. Simulated load current for the circuit in Figure 44. 
regulated buck converter as it has been implemented for the simulation. The zero-voltage source $\mathrm{V}_{01}$ is used to measure the inductor current. The zero-current sources $I_{01}$ and $I_{02}$ measure the output voltage $V_{\text {out }}$ and the control voltage $V_{F}$ respectively. The component values are listed in Table $\mathrm{X}$. The reader should note that the control loop is actually "closed" by applying equation (75) straightforwardly. This is in contrast to [19], where extra circuitry is needed to implement the control laws for the power electronic system. If equation (75) is used, then the control laws are described in form of a mathematical equation and the size of the matrices in equation (45) is considerably reduced. This clearly contributes to a reduction of computation time.

The simulation was started with zero initial conditions and the simulated output and control voltages are shown in Figure 49. The output voltage is rising slowly due to the slow-start mechanism of the control circuitry. The computed inductor current is shown in Figure 50. Note that the buck converter is operating in different modes before periodic steady state is reached. In the beginning of the transient, the over-current protection limits the inductor current to $4 \mathrm{~A}$. Shortly afterwards, the buck converter operates in discontinuous conduction mode. Figure 51 shows the detailed inductor current when the converter switches from continuous to discontinuous conduction mode.

Furthermore, the regulated buck converter has been subject to a step change in the input voltage $E_{\text {in }}$ from $20 \mathrm{~V}$ to $40 \mathrm{~V}$ while operating in steady state. The response of the regulator is given in Figure 52 and 53 . We can identify a lightly damped oscillation of the output voltage indicating that an improved design of the converter is necessary to make it more suitable for operation with $E_{i n}=40 \mathrm{~V}$. 


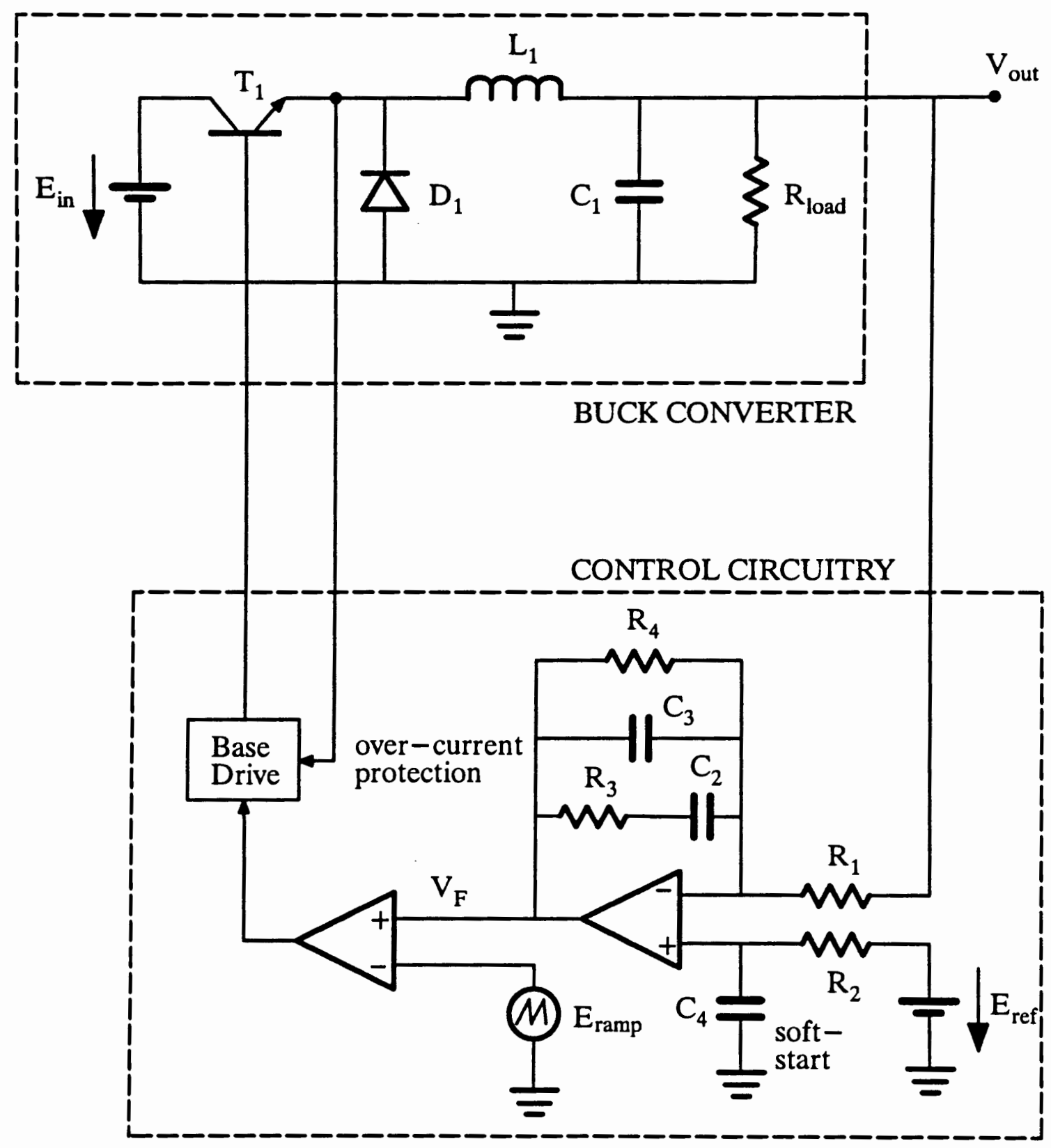

Figure 47. Schematic diagram of regulated buck converter. 


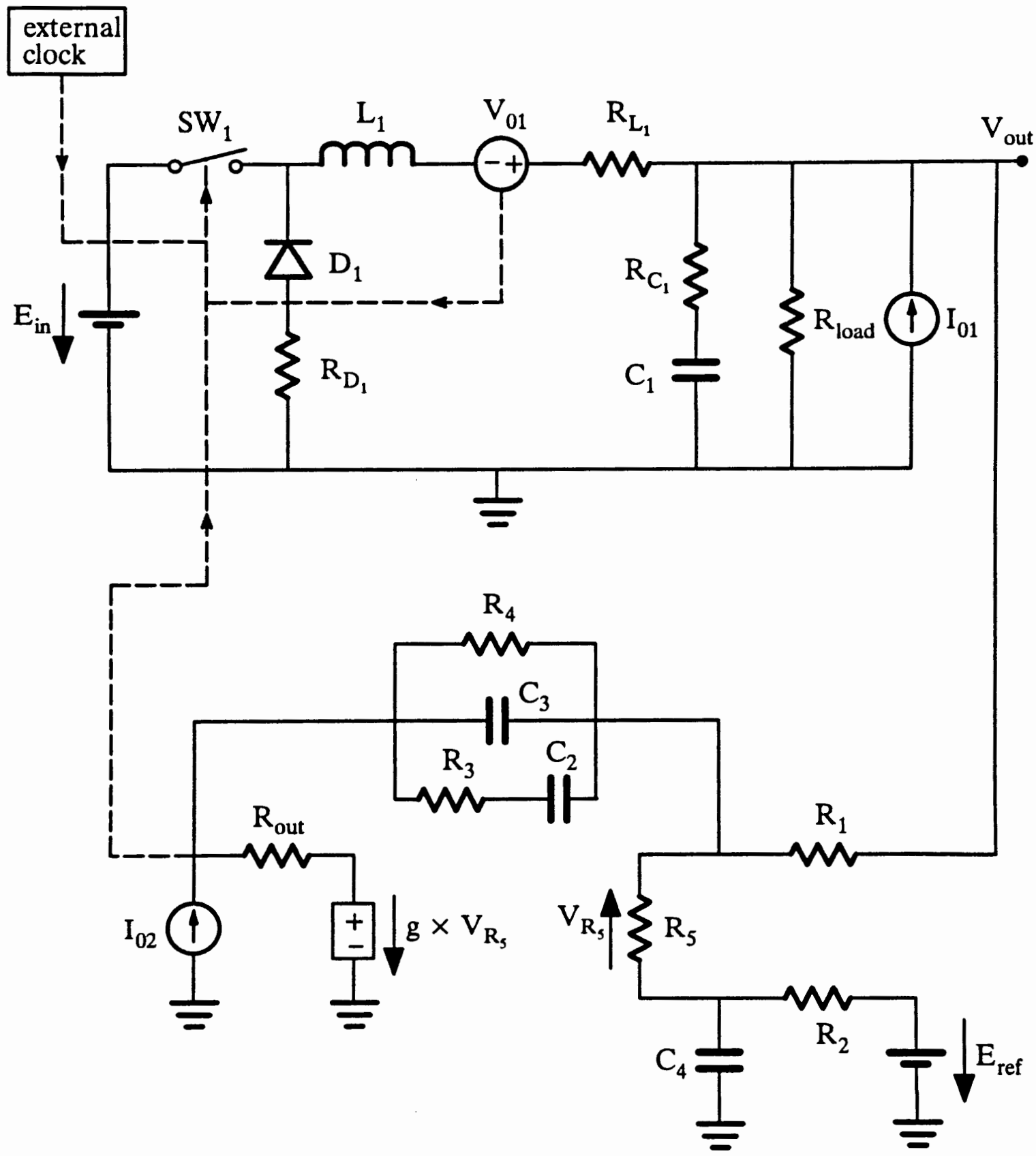

Figure 48. Regulated buck converter as implemented for simulation. 
TABLE X

COMPONENT VALUES FOR THE CIRCUIT IN FIGURE 48

$\begin{array}{lll}\mathrm{E}_{\text {in }}=20 \mathrm{~V} & \mathrm{R}_{1}=600 \Omega & \mathrm{C}_{2}=3.3 \mu \mathrm{F} \\ \mathrm{R}_{\mathrm{D}_{1}}=0.05 \Omega & \mathrm{R}_{2}=1 \mathrm{k} \Omega & \mathrm{C}_{3}=2 \mu \mathrm{F} \\ \mathrm{L}_{1}=200 \mu \mathrm{H} & \mathrm{R}_{3}=4.7 \mathrm{k} \Omega & \mathrm{C}_{4}=1.8 \mu \mathrm{F} \\ \mathrm{R}_{\mathrm{L}_{1}}=0.25 \Omega & \mathrm{R}_{4}=300 \mathrm{k} \Omega & \\ \mathrm{C}_{1}=1 \mathrm{mF} & \mathrm{R}_{\text {out }}=50 \Omega & \mathrm{f}_{\mathrm{s}}=20 \mathrm{kHz} \\ \mathrm{R}_{\mathrm{C}_{1}}=0.1 \Omega & \mathrm{g}=10^{4} & \mathrm{D}_{\max }=0.85 \\ \mathrm{R}_{\text {load }}=5 \Omega & \mathrm{E}_{\text {ref }}=5 \mathrm{~V} & \mathrm{I}_{\mathrm{L}_{1} \max }=4 \mathrm{~A}\end{array}$

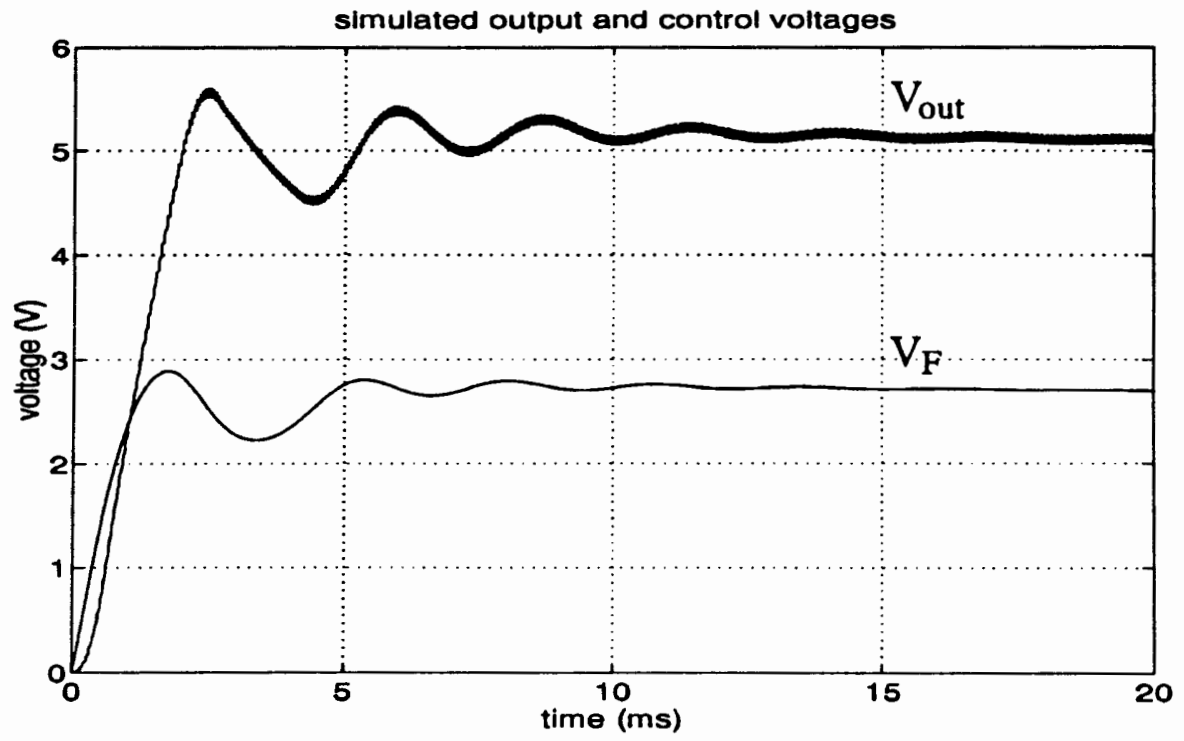

Figure 49. Simulated output and control voltages for the circuit in Figure 47 from start-up. 


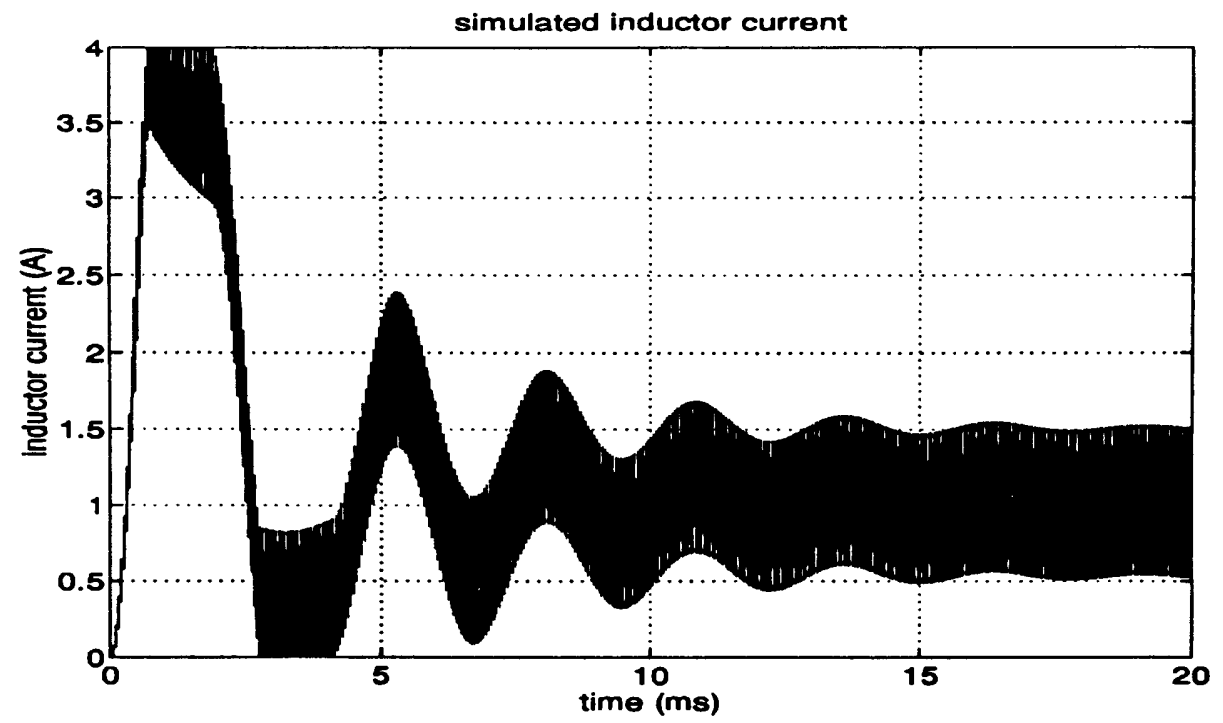

Figure 50. Simulated inductor current for the circuit in Figure 47 from start-up.

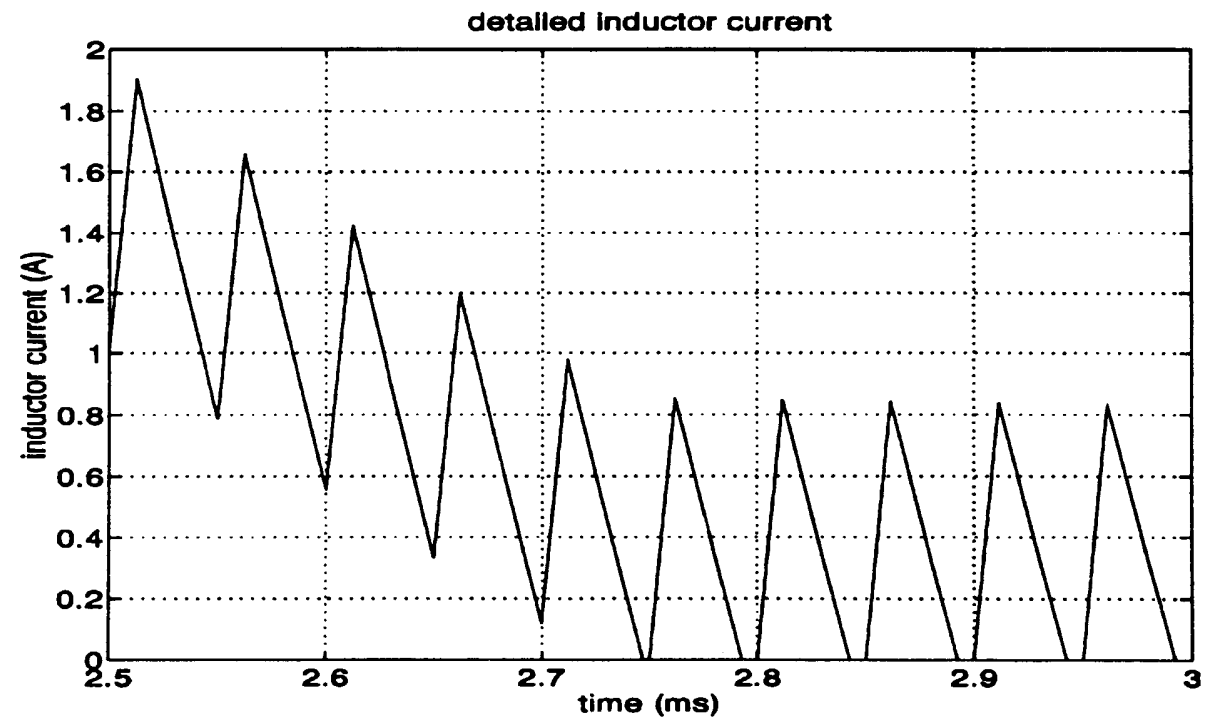

Figure 51. Detailed inductor current of Figure 50. 


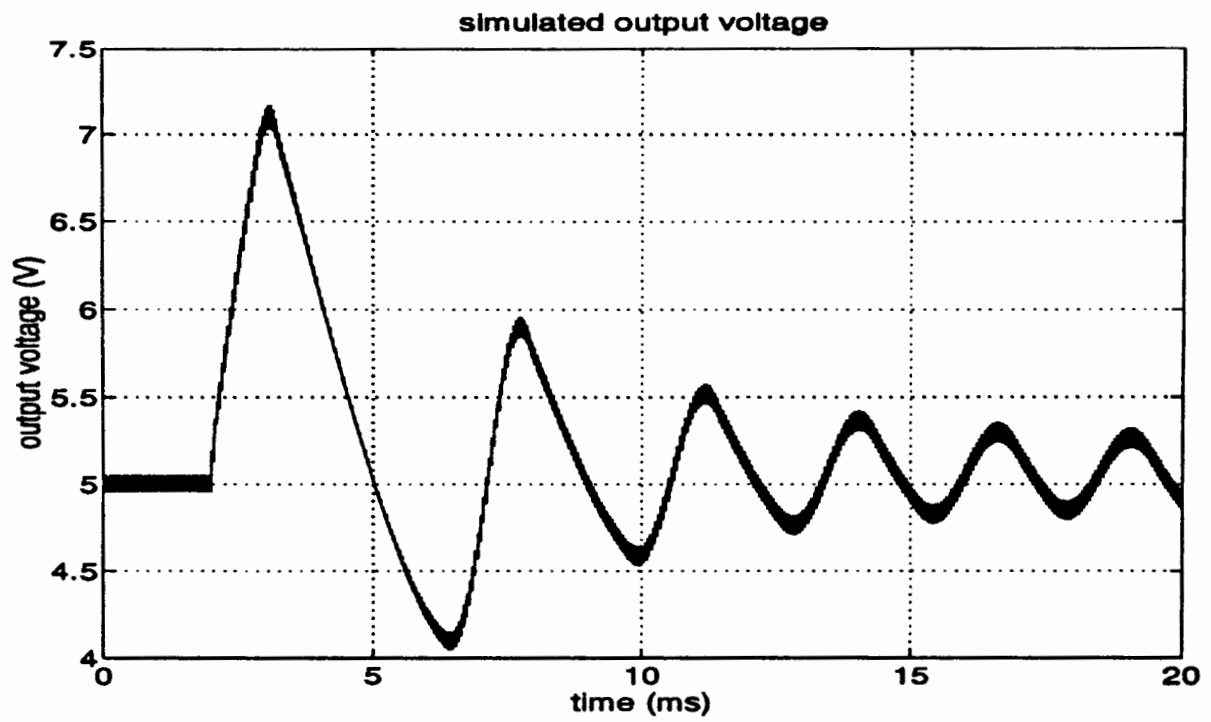

Figure 52, Simulated output voltage for the circuit in Figure 47 after a step change in $E_{\text {in }}$ from $20 \mathrm{~V}$ to $40 \mathrm{~V}$ at $\mathrm{t}=2 \mathrm{~ms}$.

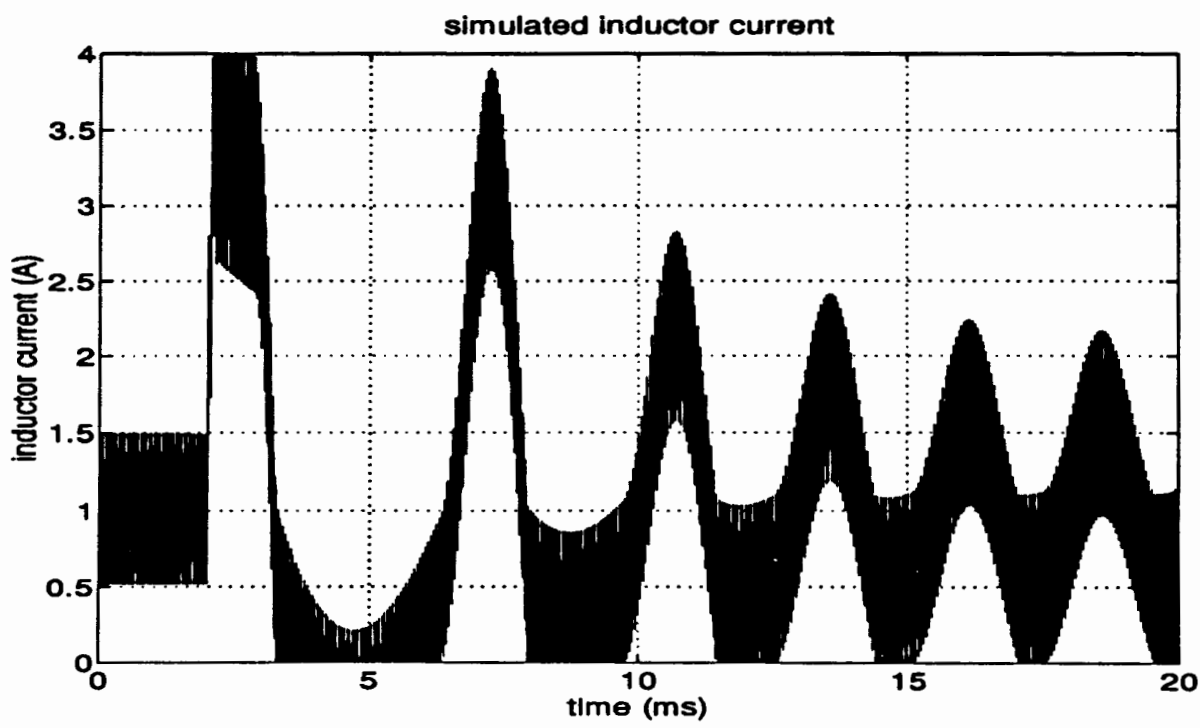

Figure 53. Simulated inductor current for the circuit in Figure 47 after a step change in $E_{\text {in }}$ from $20 \mathrm{~V}$ to $40 \mathrm{~V}$ at $\mathrm{t}=2 \mathrm{~ms}$. 


\section{CHAPTER V}

\section{CONCLUSION}

Two numerical methods suitable for the analysis of switched linear networks have been discussed.

The transmission-line modelling method derives a discrete model from the electrical network which can easily be solved in the time domain. A general approach to the solution of a transmission-line modelled network has been given by applying the one-graph modified nodal description straightforwardly. Using our tables, network equations can simply be set up by inspection. The numerical equivalence of TLM and trapezoidal rule, a 2 nd order method, has been proven. This rises the question, whether a simulator based on the TLM integration method can be efficient. A 2 nd order method clearly requires smaller time steps than a higher order method to meet a certain error

criterion. Small time steps obviously increase the number of necessary calculations in a simulation and reduce the speed of the simulator.

The numerical inverse Laplace transform has been reviewed. It has been shown that a number of useful properties for the analysis of switched linear networks arise from the fact that the numerical inverse Laplace transform operates in the frequency domain. Inconsistent initial conditions and Dirac impulses are handled correctly by the method. Dirac impulses can be used to determine the correct topology immediately after a switching instant as long as they can be identified among the numerical errors by choosing a suitable threshold value. Since every switch is treated individually (which is highly desirable in a general simulator), several topology changes may be necessary at a switching instant. The number of all possible topologies is determined by the 
number of switches and for any topology the system matrix $(\mathbf{G}+\mathrm{sC})$ has to be invertible to ensure proper functioning of the method of Dirac impulses. We like to point out that in most applications the above limitation is only of theoretical interest. The features and capabilities of the developed simulator based on the 4th order numerical Laplace transform have been demonstrated by several simulation examples. 


\section{REFERENCES}

[1] J. Vlach, K. Singhal, "Computer methods for circuit analysis and design", Van Nostrand Reinhold, New York, 1983.

[2] L. O. Chua, P.-L. Lin, "Computer-aided analysis of electronic circuits", Prentice-Hall, Inc., Eaglewood Cliffs, New Jersey, 1975.

[3] A. E. Ruehli, "Circuit analysis, simulation and design", chapter 5, Elsevier science publishers B. V. (North-Holland), 1986.

[4] K. Ogata, "Modern control engineering", pp. 303 - 314, Prentice-Hall, Inc., Eaglewood Cliffs, New Jersey, 1990.

[5] S. Y. R. Hui, C. Christopoulos, "Discrete transform technique for solving coupled integro-differential equations in digital computers", IEE Proc.-A., Vol. 138, No. 5, pp. $273-280,1991$.

[6] J. W. Bandler, P. B. Johns, M. R. M. Rizk, "Transmission-line modelling and sensitivity evaluation for lumped network simulation and design in the time domain", Journal of The Franklin Institute, Vol. 304, No. 1, pp. 15 - 32, 1977.

[7] S. Y. R. Hui, C. Christopoulos, "A discrete approach to the modelling of power electronic switching networks", IEEE Power Electronics Specialists Conf. Rec., Vol. I, Milwaukee, WI, pp. 130 - 137, 1989.

[8] S. Y. R. Hui, C. Christopoulos, "Computer simulation of a converter-fed DC drive using the transmission-line modelling technique", IEEE Transactions on Power Electronics, Vol. 6, No. 4, pp. 636 - 644, 1991.

[9] S. Y. R. Hui, C. Christopoulos, "Numerical simulation of power circuits using transmission-line modelling", IEE Proc., Vol. 137, Pt. A, No. 6, pp. 379 - 384, 1990.

[10] L. A. Newcombe, J. E. Sitch, "Reactive nonlinearities in transmission-line models", IEE Proc., Vol. 132, Pt. A, No. 2, pp. 95 - 98, 1985.

[11] I. N. Bronstein, K. A. Semendjajew, "Taschenbuch der Mathematik", B. G. Teubner Verlagsgesellschaft, Leipzig, 1987. 
[12] P. B. Johns, R. L. Beurle, "Numerical solution of 2-dimensional scattering problems using a transmission-line matrix", IEE Proc., Vol. 118, No. 9, pp. 1203 - 1208, 1971.

[13] S. Y. R. Hui, C. Christopoulos, "Application of the transmission-line modelling technique to the simulation of power electronic circuits", Journal of Electrical and Electronics Engineering, Australia - IE Aust. \& IREE Aust., Vol. 11, No. 2, pp. 110 - 116, 1991.

[14] K. Singhal, J. Vlach, "Computation of time domain response by numerical inversion of the Laplace transform", Journal of The Franklin Institute, Vol. 299, No. 2, pp. 109 - 126, 1975.

[15] K. Singhal, J. Vlach, M. Nakhla, "Absolutely stable, high order method for time domain solution of networks", Archiv für Elektrotechnik und Übertragungstechnik, Band 30, Heft 4, pp. 157 - 166, 1976.

[16] A. Opal, J. Vlach, "Consistent initial conditions of linear switched networks", IEEE Transactions on Circuits and Systems, Vol. 37, No. 3, pp. 364 - 372, 1990.

[17] J. Vlach, "Numerical method for transient responses of linear networks with lumped, distributed or mixed parameters", Journal of The Franklin Institute, Vol. 288, No. 2, pp. 99 - 113, 1969.

[18] C. J. Wellekens, "Generalisation of Vlach's method for the numerical inversion of the Laplace transform", Electronics Letters, Vol. 6, No. 23, pp. 742 - 744, 1970.

[19] D. Bedrosian, J. Vlach, "Time-domain analysis of networks with internally controlled switches", IEEE Transactions on Circuits and Systems, Vol. 39, Vol. 3, pp. $199-212,1992$.

[20] R. Tymerski, "A fast time domain simulator for power electronic systems", IEEE Applied Power Electronics Conference, San Diego, CA, 1993.

[21] J. R. Johnson, "Introduction to digital signal processing", pp. 5 - 7, Prentice-Hall, Inc., Eaglewood Cliffs, New Jersey.

[22] R. L. Burden, J. D. Faires, "Numerical analysis", p. 470, PWS Publishing Company, Boston, 1993. 